DANIELLE ALINE BARATA ASSAD

\title{
"DESENVOLVIMENTO DE BARRA DE APOIO MODULAR REMOVÍVEL PARA INDIVÍDUOS COM APARELHO LOCOMOTOR ACOMETIDO"
}

Dissertação de mestrado apresentada ao Programa de PósGraduação Interunidades Bioengenharia - Escola de Engenharia de São Carlos / Faculdade de Medicina de Ribeirão Preto / Instituto de Química de São Carlos da Universidade de São Paulo como parte dos requisitos para a obtenção do título de mestre em Ciências.

Área de Concentração: Bioengenharia

Orientadora: Prof. Dra. Valéria Meirelles Carril Elui

\section{Versão Corrigida}




\section{AUTORIZO A REPRODUÇÃO E DIVULGAÇÃO TOTAL OU PARCIAL DESTE TRABALHO, POR QUALQUER MEIO CONVENCIONAL OU ELETRÔNICO, PARA FINS DE ESTUDO E PESQUISA, DESDE QUE CITADA A FONTE.}

Dissertação (Mestrado) - Programa de Pós-Graduação Interunidades Bioengenharia e Área de Concentração em Bioengenharia -- Escola de Engenharia de São Carlos; Faculdade de Medicina de Ribeirão Preto; Instituto de Química de São Carlos, da Universidade de São Paulo, 2013.

1. Adaptação Doméstica. 2. Desenvolvimento de Produto. 3. Tecnologia Assistiva. 4. Terapia ocupacional. I. Título. 


\title{
DANIELLE ALINE BARATA ASSAD
}

Título: "Desenvolvimento de barra de apoio modular removível para indivíduos com aparelho locomotor acometido".

\begin{abstract}
DISSERTAÇÃO APRESENTADA AO PROGRAMA DE PÓS GRADUAÇẪO INTERUNIDADES BIOENGENHARIA - EESC/FMRP/IQSC DA UNIVERSIDADE DE SÃO PAULO PARA OBTENÇÃO DO TITULO DE MESTRE EM CIÊNCIAS NA ÁREA DE BIOENGENHARIA.
\end{abstract}

Aprovada em: $27 / 03 / 2013$

PROFa. DR ${ }^{\mathrm{a}}$. VALÉRIA MEIRELLES CARRIL ELIII (ORIENTADORA)

Resultado: APROVADO

PROF $^{a}$. DR ${ }^{\mathrm{a}}$. LUCIANE FERNANDES RODRIGUES MARTINHO FERNANDES

Resultado: aprovade

PROF. DR. CARLOS ALBERTO FORTULAN

Resultado:

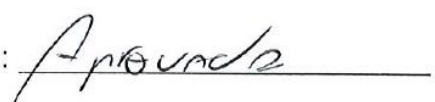

Faculdade de Medicina de Ribeirão Preto - USP
Universidade Federal do Triângulo Mineiro UFTM

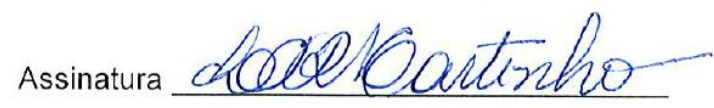

Escola de Engenharia de São Carlos - USP

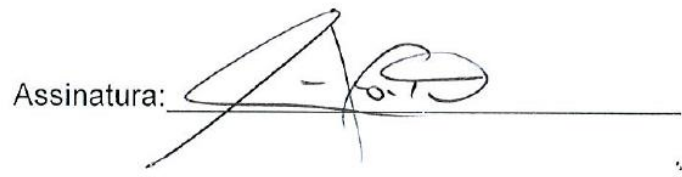


A meus pais, Fátima e Claudemir, que por toda minha vida me apoiaram na busca pelo conhecimento. A meus irmãos, Camila e Felipe, pela ajuda incondicional. A meu marido João pelo incentivo, amor, carinho e compreensão. 


\section{AGRADECIMENTOS}

À Deus por me permitir manter a fé diante das dificuldades e obstáculos envolvidos no desenvolvimento deste trabalho bem como em toda minha vida.

A minha orientadora Profa. Dra. Valéria Meirelles Carril Elui, por me incentivar na busca pelo conhecimento, em aprimorar-me enquanto profissional da saúde e pela amizade ao longo dos anos de convivência.

Ao Prof. Dr. Carlos Alberto Fortulan, pela sua incrível capacidade de proporcionar momentos descontraídos em momentos de trabalho e pela sua dedicação, disponibilidade e paciência que proporcionaram a conclusão deste trabalho.

A Taiuani Marquine Raymundo, amiga que me acompanhou durante todo o processo deste trabalho e que espero poder ter o prazer da companhia pela vida.

Aos amigos que me acompanharam durante o Programa de Mestrado, durante as disciplinas, pelas trocas, alegrias e desesperos.

A minhas amigas de graduação em terapia ocupacional, que se mantêm presentes mesmo após a finalização desta etapa me incentivando e apoiando.

A minhas colegas de trabalho que tiveram a paciência e me estimularam a não desanimar.

A minhas chefes, Thaura e Silvia, pela compreensão e pela confiança.

Aos funcionários do HCFRMP-USP, aos funcionários da USP-SC e aos funcionários do Programa Interunidades em Bioengenharia pelo apoio e auxílio direto e que de alguma forma contribuíram no desenvolvimento deste trabalho.

Aos pacientes do HCFMRP-USP que aceitaram participar deste trabalho e enriqueceram-me com suas necessidades.

À FAPESP (Fundação de Amparo á Pesquisa do Estado de São Paulo) e CNPq (Conselho Nacional de Pesquisa) pelo apoio financeiro.

A todos que de forma direta ou indiretamente contribuíram para a realização deste trabalho. 


\section{RESUMO}

ASSAD, D. A. B Desenvolvimento de barra de apoio modular removível para indivíduos com aparelho locomotor acometido. 2013.121f. Dissertação (Mestrado) - Programa de PósGraduação Interunidades Bioengenharia. EESC/FMRP/IQSC, Universidade de São Paulo, São Carlos, 2013.

Grande parte da população brasileira apresenta condições socioeconômicas desfavoráveis á utilização de recursos de tecnologia assistiva embora possa haver necessidades. O movimento sentado para de pé (ST-DP) é definido operacionalmente como uma transferência bem sucedida do centro de massa $(\mathrm{CM})$ do corpo de uma posição sentada para uma posição estável de pé. A atividade de passar de ST-DP é pré-requisito para a posição vertical, e requer uma complexa coordenação entre o sistema nervoso central e o sistema neuromuscular. Há diversas patologias que comprometem o movimento de passar de sentado para em pé (ST-DP) e vice-versa e que atrapalham o desempenho das atividades de vida diária. Este trabalho objetiva projetar e desenvolver um sistema baseado em barra de apoio, que não exige modificação estrutural das residências, com a função de promover a independência e segurança aos indivíduos no movimento de ST-DP. Baseada na metodologia de projeto foi dividido em cinco fases: informacional (aplicação de questionário com perguntas fechadas e uma dissertativa junto a população alvo); conceitual (pesquisa das especificações necessárias ao desenvolvimento da barra, soluções e decisões); protótipo (elaboração do projeto e desenho da barra, protótipos e avaliação); validação (validação do protótipo) e descontinuidade (descarte após uso). Como resultados conseguiu-se: determinar o modelo e protótipo utilizando o programa $C A D$ solid edge Insight тм; classificar os possíveis materiais; dimensionar o sistema baseado em barra de apoio de acordo com os materiais disponíveis e realizar ensaios mecânicos de bancada e testes em pacientes que possibilitaram verificação da aplicabilidade e a facilitação do movimento de passar de ST-DP. O sistema baseado em barra de apoio desenvolvida é de fácil instalação, utiliza materiais renováveis e obteve a eficácia e a opinião favorável dos voluntários ao uso da barra de apoio. Com este trabalho, integraram-se as áreas da saúde e tecnológica em prol da troca do conhecimento técnico entre ambas contribuindo para o desenvolvimento de um produto que objetiva a promoção da independência do(s) indivíduo(s) na realização de suas atividades diárias.

Palavras-chaves: Adaptação Doméstica. Desenvolvimento de Produto. Tecnologia Assistiva. Terapia Ocupacional. 


\begin{abstract}
ASSAD, D. A. B "Development of a Movable Support Bar for Individuals with Impaired Locomotor Function".2013. 121f Dissertação (Mestrado) - Programa de Pós-Graduação Interunidades Bioengenharia. EESC/FMRP/IQSC, Universidade de São Paulo, São Carlos, 2013
\end{abstract}

The Brazilian population presents unfavorable socioeconomic conditions the use of assistive technology resources although they need. The movement sitting to standing (STS) is operationally defined as a successful transfer of the center of mass (CM) of the body from a sitting position to a stable upright position. The activity of STS is prerequisite to the vertical position and requires a complex coordination between the central nervous system and the neuromuscular system. There are several diseases that affect the movement of sitting to standing (STS) and vice versa and that hinder the performance of activities of daily living. This work aims to design and develop a system based on support bar that requires no structural modification of households, with the task of promoting the independence and safety for individuals in the movement of STS. Based on the product methodology, was divided into five phases: informational (questionnaires with closed questions and Essay along the target population), conceptual (search specifications necessary for the bar, solutions and decisions); prototyping (project design and bar design, prototyping), evaluation and discontinuity. As results was achieved: determining the prototype model and using the CAD program Insight Solid Edge TM; possible to classify the material; dimensioning the system based on support bar according to the materials available and performing mechanical tests and bench testing in patients who enabled verification applicability and facilitating the movement of STS. The system based on support bar is designed for easy installation, uses renewable materials and obtained favorable opinion of the effectiveness and use of volunteers to support bar. This work integrated the health and technology areas in favor of the technical knowledge exchange between both, contributing to the development of a product that aims to promote independence of individual (s) in carrying out their daily activities.

Keywords: Domestic Adaptation. Product Development. Assistive Technology. Occupational Therapy. 


\section{LISTA DE ILUSTRAÇÕES}

Figura 1 - Definição das fases ST-DP e DP-ST. Fonte: Tsukahara et al, (2010) (adaptado de) ...........................20

Figura 2 - Localização dos oitos músculos no modelo musculoesquelético do movimento de ST-DP. Fonte:

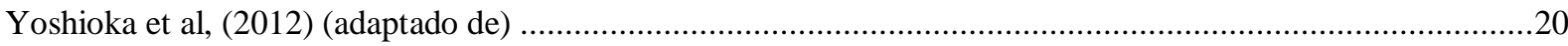

Figura 3 - Definição dos sistemas de parâmetros e variáveis. Fonte: Tsukahara et. al., (2010). (adaptado de) .....22

Figura 4 - Empunhadura Fonte: NABNT9050, (2004) (adaptada de)

Figura 5 - Barra de apoio utilizadas no banheiro, para sanitários e lavatórios Fonte: http://www.barrasdeapoio-

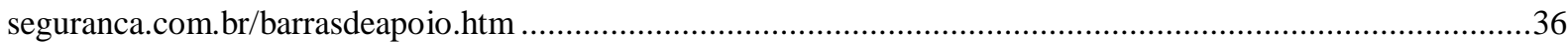

Figura 6 - Barra de apoio para box Fonte: http://barradeapoio-acessibilidade.blogspot.com/ ............................36

Figura 7 - Barra de apoio em inox para abertura de porta Fonte: http://adaptafacil.com.br/ ................................36

Figura 8- Exemplo 1 de Barra de Apoio Figura 9 - Exemplo 2 de Barra de Apoio .......................46

Figura 10- Super Pole System Figura 11- Advantage Rail...................................................47

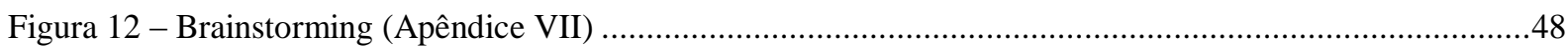

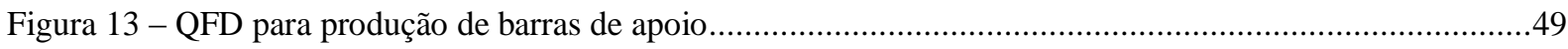

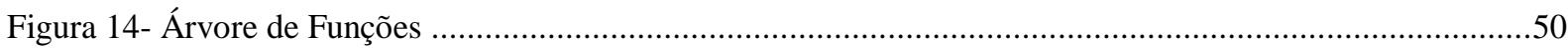

Figura 15 - Primeiro modelo da barra de apoio e detalhe da trava de segurança ..................................................51

Figura 16- Simulação de tensão máxima imposta ao material ........................................................................

Figura 17 - Efeitos das diferentes fases do ciclo de vida sobre o custo do produto. Fonte: (BLANCHARD e

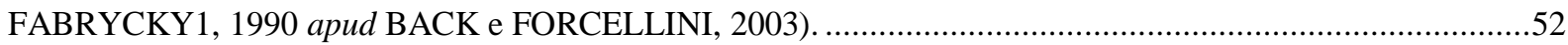

Figura 18- Alcance manual frontal - pessoa sentada. Fonte: NABNT9050, 2004 ……....................................53

Figura 19- Alcance manual frontal - pessoa em pé. Fonte: NABNT9050, 2004 ……...........................................53

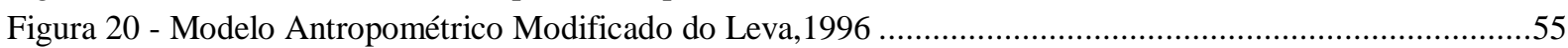

Figura 21 - Modelo para cálculo da máxima tensão atuante e flecha ............................................................59

Figura 22 - Esquema para determinação da seção tubular ..............................................................................59

Figura 23 - Fixadores por pressão a)ventosa de borracha b)ventosa única c) ventosa dupla d)ventosa tripla Fonte:

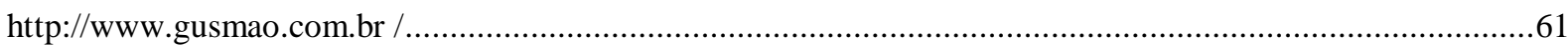

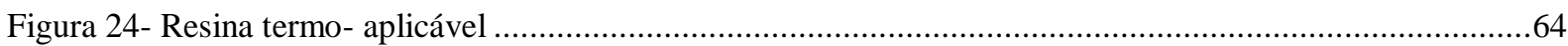

Figura 25 - Segundo modelo da barra de apoio e detalhe do encaixe do tubo a base .........................................65

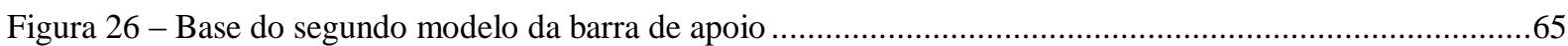

Figura 27 - a) Base $0,50 \mathrm{~cm}$; b) Tubo de 90 a $120 \mathrm{~cm}$; c) Cotovelo $90^{\circ}$; d) Tee; e) cotovelo mais de $30^{\circ} ; \ldots \ldots \ldots . . .67$

Figura 28- Exemplo 1 de uso da barra de apoio em um quarto.....................................................................67

Figura 29 - Exemplo 2 de uso da barra de apoio, utilizando 2 bases, 1 tubo de $82 \mathrm{~cm}, 1$ tubo de $70 \mathrm{~cm}, 1$ tubo de

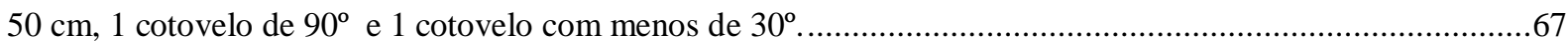

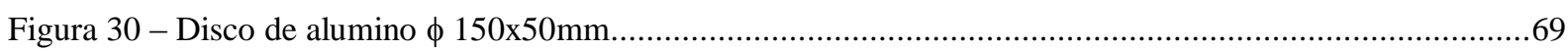

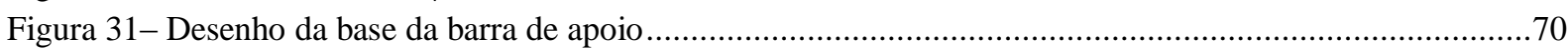

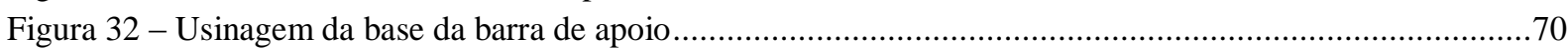

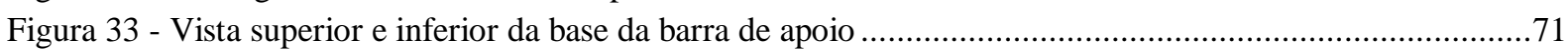

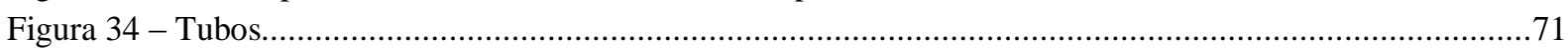

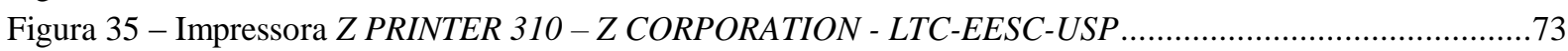

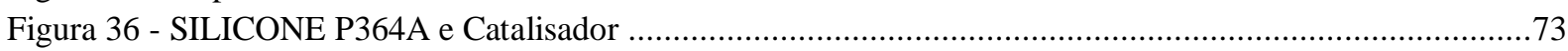

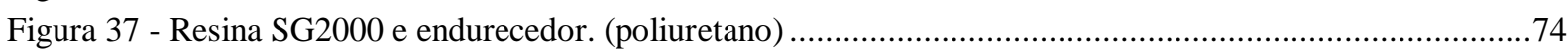

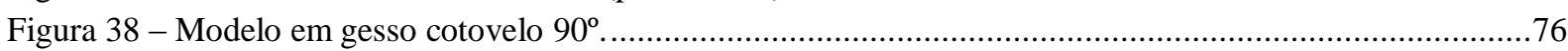

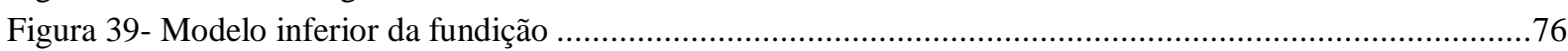

Figura 40 - Modelos em gesso preparado no vidro com suporte do alumínio para fundição do silicone ...............76

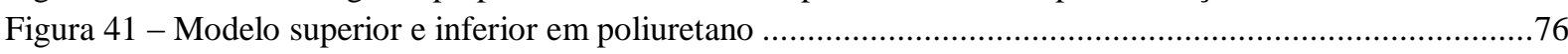

Figura 42 - Modelo Superior e Inferior Moldes em Gesso, Silicone e Poliuretano ...............................................77

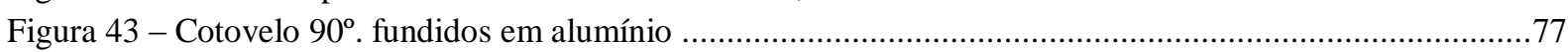

Figura 44 - Meio tee em gesso e preparação para moldagem em silicone.........................................................78

Figura 45 - a) Modelo para fundição direta b) Molde Tee para fundição direta lado a e lado b c) Molde Tee para

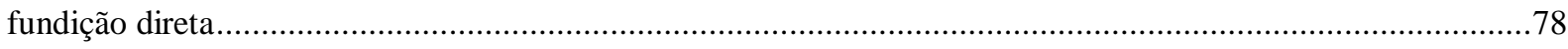

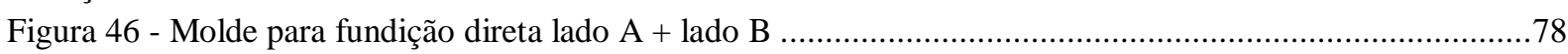

Figura 47 - a)Tee recém-fundido e b) Tee fundido em alumínio ............................................................................ 
Figura 48 - Molde dos cotovelos a) molde 60-120 lado direito b) molde 60-120 lado esquerdo c) molde 60-120 vista frontal d) molde 60-120 - fechado e) molde esquerdo e direito para fundição direta f) molde para fundição

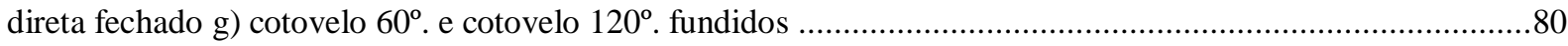

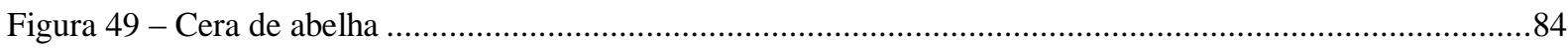

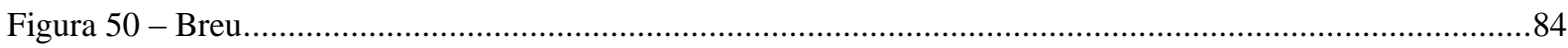

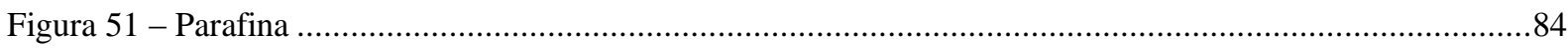

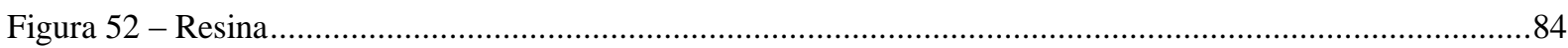

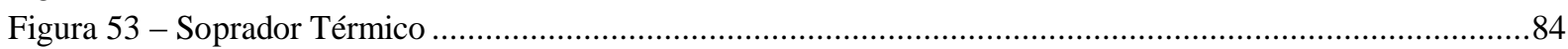

Figura 54 - Base vista inferior com resina termo -aplicável.................................................................84

Figura 55- Aquecimento da superfície com soprador térmico e fixação da base com resina termo aplicável à superfície.

Figura 56 - a)Piso frio e rejunte b) base fixa á superfície c) piso sem danos após aquecimento da resina com soprador térmico e retirada da base com resina

Figura 57 - a) Piso frio b) base fixada á superfície do piso frio c) piso sem danos após aquecimento da resina com soprador térmico e retirada da base com resina.....

Figura 58 - a) Granito b) base fixada á superfície do granito c) granito sem danos após aquecimento da resina com soprador térmico e retirada da base com resina

Figura 59 - a) Piso cimento queimado ("vermelhão") b)base fixada á superfície c) Piso sem danos após aquecimento da resina com soprador térmico e retirada da base com resina

Figura 60 - a)Piso em concreto b) base fixada no piso de concreto c) piso sem danos após aquecimento da resina com soprador térmico e retirada da base com resina.

Figura 61 - Barra de apoio modular removível. Legenda: A: base da barra de apoio,- B: tubos verticais de $90 \mathrm{~cm}$, C: tubo horizontal de $120 \mathrm{~cm}, \mathrm{D}$ : cotovelos $90^{\circ}$. .88

Figura 62 - MTS - Bionix Servohydraulic Test System e detalhe do braço fixo e braço móvel (LTC-EESC-USP)

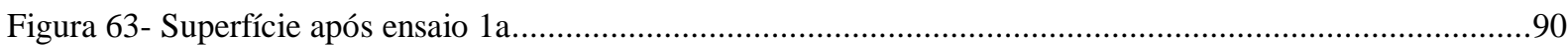

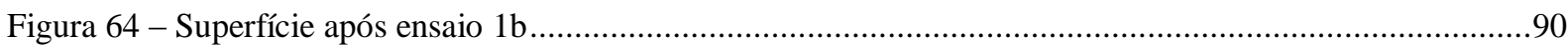

Figura 65- Voluntário 1 sentado e voluntário 2 em pé ..............................................................................92

Figura 66 - Voluntário 2 sentado e voluntário 2 em pé ..........................................................................93

Figura 67 - Voluntário 3 sentado e voluntário 3 em pé .............................................................................94

Figura 68 - Voluntário 4 sentado e voluntário 4 em pé .............................................................................94

Figura 69 - Exemplo a) e b) possíveis de uso da barra de apoio .................................................................95

Figura 70 - Exemplo c) e d) possíveis de uso da barra de apoio no quarto .....................................................95 


\section{LISTA DE TABELAS}

Tabela 1 - Características sócio demográficas e profissionais do grupo de estudo .......................................44

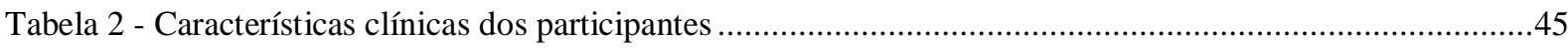

Tabela 3 - Classificação geral dos materiais disponíveis na forma de tubos................................................58

Tabela 4- Tubos, material, dimensões, tensão, flecha e coeficiente de segurança.........................................59

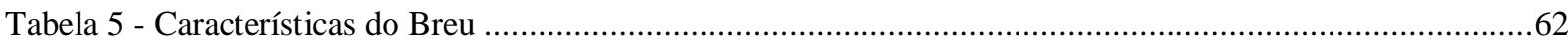

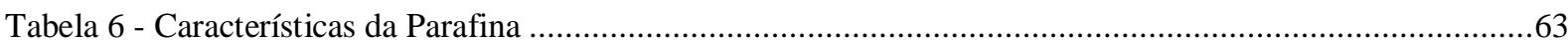

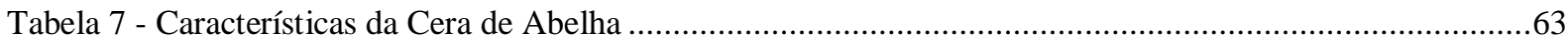

Tabela 8 - Especificações da barra de apoio modular removível ................................................................68

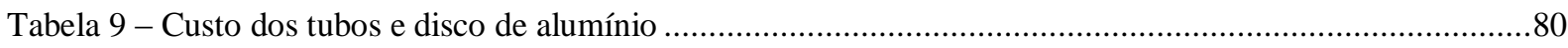

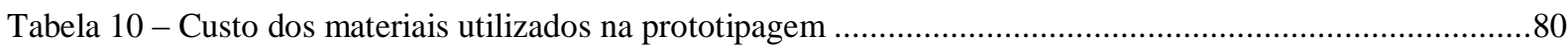

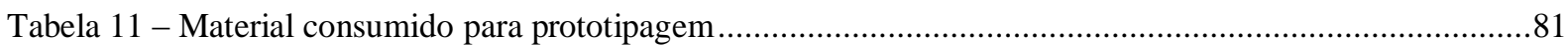

Tabela 12 - Custo da matéria - prima para resina termo reversível .............................................................81

Tabela 13 - Custo do serviço de terceiro para usinagem e fundição das peças............................................81 


\section{LISTA DE SÍMBOLOS}

$\begin{array}{ll}\Theta & \text { Radianos } \\ \mathrm{N} & \text { Newton } \\ \mathrm{Kg} & \text { Kilograma } \\ \mathrm{cm} & \text { Centímetros } \\ \mathrm{m} & \text { Metro } \\ \mathrm{g} / \mathrm{cm}^{3} & \text { Grama/centímetros ao cubo } \\ \mathrm{MPa} & \text { Mega Pascal } \\ \mathrm{GPa} & \text { Giga Pascal } \\ \mathrm{Cu} & \text { Cobre } \\ \mathrm{W} / \mathrm{mh} & \text { Watts } \\ \sigma & \text { Sigma } \\ \mathrm{F} & \text { Flexa } \\ \phi & \text { Diâmetro } \\ { }^{\circ} \mathrm{C} & \text { Graus Celsius } \\ \mathrm{ppm} & \text { Partes por milhão } \\ \mathrm{lt} & \text { Litro }\end{array}$




\section{SUMÁRIO}

4.1.3 Critérios de inclusão

4.1.5 Instrumento de coleta $\quad \mathbf{4 2}$

4.1.6 Dados sócios demográficos, sócio econômico e clínicos $\quad 42$

$\begin{array}{lr}\text { 4.1.7 Análise dos dados } & 43\end{array}$

4.1.8 Características sócio demográficas, econômicas e clínicas 4

4.1.9 Desempenho ocupacional quanto a dificuldade de levantar/sentar 45

4.1.10 Percepção dos participantes quanto às características da barra de apoio 46

4.1.11 Pesquisa de Produtos existentes no mercado $\quad 46$

$\begin{array}{ll}\text { 4.1.12 "Brainstorming" } & 47\end{array}$

4.2 Projeto Conceitual $\quad 52$

4.2.1 Normas Brasileiras de Acessibilidade - NBR 9050 - Acessibilidade de pessoas portadoras de deficiência a edificações, espaço, mobiliário e equipamento urbano 5 $\begin{array}{lr}\text { 4.2.2 Antropometria } & 53\end{array}$ $\begin{array}{lr}\text { 4.2.3 Materiais de mercado } & 55\end{array}$ $\begin{array}{lr}\text { 4.2.4 Fixadores por pressão } & 60\end{array}$ $\begin{array}{lr}\text { 4.2.5 Fixação por Adesivos } & 61\end{array}$ $\begin{array}{lr}\text { 4.2.6 Adesivo termo - aplicável } & 64\end{array}$ 
5.1.1 Usinagem da base da barra de apoio $\quad 69$

$\begin{array}{lr}\text { 5.1.2Tubo } & 71\end{array}$

$\begin{array}{lr}\text { 5.1.3 Cotovelos e Tee } & 71\end{array}$

5.1.4 A Técnica de prototipagem rápida $\quad 72$

$\begin{array}{ll}\text { 5.1.5 Confecção das peças em gesso } & 73\end{array}$

$\begin{array}{lr}\text { 5.1.6 Confecção de molde em silicone } & 73\end{array}$

$\begin{array}{ll}\text { 5.1. } 7 \text { Confecção de peças em resina } & 74\end{array}$

$\begin{array}{lr}\text { 5.1.8 Fundição em alumínio } & 74\end{array}$

$\begin{array}{lr}\text { 5.1.9Fundição em areia } & 75\end{array}$

\begin{tabular}{lr} 
5.1.10 Protótipos do Cotovelo 90 & 75 \\
\hline
\end{tabular}

$\begin{array}{lr}\text { 5.1.11 Protótipos Tee } & 77\end{array}$

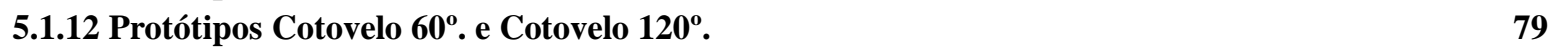

$\begin{array}{lr}5.2 \text { Despesas e custos do protótipo } & 80\end{array}$

6. VALIDAÇÃOO $\quad 83$

$1^{\circ}$. Teste - Teste de Bancada com a Resina termo aplicável 83

$2^{\circ}$. Teste - Teste de bancada com os pesquisadores (que não apresentam dificuldades de passar ST/DP)

$3^{\circ}$. Teste - Ensaio mecânico da resina termo aplicável $\quad 88$

$4^{0}$. Teste - Teste de bancada com voluntários (com dificuldade) 92

$\begin{array}{lr}\text { 6. } 1 \text { Empunhadura } & 96\end{array}$

$\begin{array}{lr}\text { 7. DESCONTINUIDADE } & 97\end{array}$

$\begin{array}{rr}\text { 8. CONSIDERAÇÕES FINAIS } & 98\end{array}$

$\begin{array}{lr}\text { 9. CONCLUSÕES } & 103\end{array}$

10. REFERÊNCIA $r$\begin{tabular}{l}
104 \\
\hline
\end{tabular}

$\begin{array}{lr}\text { APÊNDICES } & 113\end{array}$

$\begin{array}{lr}\text { ANEXOS } & 121\end{array}$ 


\section{APRESENTAÇÃO}

Na graduação em terapia ocupacional, por meio da Iniciação Científica e do Trabalho de Conclusão de Curso (TCC), foi possível identificar as dificuldades e limitações no desempenho ocupacional dos indivíduos portadores de hemofilia. A partir deste trabalho foi produzida uma monografia. Foi ressaltada a necessidade do uso de recursos de Tecnologia Assistiva (TA), um importante recurso terapêutico que a Terapia Ocupacional (TO) pode utilizar como meio de adaptação terapêutica, dispositivo de auxílio ou equipamento de autoajuda, incluindo no processo terapêutico o planejamento ou a modificação estrutural de um ambiente físico como forma de facilitar o desempenho de atividades de autocuidado, trabalho e lazer. (LUZO; MELLO; CAPANEMA, 2004)

Neste estudo, os indivíduos portadores de hemofilia relataram a necessidade do uso de recursos de tecnologia assistiva, principalmente para a higiene: no banho (barra de apoio e cadeira de banho), uso do vaso sanitário (barra de apoio e elevação de vaso sanitário) e recursos de mobilidade para a deambulação como bengala, muleta e cadeira de rodas. Os participantes justificavam as dificuldades devido às articulações mais comprometidas serem o joelho e o tornozelo, essenciais para a deambulação e para assumirem a posição ortostática sem dor e com segurança.

Associado ao acometimento do aparelho locomotor, os participantes do estudo relataram uma importante dificuldade para a realização do movimento de passar de sentado para de pé (ST-DP) e vice-versa, sendo estes movimentos essenciais na realização das atividades inerentes ao desempenho ocupacional, como levantar da cama, sentar à mesa para alimentação, usar o banheiro e dessa forma limitando a realização de outras ações.

O movimento de passar de ST-DP se caracteriza, biomecanicamente, pela geração de um momento de inércia horizontal e outro vertical. Inicialmente ocorre um deslocamento anterior do centro de massa do corpo para dentro da superfície de suporte, gerando um impulso na direção do eixo horizontal, através da rotação do tronco em direção ao quadril e dos segmentos da perna em direção ao tornozelo. O movimento horizontal é finalizado com a desaceleração dos segmentos do corpo, mudando a direção do deslocamento da massa corporal para o eixo vertical, o que implica na realização da extensão do quadril, joelho e tornozelo até atingir a posição ortostática (GOURLAT et al, 2003)

$\mathrm{Na}$ prática clínica dos pesquisadores nota-se que além dos indivíduos portadores de hemofilia há outras diversas doenças que também apresentam limitações que acometem o 
sistema músculo-esquelético, principalmente os músculos relatados acima assim como as articulações ósseas necessárias para o aparelho locomotor realizar os movimentos necessários para a bipedestação e da mesma forma limitam o movimento de ST-DP.

Os dados de 2010 de acordo com o censo do IBGE relatam que cerca de 61,5 milhões de pessoas da população brasileira têm algum tipo de deficiência (física, auditiva, visual, intelectual ou múltipla) e que os dados de deficiência variam de acordo com a região do País. As regiões Norte e Nordeste têm as maiores proporções (16,1\% e 17,7\% respectivamente) de pessoas que afirmam ter pelo menos uma das deficiências investigadas pelos técnicos. A prevalência das incapacidades e deficiências é maior nas regiões mais pobres e, segundo a Organização Mundial de Saúde (OMS), entre as crianças e adolescentes estas taxas alcançam valores 10 vezes maiores que os países desenvolvidos. Diante dos quadros de incapacidade funcional, as sociedades se organizam de forma a superarem essas dificuldades promovendo a inclusão social dessas pessoas. Um dos mecanismos necessários é a utilização de Tecnologia Assistiva por essa parcela da população em qualquer faixa etária, e em qualquer situação do cotidiano.

A partir desse panorama, levantou-se na literatura as doenças que podem dificultar o movimento ST-DP e vice-versa, em consequência de problemas ortopédicos, reumatológicos e neurológicos.

Através desse levantamento foi possível elencar que além das dificuldades impostas ao movimento de ST-DP e vice-versa pelas doenças, o envelhecimento do ser humano também pode ser uma condição desfavorável à realização deste movimento, essencial para as atividades cotidianas. De acordo com Sanglard et. al., (2004) a população idosa, pessoas acima de 60 anos de idade, vem crescendo mais rapidamente do que o restante da população no Brasil. O declínio do sistema orgânico em função do envelhecimento pode variar de pessoa para pessoa, em decorrência de vários fatores, no entanto, o aumento do risco de quedas e de fraturas de quadril tem sido associado à dificuldade dos idosos em realizar movimentos que exijam força muscular em decorrência da fraqueza muscular e os distúrbios de equilíbrio naturais ao envelhecimento.

Por outro lado, nosso país, o Brasil, é um país sul americano em desenvolvimento econômico, social e científico que a partir da reforma monetária ocorrida há cerca de 20 anos, apresentou melhora das condições econômicas de grande parte da população em decorrência da estabilidade econômica vivenciada. No entanto, a população ainda está dividida em classes econômicas: baixa, média e alta, sendo que a classe baixa e média baixa representa a grande maioria da população. Devido a isto, a baixa renda financeira se reflete na dificuldade de 
acesso da maioria da população a serviços básicos como moradia, saúde e educação. Há ainda muitas famílias residindo em casas alugadas, sem condições de compra de casa própria e somado a isto, grande parte da população tem dificuldade de acesso a recursos tecnológicos também. (WIKIPEDIA, 2012)

Desta forma, na prática clínica, o Terapeuta Ocupacional não encontra variedade de produtos/equipamentos de tecnologia assistiva no mercado brasileiro voltado para a necessidade de seus usuários, e assim, é uma prática comum que este profissional desenvolva equipamentos específicos para seu paciente/cliente /usuário, seja esta de baixa ou alta tecnologia.

Em decorrência de fatores como exposto, dentre outros, recentemente, o Ministro de Estado da Saúde, divulgou a Portaria $\mathrm{n}^{\mathrm{o}}$ 793, de 24 de abril de 2012 institui a Rede de Cuidados à Pessoa com Deficiência no âmbito do Sistema Único de Saúde (SUS), por meio da criação, ampliação e articulação de pontos de atenção à saúde para pessoas com deficiência temporária ou permanente; progressiva, regressiva, ou estável; intermitente ou contínua. Essa portaria visa garantir o direito e ampliar a atenção prestada às pessoas com deficiência no Brasil, por meio da estimulação do desenvolvimento dos recursos de tecnologia assistiva.

A partir disso, desenvolveu-se um recurso de tecnologia assistiva que possa auxiliar os indivíduos com dificuldade de levantar/sentar e também não comprometer a renda financeira destes, bem como atender a necessidade de desenvolvimento de um produto que seja fácil de utilizar, não necessitando de conhecimento técnico e que possa ser usado pela população que reside em casas alugadas e não podem alterar a constituição das paredes e pisos.

Para isso, este estudo foi dividido em 1) estudo da literatura e antropometria, 2) desenvolvimento do projeto (dimensões, materiais e desenho) e 3) proposta do sistema baseado em barra de apoio modular removível. 


\section{OBJETIVOS}

\subsection{Objetivo geral}

Projetar e desenvolver um sistema de apoio modular removível baseados em barras de apoio, que exige ou não modificação estrutural das residências, com a função de promover a independência e segurança aos indivíduos no movimento de passar de sentado para em pé.

\subsection{Objetivos Específicos}

Para isto foi necessário atender os objetivos específicos, a saber:

- Classificar os possíveis materiais;

- Dimensionar a barra de apoio de acordo com os materiais disponíveis

- Determinar o modelo e protótipo utilizando o programa CAD Solid Edge

- Realizar simulação virtual, através de programa CAD solid edge Insight TM (CAD - computer aided design ou Desenho auxiliado por computador).

- Fabricar protótipos e validar por meio de ensaios mecânicos e com usuários 


\section{REVISÃO BIBLIOGRÁFICA}

A revisão bibliográfica foi realizada a partir de pesquisa as Bases de dados CINAHL, PUBMEB/MEDLINE, WEB OF SCIENCE, COCHRANE LIBRARY, SCOPUS utilizandose descritores cadastrados na Biblioteca Virtual em Saúde (BVS): biomechanical AND sit to stand, stting to standing OR stand to sit AND assistive tecnology AND products methodologies. Nas bases de dados SCIELO e LILACS utilizou-se os termos em português equivalentes: biomecânica AND sentado para em pé AND tecnologia de apoio OR tecnologia assistiva AND Metodologias de produto. Restringindo-se a pesquisa a artigos disponíveis na íntegra, na língua inglesa e portuguesa.

\subsection{Biomecânica}

Biomecânica é uma disciplina entre as ciências derivadas das ciências naturais, que se ocupa de análises físicas de sistemas biológicos, consequentemente, de análises físicas de movimentos do corpo humano. (AMADIO, 1989)

O corpo humano pode ser definido fisicamente como um complexo sistema de segmentos articulados em equilíbrio estático ou dinâmico, onde o movimento é causado por forças internas atuando fora do eixo articular, provocando deslocamentos angulares dos segmentos, e por forças externas ao corpo. Desta maneira definimos que a ciência que descreve, analisa e modela os sistemas biológicos é chamada Biomecânica, logo uma ciência altamente interdisciplinar dada a natureza do fenômeno investigado. Assim, a Biomecânica do movimento busca explicar como as formas de movimento dos corpos de seres vivos acontece na natureza a partir de parâmetros cinemáticos e dinâmicos (AMADIO, SERRÃO, 2007)

Um conceito importante para biomecânica é o Centro de Massa (CM), para localizar um corpo no espaço tridimensional, ele seria representado por um ponto, e este ponto é o centro de massa. De outra forma, pode-se dizer que se concentrássemos toda a massa de um corpo em um único ponto, este ponto seria o centro de massa.

Outro conceito físico essencial para o estudo da biomecânica são os torques. As articulações humanas e os mecanismos envolvidos na execução de gestos motores dependem, em parte, da força produzida pelo músculo bem como da distância que esta força é aplicada em relação ao eixo de rotação articular (distância perpendicular). Desta forma, a carga imposta aos tecidos em exercícios de reforço muscular envolve não apenas a resistência 
(força) aplicada à articulação, mas também, à distância a qual esta força é aplicada em relação ao eixo de rotação articular.

O torque muscular é determinado pelo produto da força muscular pela distância a perpendicular força muscular. A interação entre os fatores neurais (recrutamento de unidades motoras e frequência de disparo), fatores musculares (relação comprimento $x$ tensão e força $x$ velocidade) determinam a capacidade de produção de força. A variação do centro de rotação articular e variação da linha de tração muscular determinam o comportamento da distância perpendicular muscular. (AMADIO, 1989)

A partir desses conceitos pode-se analisar o movimento de sentado para de pé biomecanicamente.

\subsubsection{Aspectos Biomecânicos do movimento de passar de sentado para de pé (ST-DP)}

Os movimentos de passar de sentado para em pé (ST - DP) e / ou vice-versa (DP-ST) são importantes para as Atividades de Vida Diária e Prática, são essenciais para a mobilidade e por isso, estão associada a uma vida independente. E podem ser difíceis para certos indivíduos, como os obesos, idosos, pacientes com desordens neurológicas, e ortopédicas, como por exemplo, doença de Parkinson, indivíduos com próteses de quadril e/ou joelho totais e ainda, mulheres durante gravidez (ABE et. al.,2010)

O movimento sentado para de pé (ST-DP) é definido operacionalmente como uma transferência bem sucedida do centro de massa $(\mathrm{CM})$ do corpo de uma posição sentada para uma posição estável de pé. A atividade de passar de ST-DP é pré-requisito para a posição vertical, e requer uma complexa coordenação entre o SNC e o sistema neuromuscular. (LANA, 2010)

Na figura 1, temos a ilustração das fases de ST-DP e vice-versa. 


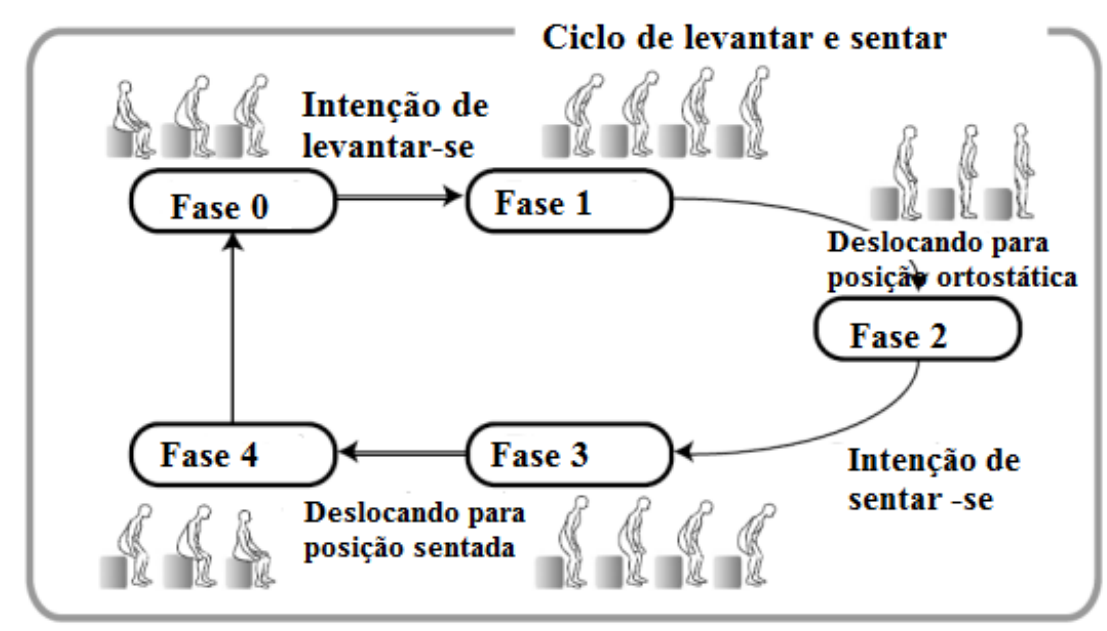

Figura 1 - Definição das fases ST-DP e DP-ST. Fonte: Tsukahara et al, (2010) (adaptado de)

$\mathrm{Na}$ "fase sentado" uma pessoa está sentada em uma cadeira. A fase muda para a fase seguinte, a "fase de transferência de sentado para em pé", quando a intenção de levantar-se é observada. A próxima fase, a "fase de pé" começa quando o usuário tem uma postura ereta. Em seguida, a fase desloca-se para a fase seguinte, "a transferência de em pé para sentado", quando a intenção do usuário de sentar-se é observada. Finalmente, o usuário senta-se na cadeira, na "fase sentado".

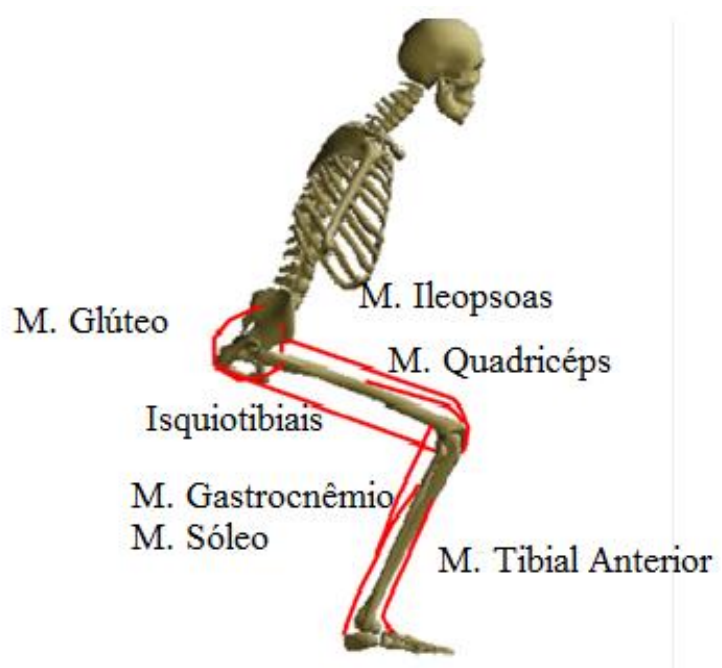

Figura 2 - Localização dos oitos músculos no modelo musculoesquelético do movimento de ST-DP. Fonte: Yoshioka et al, (2012) (adaptado de)

Os muscúlos ileopsoas, glúteo, quadríceps, gastrocnêmio e sóleo, tibial anterior, reto femoral e isquiotibiais estão envolvidos no movimento de ST-DP. Os isquiotibiais, gastrocnêmicos e reto femoral são músculos biarticulares. As funções dos músculos são: ileopsoas (flexão do quadril); glúteo (extensão do quadril); isquiotibiais (extensão do quadril e 
flexão do joelho), reto femoral (flexão do quadril e extensão do joelho), quadríceps (flexão do joelho e flexão plantar do tornozelo), gastrocnêmio (flexão plantar do tornozelo) e tibial anterior (flexão do tornozelo).

No estudo de revisão de Gourlat, (2003), foram levantados estudos prévios que analisaram o movimento de passar de ST-DP, descrevendo-o em várias fases. Schenkman et. al.(1990), definiram quatro importantes fases para o movimento de levantar-se de uma cadeira e, segundo vários autores esta análise é a classificação utilizada com maior frequência, a qual será descrita a seguir.

A fase 1 (momento de inércia de flexão) é caracterizada pela flexão de tronco e pelves resultando em um deslocamento anterior do centro de massa. A primeira atividade muscular parece ser do paravertebral lombar (PL), atuando excentricamente para controlar o movimento do tronco. Posteriormente, a ativação do quadríceps (QUA) prepara o levantar e a fase é finalizada com a perda do contato das nádegas com a superfície da cadeira.

A fase 2 (momento de transferência) inicia com a perda do contato das nádegas com a cadeira e finaliza com a máxima dorsiflexão de tornozelo. Durante esta fase, o centro de massa deve ser mantido dentro da base de suporte enquanto a transição para o movimento de pé é realizada. Isso parece ser acompanhado pela atividade excêntrica do bíceps femural no joelho e glúteo máximo (GLM) no quadril. A atividade muscular dos isquiotibiais (ISQ) ocorre em seqüência imediata a atividade do QUA. O pico de atividade muscular no PL, QUA, ISQ e GLM também ocorre durante esta fase e, devido à grande mudança de estabilidade durante este processo, é necessário que haja constantes ajustes posturais sendo, muitas vezes, recrutada a musculatura do pescoço.

A fase 3 (momento de extensão) inicia com a máxima dorsiflexão e finaliza com a extensão terminal de quadril e tronco. A atividade muscular começa a diminuir em amplitude à medida que a posição de pé é alcançada. A fase 4 (momento de estabilização) começa com extensão terminal de quadril e, teoricamente, finaliza quando a estabilidade postural é alcançada em bipedestação.

As características biomecânicas podem ser mais bem descritas a partir do modelo vetorial descrito na figura 3 : 


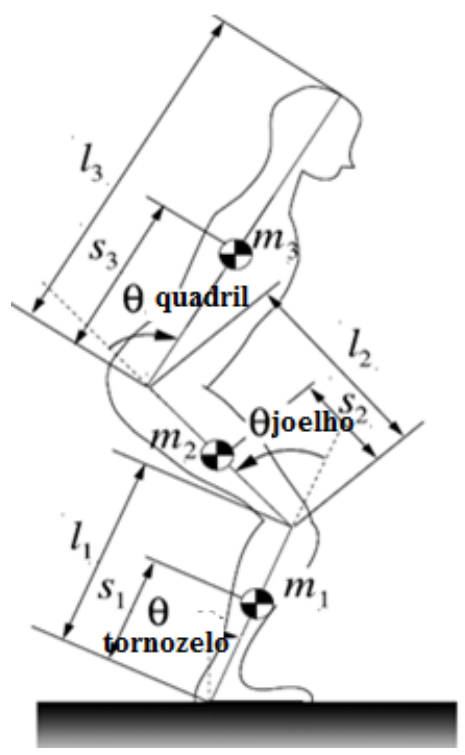

Figura 3 - Definição dos sistemas de parâmetros e variáveis. Fonte: Tsukahara et. al., (2010). (adaptado de)

A direção da flexão de cada articulação pode ser positiva e cada ângulo da articulação se inicia em 0 radianos na postura ereta.

Para realizar o movimento de ST-DP, é necessária a geração de uma força de propulsão para iniciar o movimento anteriormente e uma força de desaceleração seguida da transferência do corpo em um movimento ascendente. (LANA, 2010)

Existem três importantes tarefas relacionadas com os desafios da transição de sentado para em pé: (a) colocar o centro de massa $(\mathrm{CM})$ para a frente, (b) na vertical elevando o $\mathrm{CM}$ a partir do assento para a posição de pé, e (c) fazer a transição a partir de uma base relativamente grande e estável de apoio sentado a uma base de apoio consideravelmente menor em pé. Riley et al. (1997) apud Akram, McIlroy, (2011) definiu os tipos diferentes de ST-DP que fracassam. A primeira, insuficiência de voltar a sentar, ocorre quando o indivíduo sobe só um pouco fora da cadeira e depois se senta novamente. O segundo tipo de falha ocorre quando a pessoa se levanta com sucesso, no entanto, o indivíduo é incapaz de parar num posição de pé estável. As falhas podem ser devido à fraqueza muscular ou a deficiência do equilíbrio ou uma combinação dos dois, e poderia resultar em uma queda. (AKRAM, MCILROY, 2011)

O desafio para a estabilização do CM no final da tarefa está ligado, em parte, para a necessidade de controlar um movimento dinâmico do CM. Em particular, o movimento para a frente da CM deve ser precisamente controlada com sucesso manter a estabilidade ânteroposterior. Fatores como a posição dos pés pode influenciar o movimento horizontal do CM e pode desafiar o controle de estabilidade. Geralmente, uma maior distância dos pés da cadeira 
afeta negativamente a facilidade do ST-DP, devido a maior dificuldade de mover o CM horizontalmente, a qual pode, então, contribuir para um desafio maior do controle dinâmico da estabilidade.

Quando os pés estão posicionados mais longe do corpo, o CM deve deslocar uma distância mais longa para posicionar-se dentro da base mais estreita no apoio. Assim, a manutenção da velocidade neste movimento, e a transição de ST-DP requer mais tempo e maior força nos músculos extensores dos joelhos e amplitude de movimento nos membros. (AKRAM, MCILROY, 2011)

Para evitar a perda de equilíbrio durante ST-DP, é crucial, para manter o CM do corpo dentro da base de apoio durante toda a tarefa. Coerente com a idéia de que são duas competências essenciais para o sucesso do ST-DP, há estudos que mostraram que em adultos mais velhos com limitações funcionais, a força da extremidade inferior e a capacidade de equilíbrio são preditores do sucesso do desempenho, sendo a força muscular o preditor mais forte. (AKRAM, MCILROY, 2011)

O resultado das falhas mecânicas durante o ST-DP é gerador de uma importante causa de incapacidade nos idosos: as quedas, mais de um terço dos adultos mais velhos vem experimentando uma queda a cada ano na Europa. (GOLDBERG, 2011)

Em muitos casos, as ameaças para o equilíbrio postural pode ser anulada pela ativação de estratégias musculares do tornozelo e quadril para mover o CM sobre a base de apoio para restaurar o equilíbrio. Nos casos em que as ameaças à estabilidade são particularmente desafiadoras, a rápida intensificação compensatória pode ser a estratégia utilizada para alterar a base de apoio para restaurar equilíbrio. (GOLDBERG, 2011)

A fim de estabelecer estratégias compensatórias para a realização segura do movimento de ST-DP, vários estudos têm realizado ensaios clínicos utilizando plataformas de força, marcadores biomecânicos para análise de imagem e acelerômetros.

No estudo de Yoshioka et al., (2012), foram combinados procedimentos experimentais e de processamento computacional, para analisar e calcular com um método de dinâmica inversa e um método de optimização estática numérica as forças musculares durante o movimento de ST -DP. Os resultados mostraram diferença na força muscular total exigida dos extensores de quadril e joelho. Especificamente, (1) a força total de extensores do quadril e do joelho é apropriado como o índice da força muscular mínima requerida para uma tarefa de ST-DP e (2) a força mínima requerida está dentro da gama de 35,3-49,2 N / kg. 
No estudo de Van der heijden, (2009), as forças de reação do solo (FRS) foram medidas no movimento de ST-DP e os resultados mostraram que quando há fraqueza dos músculos extensores do joelho há diminuição do desempenho do movimento de ST-DP.

A limitação da extensão dos joelhos pode ser verificada em adultos mais velhos que gastam um tempo maior na execução comparado aos adultos mais jovens, possivelmente devido à diminuição da força muscular da perna e massa magra da coxa, onde se encontram os principais músculos extensores do joelho. (ABE et. al. 2010)

Yoshioka et. al., (2009) afirma que a lentidão de movimentos pode ser um fator causador da diminuição da qualidade de vida diária. O movimento de ST-DP nas pessoas jovens, geralmente ocorre em menos de 2 segundos. Por outro lado, os idosos ou pessoas com mobilidade reduzida são necessários mais de 2 segundos.

A articulação do joelho controla os movimentos das extremidades inferiores das pernas, de modo que uma possível redução do stress físico colocado nos músculos do quadríceps durante o ST-DP contribuiria para a prevenção e tratamento da lesão das extremidades inferiores das pernas. (ABE et.al., 2010)

Estudos recentes também examinaram os efeitos do pé, da força muscular, altura do salto de sapatos, e a posição do assento de forma a encontrar uma melhor estratégia para uma execução de ST -DP e / ou DP- ST, no entanto, poucas informações estão disponíveis no que diz respeito à prática de avaliação de qualquer equipamento simples e prático ou dispositivos para auxílio a estes movimentos. (ABE et. al., 2010)

No estudo de Bahrami et. al., (2000), foi analisado biomecanicamente o movimento de ST-DP com e sem o apoio dos braços em sujeitos saudáveis e em sujeitos paraplégicos com ou sem estimulação elétrica do músculo quadríceps. Para avaliar as características físicas, foi utilizada uma plataforma de força no solo, sensores na cadeira e sensores para medir os momentos em barras fixas posicionadas na frente do sujeito sentado. O estudo mostrou que nos sujeitos saudáveis, o apoio dos braços amplia a base de suporte do corpo e, isto aumenta a estabilidade postural. O uso dos braços durante o movimento de ST-DP reduz os torques nas articulações do quadril e do joelho em 50\%. Foi observado que os sujeitos saudáveis aumentam o braço de alavanca como estratégias para facilitar a transferência do movimento de ST-DP.

Assim, podemos refletir sobre possíveis estratégias de facilitação do movimento de ST-DP a partir de dispositivos de auxílio, como os equipamentos de tecnologia assistiva. 


\subsection{Tecnologia Assistiva}

O ser humano vem a muito procurando instrumentos para aumentar ou compensar ou manter uma função, como forma de potencializar a função humana. Na reabilitação física utiliza-se um arsenal de aparatos com a finalidade de compensar ou substituir funções quando as técnicas de reabilitação não foram eficientes no alcance destas funções em sua totalidade. Sendo assim, a Tecnologia Assistiva (TA) é fruto da aplicação de avanços tecnológicos em áreas já estabelecidas. É uma disciplina de domínio de profissionais de várias áreas do conhecimento, que interagem para restaurar a função humana. Tecnologia Assistiva diz respeito à pesquisa, fabricação, uso de equipamentos, recursos ou estratégias utilizadas para potencializar as habilidades funcionais das pessoas com deficiência.

A aplicação de Tecnologia Assistiva abrange todas as ordens do desempenho humano, desde as tarefas básicas de autocuidado até o desempenho de atividades profissionais.

$\mathrm{O}$ interesse da sociedade brasileira sobre a temática tem-se ampliado continuamente, o que pode ser observado pelo crescimento de participantes e expositores em feiras desta tecnologia, muitas das quais se sucedem em edições anuais e que têm encontrado lugar em diversas localidades de nosso país, indicando um potencial vigor deste segmento da economia. No País existem vários grupos de pesquisa do terceiro setor e de pesquisa acadêmica trabalhando no tema em todas as regiões.

No sistema SUS há entidades cadastradas como concessoras de órteses e próteses, distribuídas de acordo com a densidade populacional no território nacional.

A partir disso, o legislativo brasileiro indicou, na Lei no 10.098, de 19 de dezembro de 2000, a necessidade de proporcionar condições equânimes a todo conjunto de pessoas com deficiência, o que foi regulamentado pelo Poder Executivo, por meio do Decreto no 5.296, de 2 de dezembro de 2004. Tal instrumento determina a criação de um Comitê de Ajudas Técnicas, com a finalidade principal de propor a criação de políticas públicas, aos órgãos competentes, relacionadas com o desenvolvimento e uso de Tecnologia Assistiva. Neste decreto foram definidos os termos: acessibilidade, ajudas técnicas e desenho universal.

O Decreto $n^{\circ} 5.296$, de 2004, que regulamenta a Lei $n^{\circ} 10.098$, de 19 de dezembro de 2000, que dá prioridade de atendimento e estabelece normas gerais e critérios básicos para a promoção da acessibilidade das pessoas com deficiência ou com mobilidade reduzida, possui um capítulo específico sobre as Ajudas Técnicas (VII). Nele consta:

"Consideram-se ajudas técnicas os produtos, instrumentos, equipamentos ou tecnologia adaptados ou especialmente projetados para melhorar a funcionalidade de 
pessoas portadoras de deficiência, com mobilidade reduzida favorecendo autonomia pessoal, total ou assistida". (Brasil, 1999)

Sendo assim, as ajudas técnicas ou Tecnologia Assistiva (TA), nome comumente utilizado no Brasil, é conhecida por ser uma ciência multidisciplinar que agrega saberes diversos tanto dos profissionais da saúde (terapeutas ocupacionais, entre outros), diretamente ligados ao cuidado do individuo quanto da área tecnológica (engenheiros, entre outros) capazes de aplicar os conhecimentos matemáticos, técnicos e científicos na criação, aperfeiçoamento e implementação de utilidades, tais como materiais, estruturas, máquinas, aparelhos, sistemas ou processos, que realizem uma determinada função ou objetivo.

A Ajuda Técnica ou Tecnologia Assistiva é definida neste decreto como produtos, instrumentos, equipamentos ou tecnologia, adaptados ou/e especialmente projetados para melhorar a funcionalidade da pessoa com alguma limitação funcional, favorecendo a autonomia pessoal, total e assistida.

O conceito de tecnologia de apoio deve ser sempre considerado em conjunto com o conceito de desenho universal que propõe que os espaços sejam projetados de forma a atender à população, considerando as variações de idade, sexo, tamanho, peso, habilidades ou limitações das pessoas. Estão envolvidos com a Tecnologia de Apoio os utilizadores finais e outros agentes. São considerados utilizadores finais pessoas com deficiências, com incapacidades transitórias e os idosos, familiares, cuidadores pessoais e outros agentes profissionais de reabilitação, prestadores de serviços de TA (TA como instrumento para a atividade profissional) fabricantes, fornecedores, consultores de TA. (ROCHA; CASTIGLIONI, 2005)

Nos Estados Unidos, a tecnologia assistiva foi definida em 1988, pela lei pública americana (Technology-Related Assistance for Individuals with Disabilities-Act Public 100407) como "qualquer equipamento ou conjunto de produtos, comprados ou modificados ou feitos sob medida, usado para aumentar, manter ou melhorar o desempenho funcional". No Americans with Disabilities Act (ADA), de 1990, encontra-se uma definição de Tecnologia Assistiva que estabelece claramente duas atribuições ao conceito, ou seja, Tecnologia Assistiva são recursos e serviços.

"O termo recurso de TA significa qualquer item, peça de equipamento ou um sistema de produto, quer seja adquirido comercialmente, modificado ou customizado que é usado para aumentar, manter ou melhorar as capacidades funcionais de indivíduos com deficiências. O termo serviço de TA significa qualquer serviço que diretamente assiste um indivíduo com uma deficiência na seleção, aquisição ou uso de um recurso de TA." 
No documento Empowering Users Through Assistive Technology (EUSTAT), que foi elaborado por uma comissão de especialistas de países da União Européia, encontra-se outra referência sobre a compreensão do que seja tecnologia: "Em primeiro lugar, o termo tecnologia não indica apenas objetos físicos, como dispositivos ou equipamento, mas antes se refere mais genericamente a produtos, contextos organizacionais ou "modos de agir" que encerram uma série de princípios e componentes técnicos". (EUROPEAN COMMISSION DGXIII, 1999)

Sendo assim, nos conceitos de Tecnologia Assistiva constantes nos decretos brasileiros, EUSTAT, e ADA, não aparece como objetivo da TA eliminar ou compensar a deficiência (que diz respeito à condição do corpo). O foco destes documentos é a ampliação ou obtenção de uma habilidade na realização da atividade pretendida e, consequentemente, de participação social das pessoas com deficiência.

Estes documentos nacionais e internacionais evidenciam uma compreensão conceitual abrangente, sendo a Tecnologia Assistiva entendida como a aplicação de um conhecimento que se traduz numa técnica, procedimento, metodologia ou recurso específico, que busca ampliar ou proporcionar o desempenho de atividades necessárias e pretendidas por uma pessoa com deficiência ou incapacidade.

Neste contexto, a implantação do uso de equipamentos destina-se a assistir, aumentar ou favorecer o desempenho funcional do indivíduo frente a uma tarefa a ser realizada. Assim, a escolha de um dispositivo de assistência, ou seja, um equipamento que promova o aumento e/ou participação do indivíduo com incapacidade na execução de uma atividade, pode ser uma tarefa complexa. Todas as limitações e necessidades do usuário, do cuidador e do ambiente devem ser consideradas, pois seu somatório definirá como o dispositivo funcionará e como sua função será percebida (PAIN; McLELLAN, 2003).

Para a melhor compreensão desta ciência, também é importante esclarecer as diferenças de definições de tecnologia assistiva, tecnologias de reabilitação, Sistema de Prestação de Serviços -SPS em Tecnologia Assistiva, Tecnologia Social e design universal, pois em muitos casos há a confusão dos limites e dos enquadres de cada um destes conceitos.

As tecnologias de reabilitação são os dispositivos utilizados em ambiente terapêutico pelos profissionais capacitados para sua utilização com o objetivo de retornar um individuo a um nível anterior de função depois do surgimento de uma condição patológica, por exemplo: modalidades de agentes físicos como ultra-som, diatermia, parafina e estímulos elétricos funcionais são recursos de tecnologia de reabilitação. (ANSON, 2005)

O conceito do Desenho Universal é definido pelo Decreto n 5.296 de 2004 diz: 


\begin{abstract}
"Desenho Universal: concepção de espaços, artefatos e produtos que visam atender simultaneamente todas as pessoas, com diferentes características antropométricas e sensoriais, de forma autônoma, segura e confortável, constituindo-se nos elementos ou soluções que compõem a acessibilidade.” (BRASIL, 2004)
\end{abstract}

Com isso, o design universal busca através da aplicação de seus princípios, tanto na relação individuo/produto quanto na concepção do meio ambiente viabilizar fatores relevantes da sua usabilidade como meio de proporcionar que estes produtos ou espaços atendam a maioria da população, com a possibilidade da diminuição da estigmatização de seus usuários. (RIBEIRO, 2007)

Os modelos de Sistemas de Prestação de Serviços - SPS em Tecnologia Assistiva e a rede interdisciplinar envolvida nesta prática são outro tema de central importância. Com relação aos modelos de serviços, constatou-se que em países onde a organização de serviços de Tecnologia Assistiva já existe há mais tempo, como em vários países europeus e da América do Norte, há uma tendência de revisão e mudança de paradigma, que abandona o modelo médico, pautado no déficit individual e na prescrição de um recurso de Tecnologia Assistiva específico, para um modelo social, tecnológico e ecológico (PALACIOS, 2008).

Desenvolver soluções tecnológicas valorizando o conhecimento do usuário, de suas demandas e do contexto em que esta tecnologia será aplicada, colabora para que este usuário se aproprie e realmente usufrua de uma tecnologia que atenda à sua necessidade e expectativa. Neste sentido, o conhecimento da Tecnologia Social entendida como "um conjunto de técnicas e metodologias transformadoras, desenvolvidas e/ou aplicadas na interação com a população e apropriadas por ela e que representam soluções para inclusão social e melhoria das condições de vida" poderá ajudar a estabelecer modelos para serviços e projetos de desenvolvimento tecnológico no Brasil. (ITS, 2007)

Segundo Cook e Hussey (1994 apud Luzo, Mello, Capanema, 2004), é necessário caracterizar e contextualizar a tecnologia assistiva sob vários pontos de vista: assistiva versus reabilitadora e educacional, simples e sofisticada, concreta e teórica, equipamento versus instrumentos, geral versus específica e comercializada e individualizada.

Quando o recurso tecnológico possibilita ao indivíduo que desempenhe uma atividade funcional, ele é denominado assistivo, enquanto que quando este é uma modalidade que faz parte de um plano de reabilitação ou de educação, ajudando a desenvolver habilidades, pode ser classificada como reabilitadora ou educacional e não-assistiva. No mercado há uma enorme disponibilidade de dispositivos de tecnologia assistiva, no entanto, existem casos em 
que há a necessidade do desenvolvimento de uma tecnologia individualizada para a solução de um problema específico de um indivíduo. (LUZO; MELLO; CAPANEMA, 2004)

As tecnologias assistivas podem ser classificadas como simples, quanto a adaptação realizada exige menor utilização de recursos de tecnológicos de alta complexidade e são classificadas como sofisticadas quando se é exigido tecnologia de alta complexidade, por exemplo: adaptação no cabo de uma colher, é uma tecnologia assistiva simples enquanto que unidades computadorizadas de controle ambiental é uma tecnologia assistiva sofisticada. (WALDRON; LAYTON, 2008)

Quanto a classificação de concreta e teórica, Luzo, Mello e Capanema, 2004, definem como concreto o objeto em si, seja comercializado ou feito sob medida. A tecnologia teórica é aquela que se refere à ação humana no processo de construção de conhecimento. Assim como há diferenciação quanto a tecnologia comercializadas e as individualizadas, pois mesmo havendo uma enormidade de dispositivos disponíveis no mercado ainda há casos em que se necessite de desenvolvimento de uma tecnologia individualizada ou de adaptações nas tecnologias comercializadas para que se atinja o objetivo proposto para aquele individuo.

Há ainda as tecnologias gerais, que tem aplicação em muitas atividades, como sistemas de posicionamentos, como também, há as tecnologias específicas que visam atingir o máximo potencial em relação a uma determinada habilidade, como acontece com os aparelhos de alimentação, auditivos ou de comunicação. Finalmente há a diferenciação entre equipamentos e instrumentos, o primeiro definido como aparelhos que proveem benefícios à um individuo, independentemente de seu nível funcional; e o segundo dependem do desenvolvimento de habilidades especificas para serem utilizados. No entanto, há alguns dispositivos que podem ser considerados como ambos como ocorrem com a unidade computadorizada de controle ambiental, que em alguns momentos não exige habilidade especificas do usuário para seu funcionamento e em alguns casos o usuário é treinado para aprender a manipular as ações deste sistema. (LUZO; MELLO; CAPANEMA, 2004)

A legislação brasileira estabeleceu como critérios para Classificação de TA, três importantes referências que apresentam diferentes focos de organização e aplicação, são elas: ISO 9999, Classificação Horizontal European Activities in Rehabilitation Technology HEART e Classificação Nacional de Tecnologia Assistiva, do Instituto Nacional de Pesquisas em Deficiências e Reabilitação, dos Programas da Secretaria de Educação Especial, Departamento de Educação dos Estados Unidos.

A partir do estudo dessas classificações concluiu-se que não existe uma única forma de classificar Tecnologia Assistiva e as várias classificações existentes são aplicadas de 
acordo com os objetivos de catalogação de recursos, ensino, trocas de informação, organização de serviços de aconselhamento e concessão. O importante é ter claro o conceito de TA e os objetivos para os quais as classificações foram criadas. (BRASIL, 2009)

Outro questionamento foi quanto a ausência de consenso no referencial internacional apresentado, o Comitê de Ajudas Técnicas propôs que os termos "Tecnologia Assistiva", "Ajudas Técnicas" ou "Tecnologia de Apoio", em um primeiro momento, continuassem a ser utilizados como sinônimos e que o termo Tecnologia Assistiva correspondesse às bases conceituais já aprovadas. Entretanto, também se adotou como obrigatória a utilização do termo Tecnologia Assistiva, a partir deste momento, nos documentos oficiais brasileiros. (BRASIL, 2009)

A partir dessas discussões podem-se estabelecer as principais áreas de aplicação da tecnologia assistiva no Brasil.

\subsubsection{Principais Áreas de Aplicação}

A tecnologia assistiva pode ser aplicada em todas as modalidades de desempenho humano, desde as tarefas básicas de autocuidado até as atividades profissionais. Sendo assim, tem como áreas de aplicação: adaptações para atividades da vida diária; sistemas de comunicação alternativa; dispositivos para utilização de computadores; unidades de controle ambiental; adaptações estruturais em ambientes domésticos, profissionais ou público; adequação da postura sentada; adaptações para déficits visuais e auditivos; equipamentos para mobilidade; adaptações em veículos. (ROCHA; CASTIGLIONI, 2005)

\subsubsection{Adaptação Ambiental}

Dois dos principais objetivos de terapeutas ocupacionais são permitir o desempenho de atividades da vida diária e promover a saúde e bem-estar, bem como participação da comunidade. Para isso, o terapeuta ocupacional pode fornecer uma variedade de alternativas e possibilidades para adaptar o ambiente ou idealizá-lo para uma ambientação mais adequada à realização das atividades diárias. Geralmente, pontua-se sobre a eliminação de barreiras arquitetônicas e ambientais, devendo ocorrer com a participação de arquitetos, engenheiros, decoradores ou designers. (FÄNGE, IWARSSON 2005)

Pessoas com limitações ou capacidade funcional reduzida podem ainda necessitar de inclusão de recursos assistivos para ampliar sua independência ou controlar parte de suas ações no contexto domiciliar. Uma série de categorias de dispositivos para assistência que ampliam a função do cliente é encontrada facilmente para compra no mercado, como: 
telefones adaptados, interfones de emergência (comunicação à distância); equipamentos audiovisuais (lazer); forno de microondas e termostatos para aquecimento (gerenciamento da casa); alarmes domésticos e câmeras (segurança da família e situações de emergência). (TEIXEIRA, ARIGA, YASSUKO, 2003)

A adaptação ambiental por automação de casas é outro recurso para adaptação de ambientes e que faz parte de modernos projetos de construção de residências. A automação engloba o controle do ambiente (iluminação, ventilação e nível de ruído) e de aparelhos (televisão, som, liquidificador) por meio de dispositivos eletroeletrônicos acionado por comando de voz, botões ou programa de computador. (IWARSSON, STÅHL, 2003).

A avaliação ambiental pode ser feita por entrevistas e observação direta quando há complexidade nas adaptações apontadas. Quando um cliente possui limitação de mobilidade, a avaliação por observação direta através de visita domiciliar pode ser realizada em conjunto pelo terapeuta ocupacional e fisioterapeuta. A avaliação ambiental é administrada em três passos: avaliação dos componentes pessoais (verificando as demandas do contexto particular do cliente e as expectativas de seu papel, o nível de função no ambiente e suas ações específicas, tal como o uso do banheiro), avaliação dos componentes ambientais (observando o ambiente físico, os objetos e as qualidades sensoriais do ambiente) e análise dos problemas de acessibilidade (incluindo onde a casa está situada e qual o tipo de acomodação fornecido). (FÄNGE, IWARSSON 2005)

As alterações no ambiente mais simples e comuns geralmente apontadas como necessárias são: instalação de rampas para entrada e saída de espaços diferentes, remoção de batentes, colocação de barras de segurança, remoção ou reorganização de móveis, modificação da altura da cama, colocação de telefone e interruptor de luz próximo à cama, instalação de sistema de controle eletroeletrônico, correção de luz de emergência e luz noturna, fixação ou remoção de tapetes e substituição do piso por cerâmica antiderrapante. (ROGERS, STONE, 2002)

As modificações e adaptações em ambientes domiciliares também são efetivadas visando ampliar a acessibilidade para promover o desempenho funcional em tarefas rotineiras. A ausência de acessibilidade pode eliminar ou restringir a independência de idoso e indivíduos com deficiência no ambiente. O processo de intervenção para modificação domiciliar é embasado nos parâmetros construtivos da Norma Brasileira NBR-9050, que apontam diretrizes para planejamento de edificações, mobiliário e equipamentos urbanos com eqüidade, independência, conforto e segurança. (CAVALCANTI, GALVÃO, 2007) 
A elaboração de adaptações no domicílio deve atender a critérios de mobilidade, orientabilidade e usabilidade. A mobilidade está no desempenho do indivíduo no contexto físico; ou seja, se o espaço permite sua livre circulação, ou se possui as dimensões apropriadas à realização da tarefa. A orientabilidade diz respeito ao relacionamento do indivíduo com a arquitetura construída, isto é, se o individuo é capaz de obter do meio físico as informações necessárias para uso e acesso do ambiente. Já usabilidade é pontuada no relacionamento do individuo com equipamento ou mobiliário existente (acessar a pia da cozinha, alcançar objetos no armário, abrir e fechar portas). (IWARSSON et. al.,1998)

O processo de adaptação ambiental engloba a prática centrada no cliente, respeitando suas reais necessidades e valorizando o significado atribuído aos espaços e mobiliários existentes, que podem representar para seus ocupantes identidade familiar, status e privacidade. (CAVALCANTI, GALVÃO, 2007)

\subsubsection{Adaptações de mobilidade}

Shoemaker et. al. (2009) classificou os dispositivos mais comumente utilizados para mobilidade. Estes dispositivos aumentam ou substituem a deambulação para os indivíduos com limitações de mobilidade, e eles incluem muletas, bengalas, andadores, cadeiras de rodas (WCS), e scooters. Muitos usuários confiam em seus dispositivos de mobilidade para o desempenho das atividades diárias e participação em uma variedade de ações na comunidade.

A demanda por recursos de tecnologia assistiva para a mobilidade está crescendo devido a uma variedade de fatores, incluindo o grande número tanto de pessoas idosas com dificuldade de mobilidade quanto de pessoas com deficiências de mobilidade. A alta demanda, associada aos avanços tecnológicos, tem trazido um leque de opção de dispositivos para adultos e crianças. (SHOEMAKER et. al., 2010)

Em propósito com a prática baseada em evidências, aumentou a pressão sobre os profissionais clínicos em defender as recomendações destes dispositivos. Infelizmente, pesquisas rigorosas para provar a eficácia, efetividade e custo-efetividade dos dispositivos de mobilidade e suas características não tem acompanhado o crescimento de opções de tecnologia. (SHOEMAKER et. al., 2010)

Segundo Cavalcanti, Galvão e Miranda (2007) a mobilidade pode ser dividida em: mobilidade funcional e mobilidade na comunidade. Estas são descritas nas áreas de ocupação como tipos de atividades respectivamente da vida diária e instrumental da vida diária. A mobilidade funcional é definida como a capacidade de o indivíduo mover-se ou mudar-se de uma posição para outra ao desempenhar atividades cotidianas como a movimentar-se na 
cadeira de rodas ou na cama e realizar transferências e inclui o desempenho na deambulação funcional e no transporte de objetos.

\subsubsection{Equipamentos de TA para mobilidade mais utilizados}

As bengalas podem ser em madeira ou alumínio, em tamanho pequeno, médio e grande, como bengala de apoio simples, bengala de três pontas ou bengala de quatro pontas são os equipamentos mais comuns de ajuda para a manutenção da mobilidade. Uma vez que suportam em torno de $20 \%$ do peso corporal, são indicadas para o usuário que apresenta comprometimento apenas unilateral do membro inferior. $\mathrm{O}$ uso melhora o equilíbrio, auxilia na redução da descarga de peso sobre o membro acometido durante a deambulação e fornece estabilidade durante o deslocamento do usuário. (CAVALCANTI; GALVÃO; MIRANDA, 2007)

Os andadores suportam em torno de $50 \%$ do peso corporal do usuário e são mais estáveis que as bengalas. São indicadas quando é necessário maior suporte do usuário ou se a manutenção do equilíbrio é deficitária. É um equipamento que fornece equilíbrio, segurança, estabilidade e maior liberdade de transferência de peso na troca de passos. São comercializados nos tamanhos pequeno, médio e grande. Podem ser em modelo de apoio frontal ou posterior, ser fixo ou articulado, com formato triangular, possuir ou não rodas dianteiras e regulagem na altura. (ANSON, 2005)

As muletas são indicadas quando não é permitida descarga de peso corporal nas extremidades inferiores. Seu objetivo é fornecer mobilidade com independência e com a possibilidade de manutenção das AVD’s por proteção da extremidade inferior com redução da descarga de peso, entretanto, demanda absorção do peso corporal pelos membros superiores. Existem dois tipos de muletas: as axilares (conhecidas pelo dispositivo de apoio ser nas axilas do indivíduo) e as não axilares ou canadenses (o apoio está no terço distal do braço). As muletas canadenses são mais indicadas, pois absorvem melhor o choque e distribuem o peso corporal mais confortavelmente que os outros tipos. (LUZO; MELLO; CAPANEMA, 2004)

As cadeiras de rodas podem ser de propulsão manual ou motorizada. A mobilidade com a cadeira manual depende das habilidades do usuário ou da assistência de terceiros, enquanto as cadeiras de rodas motorizadas dependem de uma unidade de motor e do acesso aos controles do tipo joystick ou switch. Elas são indicadas de acordo com a necessidade do cliente e com base nas suas medidas antropométricas. (ANTONELI, 2003) 
Segundo Crell, et.al. (2005) os equipamentos de transferência são dispositivos que auxiliam na mudança de posição dos indivíduos com dificuldades na mobilidade. Podem ser divididos em:

- Barra de segurança para banheiro: são indicadas para facilitar a transferência da cadeira de rodas para o assento sanitário com maior segurança e conforto. A seleção e colocação de um modelo variam de acordo com a necessidade do usuário e as barras de segurança podem ser fixadas tanto no chão quanto na parede.

- $\quad$ Acessórios para transferência na cama: a mobilidade na cama pode ser auxiliada pela fixação de uma barra tubular na beirada da cama, como forma de fornecer suporte para transferência da posição sentada para a posição de pé. Além desta, pode-se utilizar tábua de transferência que auxilia os indivíduos com as extremidades superiores e inferiores incapazes de suportar o peso do corpo.

- Poltronas adaptadas: os assentos de poltronas ou cadeiras conhecidas como "cadeira do papai”, podem ser adaptados com sistema de impulso para auxiliar na transferência da posição sentada para posição de pé.

Segundo Cavalcanti, Galvão e Miranda (2007) além dos equipamentos de transferências há os sistemas elevadores que também auxiliam na mudança de posição ou lugar de pessoas com limitações de mobilidade, exemplificando os guinchos de transferência elétricos e sistemas lift, elevadores e cadeira-elevador e rampas e plataformas.

No Brasil, a Associação Brasileira de Normas Técnicas (ABNT), através da Norma Brasileira - NBR- 9050: 2004 especifica critérios e parâmetros técnicos para a normalização no campo da acessibilidade, de acordo com os preceitos de desenho universal, para que as edificações, espaços, mobiliários e equipamentos urbanos possam ser de utilização das pessoas com deficiência ou não, permitindo sua autonomia e independência

\subsubsection{Barras de apoio existente no mercado}

Dentre as adaptações para mobilidade, um dispositivo bastante utilizado atualmente são as barras de apoio. As barras de apoio hoje fabricadas no Brasil são todas regulamentadas por leis governamentais especificas a ABNT visando a segurança de usabilidade de seus usuários.

Ainda segundo a NBR 9050 (2004), quanto à empunhadura, objetos tais como corrimãos e barras de apoio, entre outros, devem ter seção circular com diâmetro entre $3,0 \mathrm{~cm}$ e 4,5 cm e devem estar afastados no mínimo $4,0 \mathrm{~cm}$ da parede ou outro obstáculo. Quando o objeto for embutido em nichos deve-se prever também uma distância livre mínima de $15 \mathrm{~cm}$. 
São admitidos outros formatos de seção, desde que sua parte superior atenda às condições desta subseção. (Figura 4)

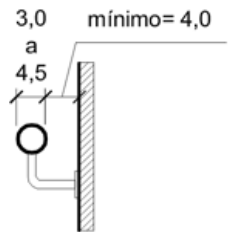

a)

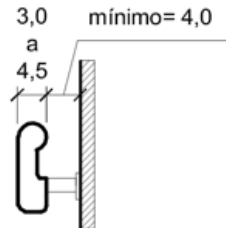

b)

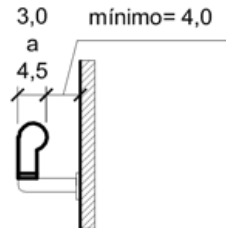

c)

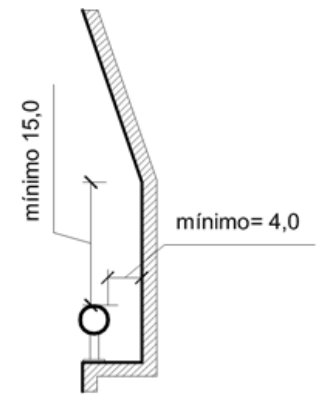

d)

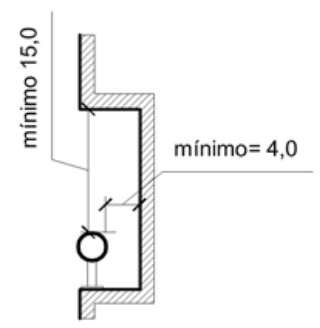

e)

Figura 4 - Empunhadura Fonte: NABNT9050, (2004) (adaptada de)

Segundo esta mesma norma, para barras de apoio fixas, ou seja, as barras de apoio utilizadas em sanitários e vestiários devem suportar a resistência a um esforço mínimo de 1,5 $\mathrm{kN}$ em qualquer sentido, ter diâmetro entre $3 \mathrm{~cm}$ e $4,5 \mathrm{~cm}$, e estar firmemente fixadas em paredes ou divisórias a uma distância mínima destas de $5 \mathrm{~cm}$ da face interna da barra. Suas extremidades devem estar fixadas ou justapostas nas paredes ou ter desenvolvimento contínuo até o ponto de fixação com formato recurvado. Quando necessários, os suportes intermediários de fixação devem estar sob a área de empunhadura, garantindo a continuidade de deslocamento das mãos.

O mesmo ocorre de acordo com o Conselho Nacional de Metrologia, Normalização e Qualidade Industrial - CONMETRO, de 1993, os balaústres, corrimãos e colunas dos ônibus devem ser construídos com seção transversal circular com diâmetro externo compreendido entre $0,03 \mathrm{~m}$ e $0,04 \mathrm{~m}$, resistindo a uma solicitação de $1500 \mathrm{~N}$ aplicada no ponto eqüidistante das extremidades de fixação e, no caso de corrimão superior, a uma solicitação de $400 \mathrm{~N}$ a cada $0,20 \mathrm{~m}$ de comprimento, tendo proteção superficial adequada quando necessária. (INMETRO, 1993)

As barras de apoio produzidas atualmente, no mercado brasileiro, são fabricadas em aço inox liso ou escovado, latão cromado, ou com pintura epoxi-branca. E a fixação da barra de apoio na parede ou no chão é feita através de parafusos, cimento, cal e areia.

Há mais de 500 tipos de modelos de barra de apoio para diversas necessidades, como principais têm-se as barra de apoio em banheiros, barra de apoio em vestiários, barra de apoio em sanitários, barra de apoio para lavatório, barra de apoio para box e barra de apoio para abertura de portas. (Figuras 5-7) 

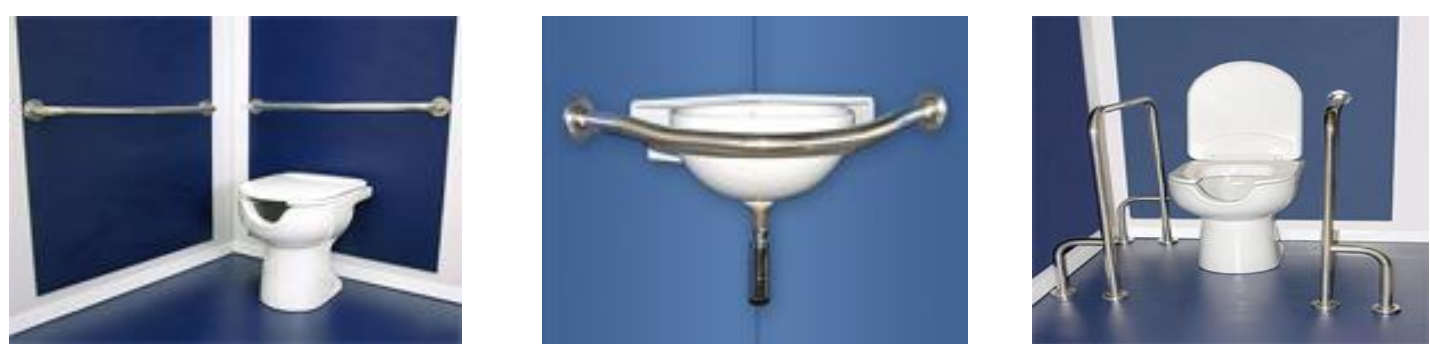

Figura 5 -- Barra de apoio utilizadas no banheiro, para sanitários e lavatórios Fonte: http://www.barrasdeapoio-seguranca.com.br/barrasdeapoio.htm

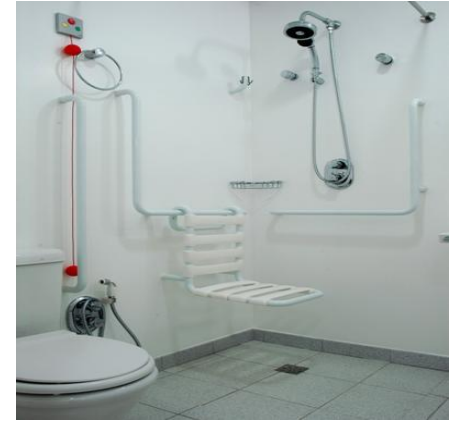

Figura 6 - Barra de apoio para box Fonte: http://barradeapoioacessibilidade.blogspot.com/

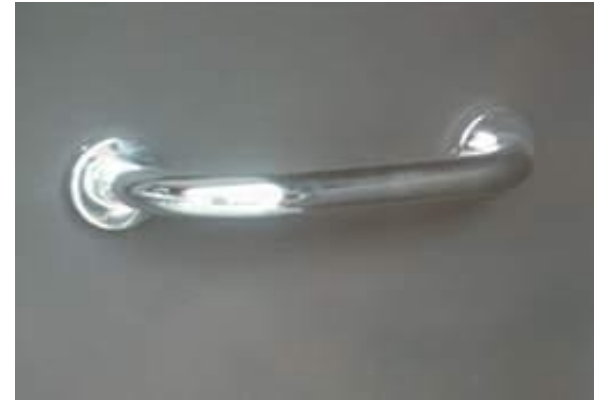

Figura 7 - Barra de apoio em inox para abertura de porta Fonte: http://adaptafacil.com.br/

\subsection{Metodologias de Projeto de Produto aplicado á Tecnologia Assistiva}

As metodologias de produtos são representações filosóficas de uma série de eventos que ocorrem com alguma sequência cronológica e formam um modelo de projeto comum. Existe uma grande variedade de metodologias de produtos e um grande número de modelos estudados, alguns estão divididos em três fases distintas (síntese, análise e avaliação), enquanto outros são divididos em diferentes sub-tarefas, fases e atividades. Os principais autores que estudaram e desenvolveram teorias específicas para esta metodologia são Ashimow (1968); Urban, Hauser (1993); Pugh (1995); Kaminski (2000); Baxter (2003); Back e Forcellini (2003); Ulrich e Eppinger (2004) e Pahl, Beitz (2005).

Asimow (1968) define projeto como "uma atividade orientada para atender as necessidades humanas, principalmente aquelas que podem ser satisfeitas por fatores tecnológicos da nossa cultura.

De acordo com Baxter (2003) uma proposta de metodologia é descrita em cinco fases, sendo a primeira fase a de reconhecimento da necessidade que está relacionada com informações sobre a necessidade e existência do produto. A segunda fase chamada especificação que inclui todas as especificações do produto (esforços e antropometria). A 
terceira fase é o conceito que está relacionado com a idéia de como será o produto, forma e design e segue-se na quarta fase que consiste na fabricação de protótipos. A última fase que é a validação dos protótipos através de dois testes: Teste 1 de validação do modelo, que é realizado em bancada pelos pesquisadores na tentativa de melhorar o protótipo e o Teste 2 de validação do modelo, que pode ser realizado com os prováveis usuários para verificar a aplicabilidade/funcionalidade do produto desenvolvido.

Na definição de Pugh (1995) o processo completo de desenvolvimento do produto é uma atividade sistemática, que reuni toda a cadeia produtiva, se inicia com a identificação do mercado e das necessidades do consumidor e finaliza com a venda de produtos capazes de satisfazer tais necessidades.

Para Kaminski (2000) o processo de desenvolvimento do produto é um conjunto de atividades envolvendo a empresa como um todo, tendo como objetivo transformar as necessidades de mercado em produtos ou serviços economicamente viáveis.

Segundo Back e Forcellini (2003) a atividade de projeto esta inserida dentro de um processo mais abrangente denominado de processo de desenvolvimento do produto, que é parte integrante do ciclo de vida do produto. O ciclo de vida de um produto pode ser dividido em fases: a avaliação das necessidades, análise (descrição e especificação), planejamento do produto (avaliação técnica e de mercado), projeto (concepção preliminar e detalhada), produção, testes, implantação (lançamento e acompanhamento), uso e fim da vida útil do produto (descarte, reciclagem e destruição). A atividade de projeto é um processo de transformação de múltiplas etapas consecutivas, que evolui da identificação das necessidades e das expectativas dos clientes e de como estas poderão ser satisfeitas, passa pela concepção de um conceito tecnicamente exeqüível, até alcançar a completa especificação de um produto comercialmente viável.

Para Ulrich e Eppinger (2004) o processo de desenvolvimento do produto é definido como a sequência de etapas ou atividades (físicas ou intelectuais) que a organização utiliza para conceber, projetar e comercializar o produto.

Entende-se como metodologia de projeto o estudo de um procedimento planejado com indicações claras de conduta a serem observadas no desenvolvimento do projeto de um sistema técnico (PAHL e BEITZ, 2005).

Considerando que um dispositivo de TA é um produto, que necessita adequar-se as necessidades de usuários específicos, pessoas com limitações funcionais, podemos relacionar as metodologias utilizadas na ciência da engenharia para desenvolvimento de produtos 
comerciais com a realidade dos profissionais de saúde que desenvolvem dispositivos de TA geralmente somente para seus pacientes/usuários/clientes.

O uso efetivo e a aceitação de um dispositivo de TA por parte do usuário e de seus cuidadores, seja ele produzido em série ou sob medida, frequentemente envolve um somatório de fatores econômicos, ergonômicos e estéticos na sua fase de desenvolvimento. Estes fatores agregam valor ao produto que, enfim, se destina a ampliar ou facilitar a participação do indivíduo e/ou cuidadores nas atividades, refletindo-se numa melhor qualidade de vida. (DUTRA, GOUVINHAS, 2010)

Segundo Soares e Martins (2000), os produtos devem ser desenvolvidos de acordo com as características de seus consumidores/usuários. Assim, estabelecer a inter-relação entre as características do produto e as necessidades do usuário pode ser considerada a fase mais importante no desenvolvimento de um produto ou dispositivo de TA.

De acordo com Baxter, (2003), a capacidade de prever as percepções de usuários e consumidores sobre as funções de um produto, de antever a importância que eles atribuem a essas funções, são caminhos que ampliam o conhecimento sobre o produto. E este conhecimento, construído sob a óptica da díade usuário/consumidor e sob o ponto de vista funcional do produto possibilita o desenvolvimento de novos conceitos.

Sendo assim, este raciocínio empregado durante a elaboração ou avaliação de um dispositivo de tecnologia assistiva possibilita prever detalhes sobre os aspectos conceituais e as especificações técnicas do equipamento.

A metodologia de projeto se inicia primeiramente pela identificação da oportunidade, seguido pelo planejamento do produto para que essa oportunidade detectada possa ser explorada e por fim pelo teste do protótipo. O design de um novo produto é considerado completo quando, na sua fase de planejamento, se tem a previsão de quem irá adquiri-lo e de como será vendido (benefícios ofertados), a fim de que o conjunto de características apresentadas ao consumidor no novo produto esteja além das encontradas nos produtos que já existem no mercado (URBAN; HAUSER, 1993).

A metodologia de escolha deste estudo é definida por Pahl \& Beitz (2005) que utilizam como proposta a divisão do projeto em quatro fases, sendo estas: projeto informacional, projeto conceitual, projeto preliminar e projeto detalhado. Primeiramente, necessita-se conhecer a população ou individuo que irá utilizar o recurso proposto e com qual objetivo além de verificar qual será a função deste produto para esta pessoa, tornando os usuários membros integrantes do processo de tomada de decisões. 
Para isto, tem-se a fase que compreende a fase pré-conceitual ou informacional do desenvolvimento de um produto que é iniciada a partir da pesquisa de mercado que consiste no levantamento de produtos disponíveis para a comercialização com as características semelhantes ao produto em questão. A partir dessa pesquisa pode-se levantar qual será o diferencial deste produto a ser elaborado, assim como o custo de venda e sua aceitação pelos consumidores.

A fase de projeto de produto envolve o desenvolvimento das especificações, ou seja, um pré-projeto com as reais necessidades do produto para que este atenda as necessidades do usuário.

Posteriormente, temos a fase conceitual, que consiste em iniciar a elaboração propriamente dita de modelos a serem realizados desse produto e segue-se com a fase de projeto de produto, na qual serão analisados os conceitos viáveis das fases anteriores e a manufatura de um protótipo, posterior validação e estudo da descontinuidade. 


\section{METODOLOGIA}

Este trabalho foi baseado na prática clínica em que foram observadas as necessidades dos indivíduos com dificuldade para realizar o movimento de sentado para em pé e a limitação na independência em decorrência disto. As queixas em relação ao uso das barras de apoio incentivaram o desenvolvimento da idéia de uma barra de apoio que permitisse o uso em diferentes pisos, que não modificasse a estrutura dos domicílios, que proporcionasse maior conforto e que fosse de fácil instalação, sendo estes os apontamentos e queixas mais comuns dentre os indivíduos com dificuldades para levantar-se/sentar-se.

Para tanto, utilizou-se a metodologia de projeto para o desenvolvimento do produto segundo Paul, Beitz (2005), que são representações filosóficas e estratégicas para a condução de um projeto. Seguindo uma metodologia descritiva quantitativa para o desenvolvimento do protótipo.

O estudo foi dividido em cinco fases, sendo a primeira fase o projeto informacional que está relacionado com informações sobre a necessidade da barra de apoio. A segunda fase chamada projeto conceitual que inclui todas as especificações da barra de apoio (esforços e medidas antropométricas). A terceira fase é o protótipo que está relacionado com a idéia da barra de apoio, forma, design e dimensões e manufatura de protótipos físicos. A quarta fase consiste na validação por meio de ensaios mecânicos e com usuários e a quinta e última fase é a descontinuidade que é o estudo do descarte do produto após o uso. Essas fases podem ser modificadas através da verificação das necessidades de acordo com o decorrer da pesquisa, à medida que as avaliações dos protótipos julgarem-se necessárias, sendo mais bem visualizado no fluxograma a seguir:

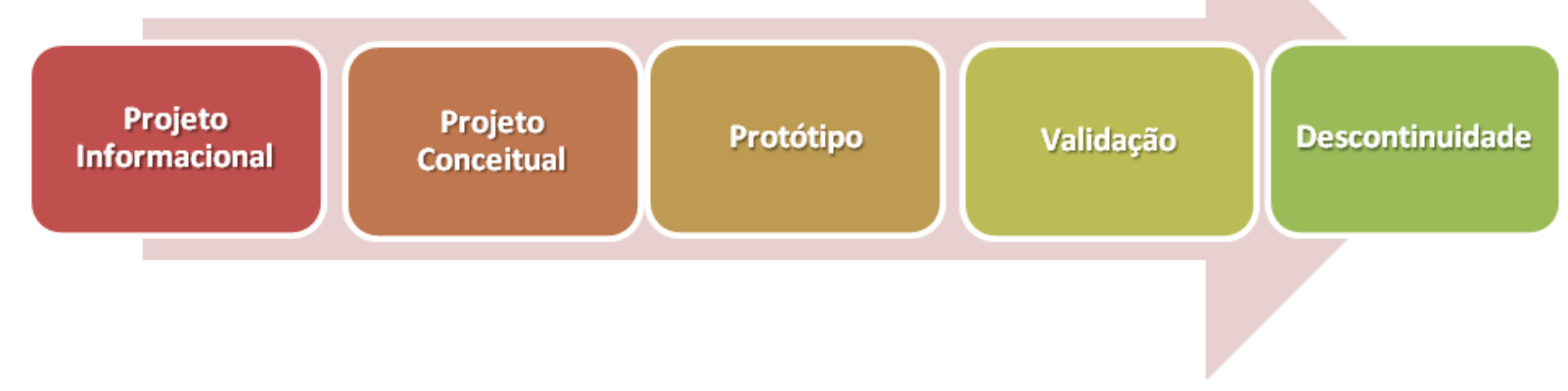




\subsection{Projeto Informacional}

Esta etapa se refere ao ponto de partida do problema de projeto, constata uma necessidade de mercado, faz uma avaliação das necessidades dos clientes, e apresenta uma especificação de produto (BACK e FORCELLINI, 2003; ROZENFELD, et. al., 2006).

A pesquisa aqui apresentada teve início em março/2011 e os dados quanto ao reconhecimento da necessidade foram coletados de agosto/2011 a janeiro/2012 após a aprovação pelo Comitê de Ética e Pesquisa do Hospital das Clínicas da Faculdade de Medicina de Ribeirão Preto - SP, (ANEXO I) em sua 323․ Reunião Ordinária realizada em 09/05/2011, assim como o Termo de Consentimento Livre e Esclarecido (APÊNDICE I), de acordo com o Processo HCRP no. 2953/2011.

Foi realizada a coleta de dados de reconhecimento de necessidade, com metodologia quantitativa, a fim de levantar junto a uma amostra com doenças ou devido ao envelhecimento que apresentem acometimento do aparelho locomotor sobre suas percepções quanto a necessidade, altura e formas de uso da barra de apoio. (APÊNDICE II)

\subsubsection{Local de Coleta}

O Hospital das Clínicas da Faculdade de Medicina de Ribeirão Preto da Universidade de São Paulo (HCFMRP/USP) é uma autarquia, mantida pelo governo do estado de São Paulo, sendo vinculada à Secretaria de Estado da Saúde (Decreto Estadual n. 26.920, de 18/3/87) associada à Universidade de São Paulo - Faculdade de Medicina de Ribeirão Preto da USP. Tem por missão desenvolver a assistência, o ensino e a pesquisa científica em estreita colaboração com as demais unidades ensino da Universidade de São Paulo na cidade de Ribeirão Preto, em particular com a Faculdade de Medicina.

Foram escolhidos como locais de coleta os ambulatórios de especialidades, dentre eles os: Ambulatório de Ortopedia do HCFMRP-USP, especificamente, ambulatório de coluna, joelho e quadril; Ambulatório de Reumatologia de HCFMRP-USP;- Serviços de Terapia Ocupacional em Neurologia e Geriatria do Centro de Reabilitação - HCFMRP-USP; Ambulatório de Ortopedia do Centro Saúde Escola - Faculdade de Medicina de Ribeirão Preto -SP; Ambulatório de Reumatologia do Centro Saúde Escola - FMRP-USP; Ambulatório de Neurologia e Geriatria do CIR -HE.

A rotina de tal serviço prevê no dia da consulta a presença de seu prontuário, e que juntamente à referida equipe foi solicitado o empréstimo do mesmo (fora do horário da consulta) para verificação de dados clínicos pela pesquisadora e enquanto aguarda ou após a 
consulta agendada, foram convidados a participar da mesma, não necessitando assim pedido de prontuário fora da rotina do serviço.

\subsubsection{Casuística}

A amostra foi selecionada por conveniência, sendo os 100 participantes pacientes do complexo Hospital das Clínicas da Faculdade de Medicina de Ribeirão Preto - USP, Centro Saúde Escola - FMRP-USP e Centro Integrado de Reabilitação do Hospital Estadual de São Paulo.

Foram esclarecidos sobre os objetivos, procedimentos e riscos, e ao concordarem em participar do estudo, assinaram o Termo de Consentimento Livre e Esclarecido, de acordo com a resolução CNS 196/96.

\subsubsection{Critérios de inclusão}

Indivíduos que apresentem patologias reumatológicas, neurológicas e ortopédicas, e pessoas idosas (acima de 60 anos) que com acometimento do aparelho locomotor e queixa de dificuldade em realizar o movimento de ST-DP, seguidos nos ambulatórios do complexo HCFMRP-USP, maiores de 18 anos, independente do sexo e condição social.

\subsubsection{Critérios de exclusão}

Indivíduos que não apresentam condições de responder ao questionário por problemas cognitivos e aqueles que não puderam comparecer ao referido Hospital.

\subsubsection{Instrumento de coleta}

Para coleta de dados foi utilizado roteiro estruturado desenvolvido pelos próprios pesquisadores a fim de levantar os dados referentes à dificuldade de passar de ST-DP, Atividades de Vida Diária (AVD’s) prejudicadas por essa limitação, estratégias utilizadas para a realização desta ação (ST-DP) com segurança, opinião acerca do material a ser fabricada a barra de apoio, bem como a altura e formas de uso desta. O roteiro encontra-se no APÊNDICE II.

\subsubsection{Dados sócios demográficos, sócio econômico e clínicos}

Foi registrado em cada roteiro as iniciais do nome do sujeito, o registro hospitalar, a data de nascimento e idade, sexo, estado civil, escolaridade e procedência. Foi questionada 
sua profissão e catalogadas de acordo com os 21 itens de ocupação principal listados pelos pesquisadores no APÊNDICE III.

As questões relacionadas às condições clínicas foram coletadas do prontuário de cada sujeito do estudo.

\subsubsection{Análise dos dados}

Os dados foram digitados no banco de dados utilizando o programa Epi Data analisados estatisticamente pelo Epi Info ${ }^{\text {TM }}$ Versão 3.5.2, 2010.

Foi realizada a análise descritiva quanto às variáveis sócio demográficas, à atividade profissional e características clínicas e quanto as preferencias relatadas pelos participantes quanto a configuração da barra de apoio vertical móvel.

A análise estatística consistiu do cálculo das medidas de tendência central (média, mediana) e dispersão (desvio padrão) para as variáveis quantitativas, bem como frequências absolutas e relativas para as variáveis qualitativas.

Abaixo se têm os resultados apresentados nesta pesquisa.

\subsubsection{Características sócio demográficas, econômicas e clínicas}

Cem indivíduos participaram deste estudo, com idade entre 24 a 84 anos, com média de 57 anos de idade. Observou-se uma predominância do sexo masculino (60\%). Mais da metade eram casados (57\%). Metade (50\%) não completaram o ensino fundamental e apresentavam a atividade profissional classificada como Comércio/Prestação de Serviços e Nível Básico. 51\% residiam em cidades do interior de São Paulo próximas a região de Ribeirão Preto. A descrição detalhada das características sócio demográficas e profissionais encontra-se na Tabela 1. 
Tabela 1 - Características sócio demográficas e profissionais do grupo de estudo

\begin{tabular}{|c|c|c|}
\hline \multirow[t]{2}{*}{ Categorias } & \multicolumn{2}{|c|}{ Resultados } \\
\hline & $n$ & $\%$ \\
\hline Sexo & & \\
\hline Masculino & 60 & 60 \\
\hline Feminino & 40 & 40 \\
\hline Total & 100 & 100 \\
\hline \multicolumn{3}{|l|}{ Idade (anos) } \\
\hline 24- 27 & 3 & 3 \\
\hline $30-39$ & 4 & 4 \\
\hline $40-49$ & 11 & 11 \\
\hline $50-59$ & 26 & 26 \\
\hline $60-69$ & 27 & 27 \\
\hline $70-79$ & 22 & 22 \\
\hline $80-84$ & 7 & 7 \\
\hline Total & 100 & 100 \\
\hline \multicolumn{3}{|l|}{ Escolaridade } \\
\hline Analfabeto & 4 & 4 \\
\hline $\begin{array}{l}\text { Ensino Fundamental } \\
\text { Incompleto }\end{array}$ & 61 & 61 \\
\hline Ensino Fundamental Completo & 11 & 11 \\
\hline Ensino Médio Incompleto & 1 & 1 \\
\hline Ensino Médio Completo & 17 & 17 \\
\hline Ensino Superior Incompleto & 1 & 1 \\
\hline Ensino Superior Completo & 5 & 5 \\
\hline Total & 100 & 100 \\
\hline \multicolumn{3}{|l|}{ Estado Civil } \\
\hline Solteiro & 15 & 15 \\
\hline Casado & 57 & 57 \\
\hline Divorciado & 7 & 7 \\
\hline Viúvo & 21 & 21 \\
\hline Total & 100 & 100 \\
\hline \multicolumn{3}{|l|}{ Procedência } \\
\hline Ribeirão Preto & 46 & 46 \\
\hline $\begin{array}{l}\text { Outra cidade do interior de São } \\
\text { Paulo }\end{array}$ & 51 & 51 \\
\hline Outro Estado & 3 & 3 \\
\hline Total & 100 & 100 \\
\hline Atividade Profissional & & \\
\hline Superior/Gerência & 5 & 5 \\
\hline Técnico/Administrativo & 7 & 7 \\
\hline Comércio/Prestação de Serviços & 36 & 36 \\
\hline Nível Básico & 37 & 37 \\
\hline Do lar & 14 & 14 \\
\hline Outro & 1 & 1 \\
\hline Total & 100 & 100 \\
\hline
\end{tabular}


Na tabela 2, têm-se os resultados quanto a características clínicas dos participantes, considerando que havia participantes com mais de uma afecção:

Tabela 2 - Características clínicas dos participantes

\begin{tabular}{|c|c|c|}
\hline Categorias de Afecções & $N$ & $\%$ \\
\hline Ortopédicas & 83 & 68 \\
\hline Reumatológicas & 12 & 9,8 \\
\hline Neurológicas & 15 & 12,2 \\
\hline Cardiovasculares & 7 & 5,7 \\
\hline Outras & 5 & 4,3 \\
\hline Total & 122 & 100 \\
\hline
\end{tabular}

As afecções foram classificadas de acordo com o ambulatório de origem do participante.

Dentre as afecções ortopédicas, os participantes apresentavam: artrose da articulação coxo-femoral e/ou do joelho, e/ou coluna lombar, torácica e cervical, e lombalgia.

As afecções reumatológicas apresentadas foram artrite reumatóide e osteoartrite/osteoartrose das articulações da coluna lombar, quadril e joelho.

As afecções neurológicas apresentadas foram o Acidente Vascular Encefálico (AVE), Doença de Parkinson, Trauma Crânio - Encefálico (TCE) e Traumatismo Raquimedular (TRM).

As doenças cardiovasculares apresentadas como morbidades associadas a doença primária de interesse foram: Hipertensão Arterial Sistêmica (HAS), enfarte do miocárdio e arritmias.

As afecções caracterizadas como outras não estavam incluídas nas categorias acima, como as dermatológicas e respiratórias, que acarretavam, por conseguinte, dificuldades na mudança de posição de levantar/sentar.

\subsubsection{Desempenho ocupacional quanto a dificuldade de levantar/sentar}

Dos indivíduos, $100 \%$ apresentam dificuldade para levantar/sentar e isto dificultava ou os atrapalhava na realização das atividades de vida diária (AVD’s). 
Em relação aos locais que apresentavam esta dificuldade de se levantar/sentar temos: $86 \%$ do sofá; $83 \%$ da cama, $83 \%$ das cadeiras utilizadas durante as refeições; $82 \%$ do vaso sanitário; $60 \%$ para vestir peças de roupas com os membros inferiores e $21 \%$ da cadeira de banho.

Todos os indivíduos (100\%) relataram se apoiar nos móveis próximos para realizar a ação de levantar/sentar e todos afirmaram que a utilização de uma barra de apoio durante essas AVD’s facilitaria e seria mais seguro.

\subsubsection{Percepção dos participantes quanto às características da barra de apoio}

Os participantes foram questionados quanto ao material a ser fabricado a barra de apoio, e destes, $40 \%$ relataram preferir o alumínio como material de base e $45 \%$ preferiam que a barra fosse fabricada com material antiderrapante.

Quanto à especificação da barra de apoio ser fixa ou móvel, 77\% relatou a preferência pela barra de apoio removível.

E como locais de uso em suas residências, obtiveram-se os seguintes resultados: $50 \%$ utilizariam no banheiro, $23 \%$ no quarto, $8 \%$ na cozinha e $5 \%$ na sala e $39 \%$ utilizariam em todos os cômodos da residência (banheiro, quarto, cozinha e sala).

Questionados sobre a altura e formato da barra de apoio móvel, $81 \%$ dos participantes preferiram a figura 8 , e $19 \%$ preferiram a figura 9 :

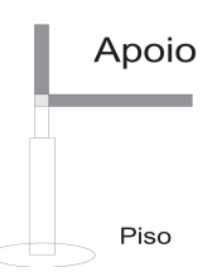

Figura 8- Exemplo 1 de Barra de Apoio

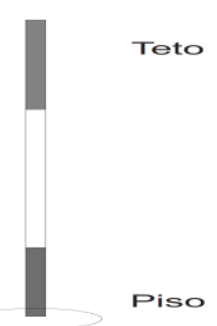

Figura 9 - Exemplo 2 de Barra de Apoio

\subsubsection{Pesquisa de Produtos existentes no mercado}

Após pesquisa através de bases de dados na internet em sites de venda de produtos de tecnologia assistiva nacionais e internacionais, constatou-se que não há no mercado brasileiro um produto que atenda as necessidades da população acima descrita. No mercado internacional, especificamente nos Estados Unidos, foram encontrados dois modelos que podem atender aos requisitos da população estudada. No entanto, estes produtos possuem mecanismo de fixação que exige que seja utilizada em apenas um dos cômodos da residência 
e também exigem uma mudança estrutural na residência, já que precisam ser fixados através de parafusos. Seguem abaixo os exemplos:

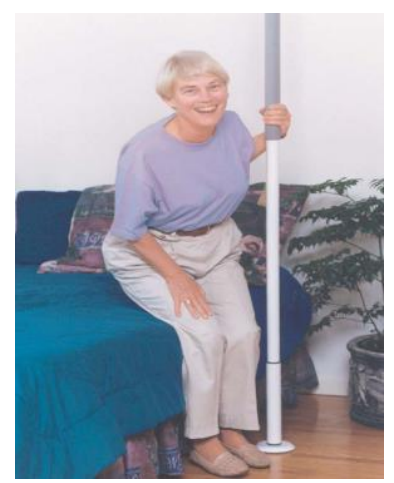

Figura 10- Super Pole System ${ }^{1}$

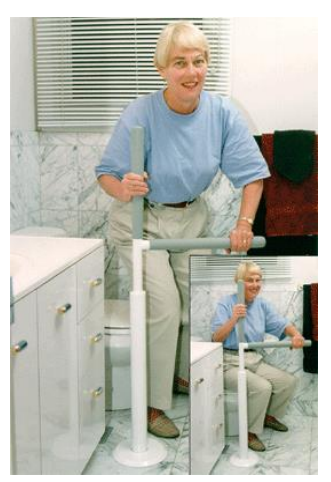

Figura 11- Advantage Rail ${ }^{2}$

\subsubsection{2 "Brainstorming"}

A partir disso, foi realizada uma discussão em grupo com 5 participantes (alunos de pós-graduação - Apêndice VII) com e sem conhecimento técnico, utilizando a técnica de Brainstorming, conhecido como método de pensamento criativo (proposto por Osborn, em 1953), que é realizado em grupo de pessoas de diferentes formações, podendo ser aplicado à qualquer fase do desenvolvimento do produto. O método tem como objetivo estimular um grupo de pessoas a gerar um número elevado de ideias, para solucionar um problema. Há um fluxo de ideias ou pensamentos que libera cadeias de pensamentos. Aparentemente ideias absurdas podem levar a soluções lógicas, aplicáveis e inéditas em projeto e devem ser estimuladas e aproveitas. A partir dessa técnica, levantou-se como atributos necessários ao produto as seguintes questões, conforme a figura 12 :

\footnotetext{
${ }^{1}$ http://www.healthcraftproducts.com/superpolesystem.htm

2 http://www.healthcraftproducts.com/superpolesystem.htm
} 


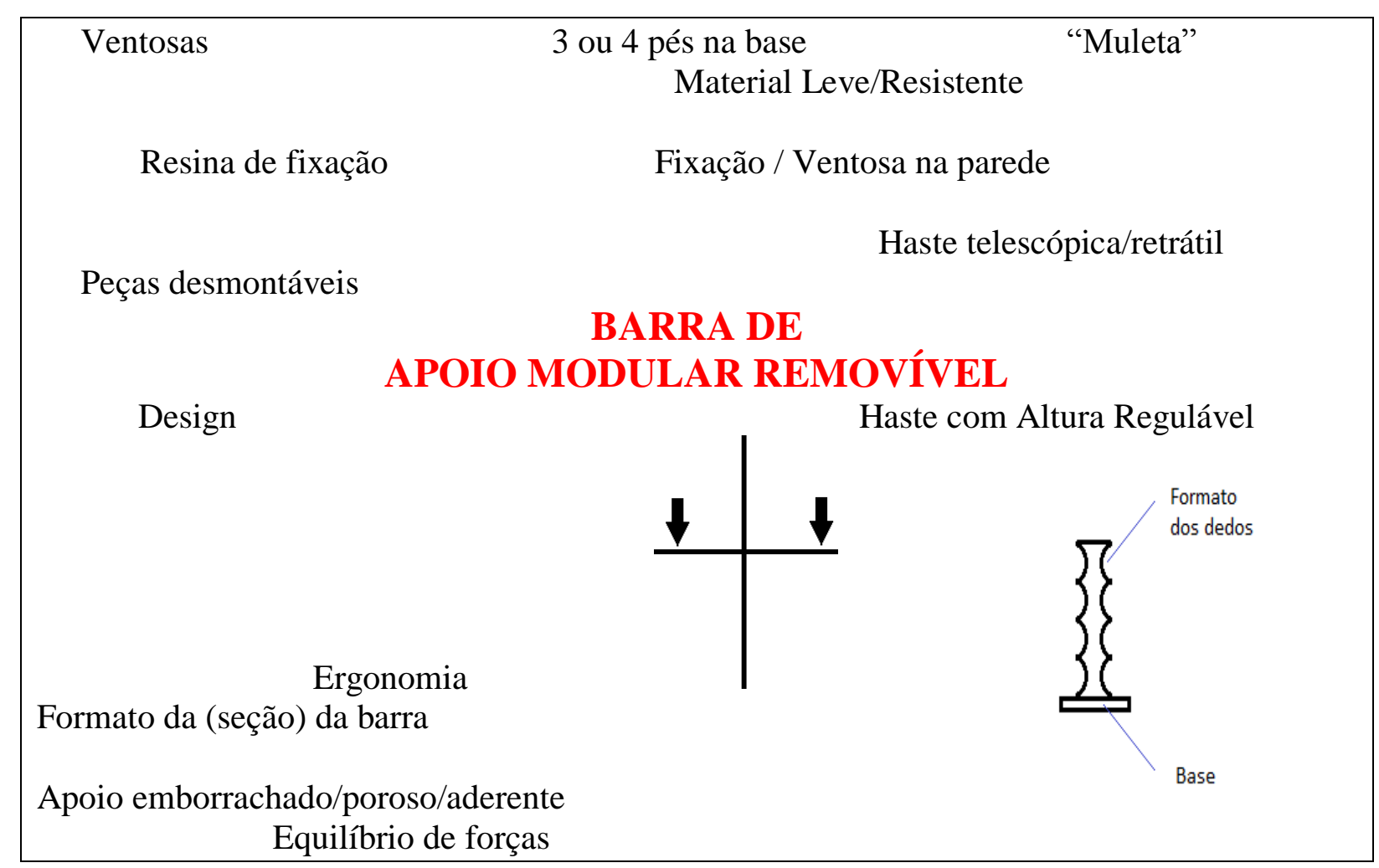

Figura 12 - Brainstorming (Apêndice VII)

Esses pensamentos levaram a elaboração da matriz do QFD, abaixo descrita: 
Primeira Matriz da Qualidade (casa da qualidade)

\begin{tabular}{|c|c|c|}
\hline \multicolumn{2}{|c|}{$\begin{array}{c}\text { Correlação entre requisitos de } \\
\text { cliente e de produto }\end{array}$} \\
\hline$\odot$ & Forte & 9 \\
\hline$\bigcirc$ & Moderado & 3 \\
\hline$\triangle$ & Fraco & 1 \\
\hline
\end{tabular}$\quad$\begin{tabular}{|c|c|}
\hline \multicolumn{2}{|c|}{ Correlação } \\
\hline $\boldsymbol{+ +}$ & Posit. Forte \\
\hline $\boldsymbol{+}$ & Posit. Fraco \\
\hline- & Inexistente \\
\hline-- & Neg. Fraca \\
\hline
\end{tabular}

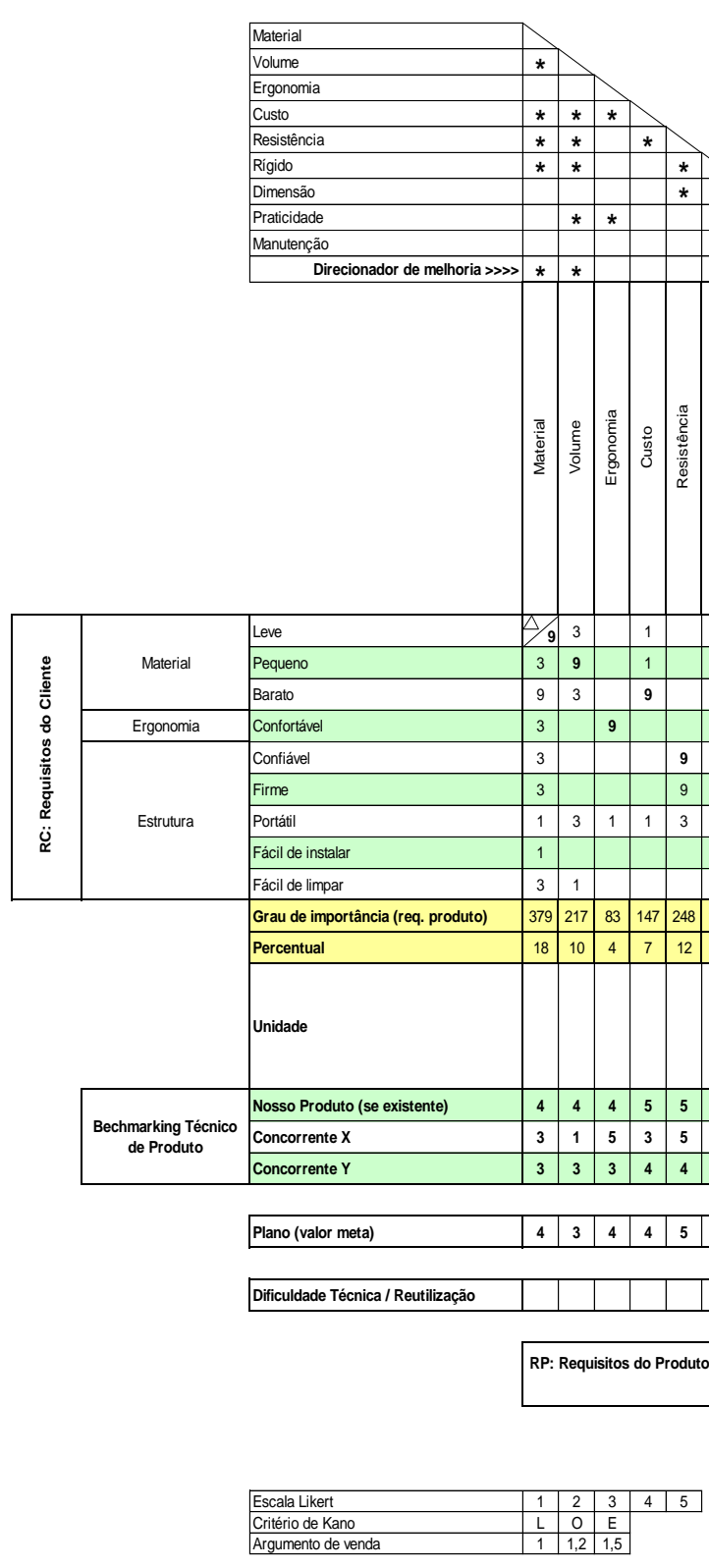

\begin{tabular}{|l} 
Criterio de Kano \\
\hline argumento de venda \\
\hline
\end{tabular}

\begin{tabular}{l|l|l|l|}
1 & 1,2 & 1,5 \\
\hline
\end{tabular}

Figura 13 - QFD para produção de barras de apoio 
A partir do QFD identificou-se como requisitos para melhora do produto: material, praticidade e dimensão.

\section{Análise de Funções}

Através da "Árvore de Funções" pudemos obter a análise de funções analisando as características principais e secundárias do produto, em virtude de analise "como? porquê?". (Fig.14)

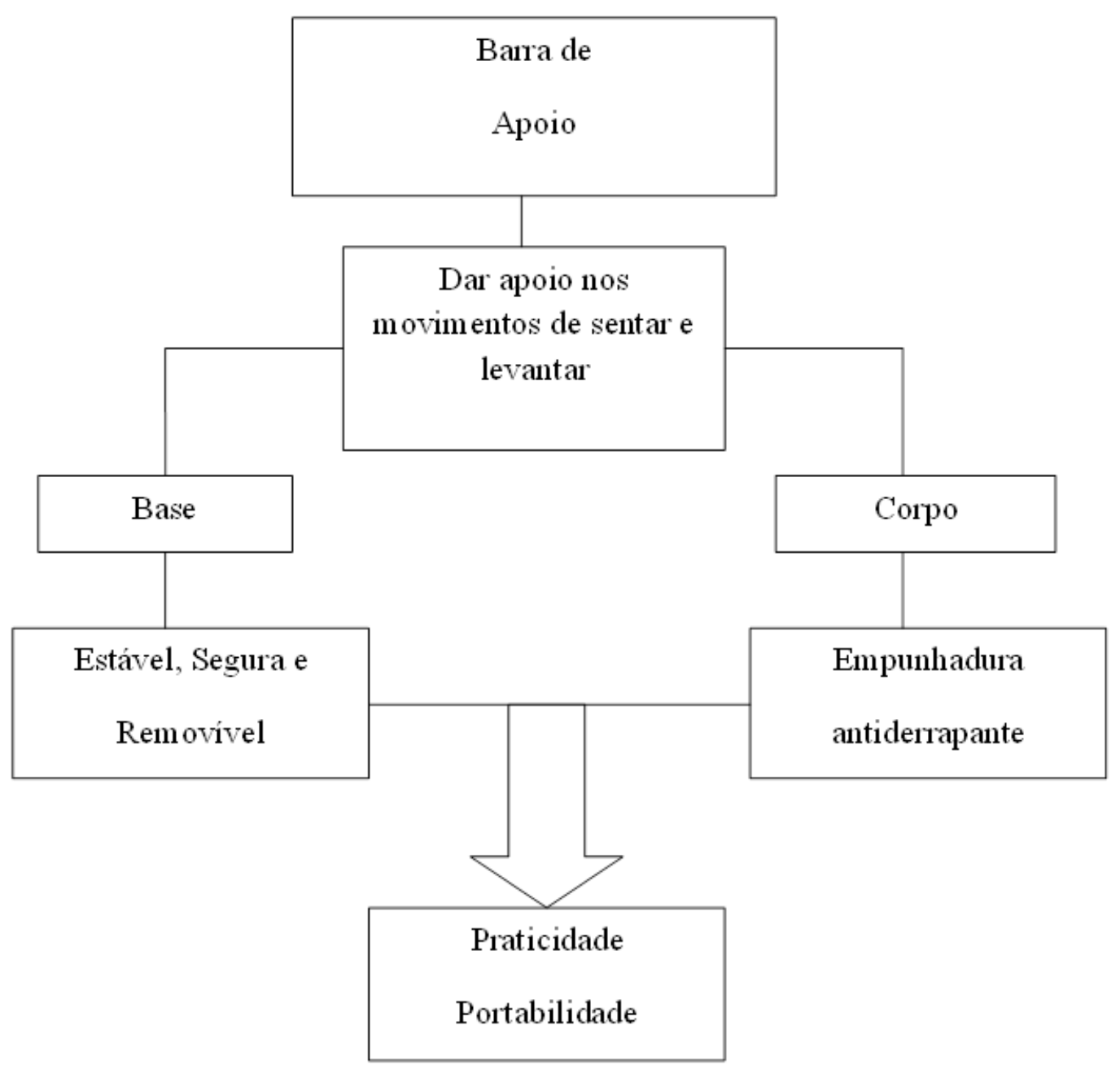

Figura 14- Árvore de Funções

Após isso, elaborou-se o primeiro modelo da barra de apoio como sendo do chão ao teto com a fixação por pressão e com uma trava de segurança (Fig. 15) 

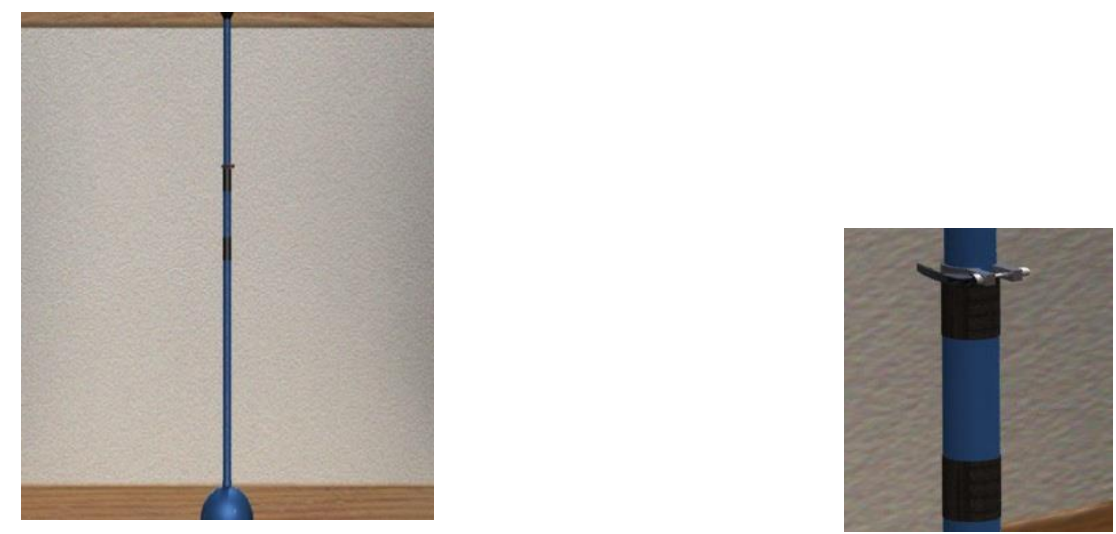

Figura 15 - Primeiro modelo da barra de apoio e detalhe da trava de segurança

Neste modelo, seguindo as normas da ABNT-9050, a altura total da barra seria de 180 cm a 230 cm, já que o pé direito das casas apresentam essa variação.

Já que o alcance médio de pessoa sentada é de $120 \mathrm{~cm}$ e o alcance médio de pessoa em pé $155 \mathrm{~cm}$, o apoio da mão teria a variação de $35 \mathrm{~cm}$ e se localizaria abaixo da trava de segurança.

A espessura da barra teria a seção circular com diâmetro de $3,5 \mathrm{~cm}$, sendo que a espessura da seção circular do apoio emborrachado teria diâmetro de 4,5 cm.

Além disso, foi realizada uma simulação da tensão máxima imposta ao material, com Liga de alumínio 2024-T4; 2024-T351, Densidade: 2,78 g/c 3 , Tensão de escoamento: 260 MPa e Modulo de Elasticidade: 73,1 GPa.(Fig.16)

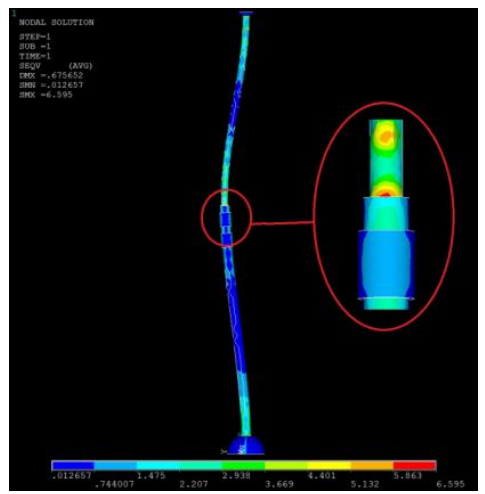

Figura 16- Simulação de tensão máxima imposta ao material

Observa-se que a tensão máxima imposta ao material, considerando-o suportando o peso de uma pessoa de $85 \mathrm{~kg}$ em uma análise estática, ainda é bem abaixo da tensão de escoamento do mesmo, o que indica que a escolha da liga de alumínio em pauta é adequada, haja vista a leveza e a resistência desse material. Além disso, o alumínio é fonte renovável de material e apresenta custo baixo. 
Após esse primeiro modelo e a coleta do reconhecimento da necessidade e sua análise, os possíveis usuários relataram o desejo da barra de apoio ter uma altura menor, ou seja, que não alcançasse o teto, visando maior praticidade e funcionalidade quanto a mudança de posição da barra no domicilio do possível usuário. Para isto, na próxima etapa do estudo foram pesquisadas as alternativas para atender a necessidade dos possíveis usuários.

\subsection{Projeto Conceitual}

Com os desdobramentos e avaliações iniciais do projeto a idéia original torna-se um conceito, que é refinado e detalhado para se tornar um produto. A cada etapa, com as decisões de projeto, diminuí o número de alternativas consideradas, reduzindo as incertezas progressivamente. Na fase inicial do processo do projeto, o custo para se alterar o conceito, antes que decisões fundamentais tenham sido tomadas é relativamente baixo (BACK e FORCELLINI, 2003). A Figura 17 mostra o processo das diferentes fases do ciclo de vida sobre o custo do produto.

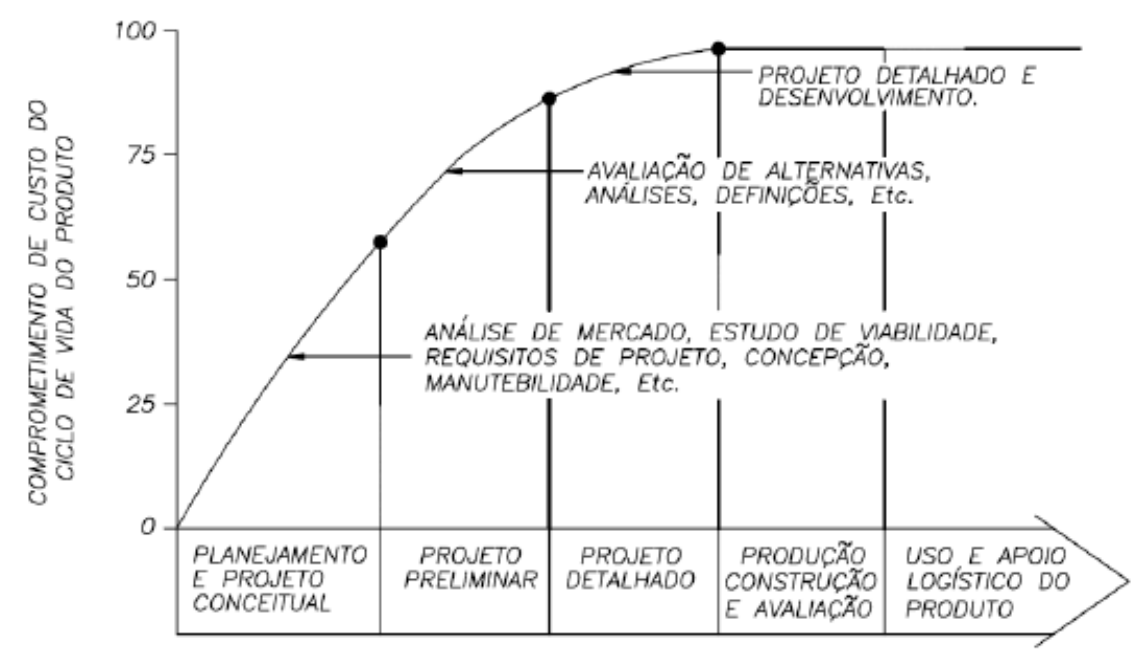

Figura 17 - Efeitos das diferentes fases do ciclo de vida sobre o custo do produto. Fonte: (BLANCHARD e FABRYCKY1, 1990 apud BACK e FORCELLINI, 2003).

O conceito de um produto é uma breve descrição da tecnologia dos princípios de funcionamento, e da forma do produto, descreve como o produto irá satisfazer as necessidades dos consumidores (SLACK, 2002).

Nesta fase do projeto serão abordados os aspectos necessários para definição do projeto do produto. Para isso serão explicitadas as normas que determinam a elaboração do produto quanto a altura, espessura, além dos esforços envolvidos, antropometria e materiais disponíveis no mercado para fabricação do produto e da fixação da barra de apoio. 


\subsubsection{Normas Brasileiras de Acessibilidade - NBR 9050 - Acessibilidade de pessoas portadoras de deficiência a edificações, espaço, mobiliário e equipamento urbano}

As medidas antropométricas que basearam a fabricação do protótipo foram definidas pelas Normas da ABNT - 9050 (2004), que apresentam as medidas de alcance frontal, quando a pessoa estiver sentada, variando de 0,80 a 1,00 m; (Figura 18) e para quando a pessoa estiver em pé de 0,90 a 1,00 m (Figura 19).
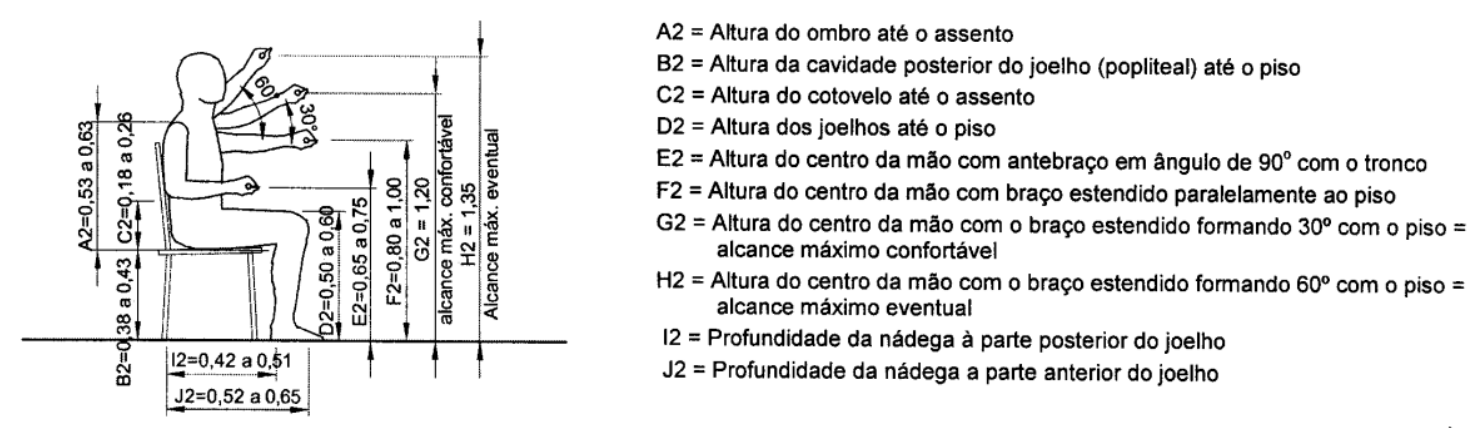

Figura 18- Alcance manual frontal - pessoa sentada. Fonte: NABNT9050, 2004
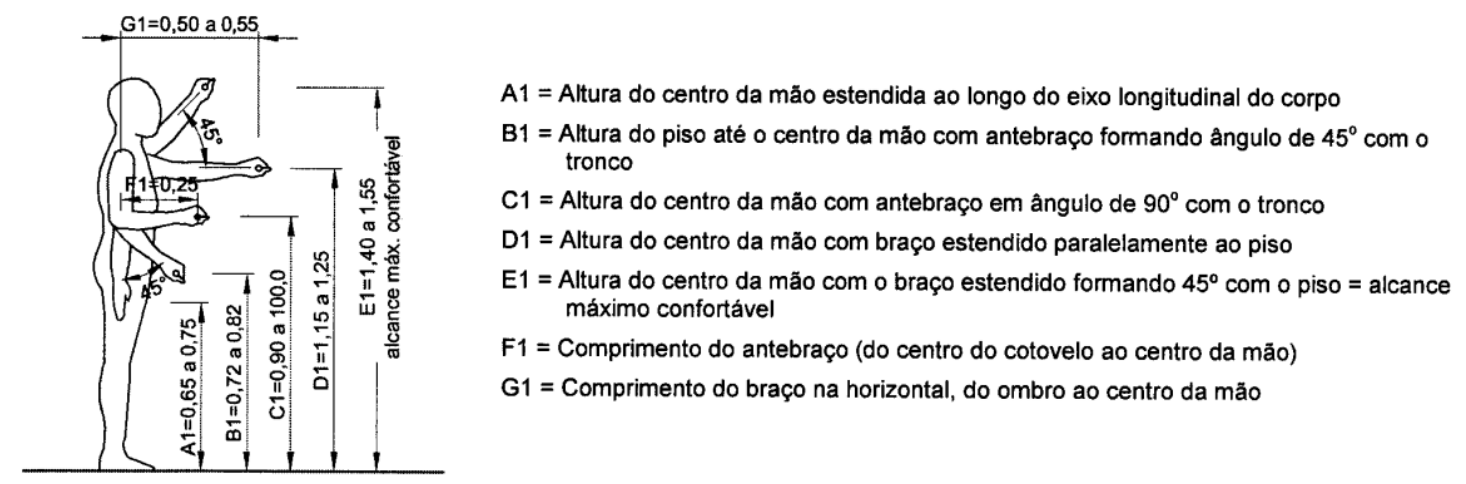

Figura 19- Alcance manual frontal - pessoa em pé. Fonte: NABNT9050, 2004

E de acordo com a ABNT 9050, foram levadas em consideração quanto a empunhadura, o diâmetro da seção circular, a distancia livre e a resistência mínima que as barras de apoio devem suportar explicitados anteriormente na revisão de literatura.

\subsubsection{Antropometria}

As grandezas derivadas da anatomia humana são objetos de estudo da antropometria. Ela determina os parâmetros geométricos e inerciais do corpo humano e também fornece a 
segmentação da estrutura do corpo humano adequadamente dividido para a análise matemática, determinando:

(a) A forma geométrica de cada segmento, as posições das articulações entre os segmentos, a posição do centro de massa de cada segmento corporal, bem como os pontos de origem e inserção dos músculos para determinação das linhas de ação das forças musculares e braços de alavanca;

(b) Os parâmetros inerciais: massa de cada segmento, momento de inércia e raio de giração.

As variáveis antropométricas fundamentais (massa, centro de massa e momento de inércia dos segmentos, bem como a localização dos pontos de ação das forças) podem ser obtidas através de procedimentos teóricos. O emprego de um determinado procedimento deve ser escolhido adequadamente, levando-se em conta o grau de precisão dos dados obtidos. (VECCHIA, 1998).

Segundo Iida (2005), para o uso dos dados antropométricos deve-se levar em consideração a etnia, a profissão, faixa etária, época e algumas condições especiais como as condições que as medidas foram coletadas. Essas medidas devem considerar uma análise da tarefa, isto é, o tipo de função exercida pelo membro. Ainda segundo o mesmo autor, existem critérios para a utilização das medidas antropométricas já existentes. Em caso de materiais industriais, devido à diminuição de custos, os dados padronizados são mais utilizados. No entanto, em caso de alguns produtos a falta de adaptação pode reduzir a eficiência do produto, sendo assim, os critérios utilizados para a aplicação da Antropometria consideram e preocupase com o dimensionamento da média da população, se é destinado para extremos na população, sua faixas relativas à população destinatária do produto, se são reguláveis e se os projetos serão adaptados ao indivíduo.

No Brasil, não há um modelo antropométrico ideal que reflita os dados antropométricos para a população brasileira, quanto a divisão de segmentos, massa corporal, centro de massa, assim como tamanho dos segmentos.

Frente a isto, este estudo adotará o modelo antropométrico descrito por ZATSIORSKY \& SELUYANOV (1983) que é composto de 16 segmentos, considerando a cabeça, os segmentos pé, perna, coxa, mão, antebraço e braço para os dois lados e tronco dividido em parte superior, média e inferior (figura 18). O tronco subdividido foi um dos fatores primordiais para a escolha do modelo de Zatsiorsky, pois no levantamento de peso, o tronco não pode ser considerado como uma haste rígida. (Fig.20) 

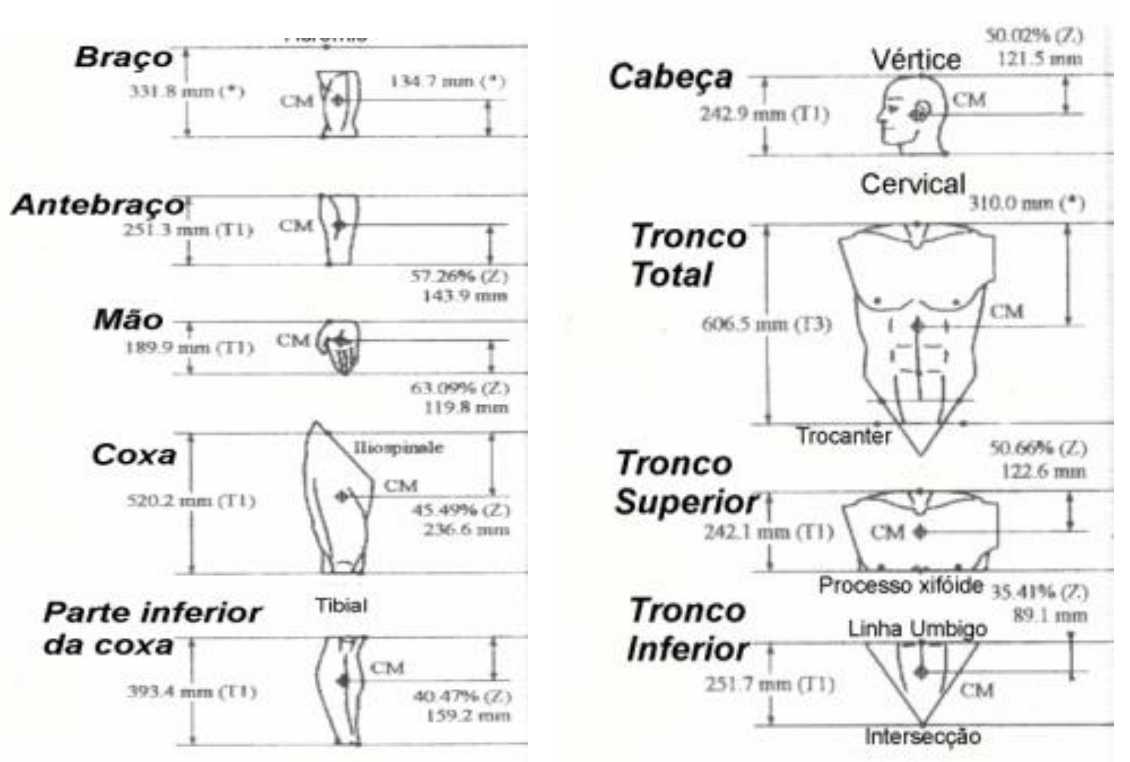

Figura 20 - Modelo Antropométrico Modificado do Leva,1996

\subsubsection{Materiais de mercado}

Os materiais disponíveis para fabricação dos protótipos da barra de apoio vertical móvel no mercado para compra são os tubos de aço (carbono e inoxidável) ligas de alumínio, os tubos de PVC e tubos de ligas de cobre (menos comum).

As descrições dos materiais tem como referencia as descrições de Smith, Hashemi, (2003). O PVC, que é uma resina termoplástica, é produzido quando as moléculas de cloreto de vinila se associam, formando cadeias de macromoléculas. Este processo é chamado de polimerização que ocorre no meio aquoso. É um material reconhecido pela sua versatilidade, sendo empregado na construção civil, indústria em geral, indústria de brinquedos, indústria automobilística, indústria de calçados, área médica/hospitalar e indústria de alimentos.

Tubos para canalização de água e esgoto são feitos com a classe denominada PVC rígido, onde são incluídos na matriz de PVC cargas minerais tais como talco, carbonato de cálcio e outros e atendem à normalização Brasileira ABNT NBR 5647-1.

As principais características do PVC rígido são durabilidade, inflamável (sem chamas), estável quimicamente, apresenta recuperação de energia, é fácil de processar e de reciclar.

Já o alumínio fundido dissolve outros metais e substâncias metalóides como o silício (que atua como metal). Quando o alumínio se resfria e se solidifica, alguns dos constituintes da liga podem ser retidos em solução sólida. Isto faz com que a estrutura atômica do metal se 
torne mais rígida. Os átomos podem ser visualizados como sendo arranjados em uma rede cristalina regular formando moléculas de tamanhos diferentes daqueles do elemento de liga principal. A principal função das ligas de alumínio é aumentar a resistência mecânica sem prejudicar as outras propriedades tais como densidade, condutividade térmica e resistência a oxidação. Assim, novas ligas têm sido desenvolvidas combinando as propriedades adequadas a aplicações específicas.

O metal aquecido pode manter mais elementos de liga em solução sólida do que quando resfriado. Consequentemente, quando resfriado, ele tende a precipitar o excesso dos elementos de liga da solução. Estes agregados de átomos metálicos tornam a rede cristalina ainda mais rígida e endurecem a liga.

A descoberta do "envelhecimento", das ligas que contém magnésio e silício conduziu ao desenvolvimento das principais ligas estruturais utilizadas hoje na engenharia. Este foi um trabalho pioneiro no campo das ligas de alumínio-magnésio, amplamente utilizadas atualmente na indústria naval. (SMITH, HASHEMI, 2003)

Outro importante emprego do alumínio é sua utilização nas ligas de fundição, que permitem um maior aproveitamento das sucatas de peças e embalagens.

Um dos aspectos que tornam as ligas de alumínio tão atraentes como materiais de construção mecânica é o fato do alumínio poder combinar-se com a maioria dos metais de engenharia, chamados de elementos de liga. Com essas associações, é possível obter características tecnológicas ajustadas de acordo com a aplicação do produto final. Mas para isso, é preciso conhecer bem as vantagens e limitações de cada elemento para fazer a melhor seleção. (SMITH, HASHEMI, 2003)

O grande alcance das ligas oferece à indústria uma grande variedade de combinações de resistência mecânica, resistência à corrosão e ao ataque de substâncias químicas, condutibilidade elétrica, usinabilidade, ductibilidade, formabilidade, entre outros benefícios.

A função de cada elemento da liga se altera de acordo com a quantidade dos elementos presentes na liga e com a sua interação com outros elementos. Em geral, podemos dividir os elementos entre:

- Elementos que conferem à liga a sua característica principal (resistência mecânica, resistência à corrosão, fluidez no preenchimento de moldes, etc.);

- Elementos que têm função acessória, como o controle de microestrutura, de impurezas e traços que prejudicam a fabricação ou a aplicação do produto, os quais devem ser controlados no seu teor máximo. 
A composição química do alumínio e suas ligas são expressas em percentagem, obedecendo a Norma NBR 6834 da ABNT.

Diferentemente dos materiais trabalháveis, que estão sujeitos a uma variação dos processos de aquecimento e de resfriamento, as ligas de fundição adquirem suas propriedades na condição de fundida (em alguns casos, com tratamento térmico) e, consequentemente, um grupo diferente de ligas tem sido formulado para a produção de peças fundidas. (SMITH, HASHEMI, 2003)

As ligas empregadas nas aplicações gerais de engenharia frequentemente contêm silício para melhorar suas características de fundição, tais como fluidez (no vazamento) e resistência a trincas de contração (quando o metal quente se solidifica e se contrai).

O cobre também é frequentemente utilizado como um elemento de liga, para proporcionar às propriedades mecânicas maior dureza e resistência exigidas em serviço.

As ligas alumínio-magnésio apresentam maiores problemas na fundição, mas possuem boa resistência e ductilidade. Elas são amplamente utilizadas, particularmente em ambientes quimicamente agressivos, como, por exemplo, em peças e acessórios de navios.

Já o aço é uma liga metálica formada essencialmente por ferro e carbono, com percentagens deste último variando entre 0,008 e 2,11\%. Distingue-se do ferro fundido, que também é uma liga de ferro e carbono, mas com teor de carbono entre $2,11 \%$ e $6,67 \%$. O carbono é um material muito usado nas ligas de ferro, porém varia com o uso de outros elementos como: magnésio, cromo, vanádio e tungstênio. O carbono e outros elementos químicos agem com o agente de resistência, prevenindo o deslocamento em que um átomo de ferro em uma estrutura cristalina passa para outro. A diferença fundamental entre ambos é que o aço, pela sua ductibilidade, é facilmente deformável por forja, laminação e extrusão, enquanto que uma peça em ferro fundido é muito frágil. (SMITH, HASHEMI, 2003)

O cobre é um elemento químico de símbolo $\mathrm{Cu}$ (do latim cuprum), número atômico 29 (29 prótons e 29 elétrons) e de massa atómica 63,6 u. À temperatura ambiente o cobre encontra-se no estado sólido. Classificado como metal de transição, pertence ao grupo 11 (1B) da Classificação Periódica dos Elementos. É um dos metais mais importantes industrialmente, de coloração avermelhada, dúctil, maleável e bom condutor de eletricidade.

A fim de determinar as vantagens e desvantagens dos materiais citados, comparou-se as propriedades físicas e químicas dos materiais comercialmente disponíveis em tubos, conforme descritos na tabela 3. 
Tabela 3 - Classificação geral dos materiais disponíveis na forma de tubos

\begin{tabular}{|c|c|c|}
\hline & Vantagens & Desvantagens \\
\hline $\begin{array}{l}\text { Alumínio } \\
\text { Liga } 6063\end{array}$ & $\begin{array}{c}\text { Baixo custo } \\
\text { Leve }\left(\text { densidade } \sim 2,7 \mathrm{~g} / \mathrm{cm}^{3}\right) \\
\text { Rígido }(\mathrm{E}=71 \mathrm{GPa}) \\
\text { Resistente ao escoamento }(\mathrm{Ga}=147 \mathrm{MPa})\end{array}$ & Condutor térmico (209W/mh) \\
\hline PVC rígido & $\begin{array}{l}\left.\text { Leve (densidade } \sim 1,5 \mathrm{~g} / \mathrm{cm}^{3}\right) \\
\text { Isolante térmico }(3,3 \mathrm{~W} / \mathrm{mh})\end{array}$ & $\begin{array}{l}\text { Inflamável, porém sem chamas; } \\
\text { Baixa rigidez (E 3,06GPa); } \\
\text { Resistência Mecânica ao Escoamento } \\
\text { ( } \sigma=48 \mathrm{MPa})\end{array}$ \\
\hline Aço & $\begin{array}{c}\text { Rígido }(\mathrm{E}=205 \mathrm{GPa}) \\
\text { Resistente ao escoamento }(\sigma=350 \mathrm{MPa}) \\
\text { Baixo custo }\end{array}$ & $\begin{array}{l}\left.\text { Pesado (densidade } 7,8 \mathrm{~g} / \mathrm{cm}^{3}\right) \\
\text { Oxidação } \\
\text { Condutor térmico }(519 \mathrm{~W} / \mathrm{mh})\end{array}$ \\
\hline Cobre & $\begin{array}{l}\text { Rigidez }(\mathrm{E}=115 \mathrm{GPa}) \\
\text { Resistente ao escoamento }(\mathrm{Ga}=220 \mathrm{MPa})\end{array}$ & $\begin{array}{c}\left.\text { Pesado (densidade }=8,94 \mathrm{~g} / \mathrm{cm}^{3}\right) \\
\text { Condutividade térmica }(341 \mathrm{~W} / \mathrm{mh}) \\
\text { Oxidação } \\
\text { Custo }\end{array}$ \\
\hline
\end{tabular}

Fonte: Matweb, 2012

Nesta primeira análise foi decidido pelos materiais: alumínio e PVC rígido. As vantagens determinantes foram: baixo peso, resistência à oxidação, baixo custo e alta disponibilidade.

Uma segunda etapa foi iniciada na verificação do comportamento mecânico dos tubos comerciais de PVC rígido e liga de alumínio 6063.

Para determinar o tipo especifico de tubo a ser utilizada na fabricação dos protótipos da barra de apoio realizou-se a simulação de uma barra bi engastadas com carregamento no centro da barra onde ocorre a máxima tensão de tração e compressão. A tensão mais crítica, ou seja, a máxima tensão atuante deve ser menor que a tensão admissível no material/tubo com coeficiente de segurança igual a 1,2, seja: $\sigma_{\mathrm{adm}} / \sigma_{\max } \geq 1,2$. (Fig.21-22) 


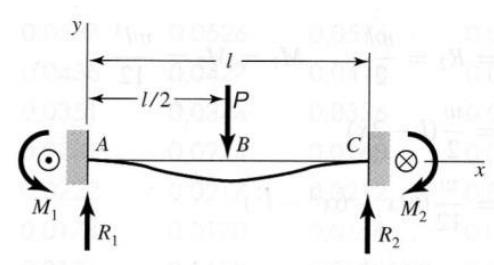

$$
\sigma_{\max }=\frac{F . l . d}{16 . I}
$$

flexa $=y_{\max }=\frac{F l^{3}}{192 . E . I}$

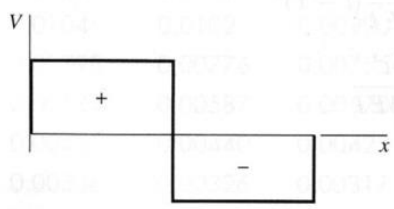

$\mathrm{P}=\operatorname{carga}(\mathrm{N})$

$\mathrm{E}=$ módulo de elasticidade

I = momento de inércia da seção

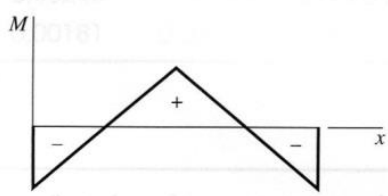

$l=$ distancia entre os apoios

$\mathrm{F}=$ flecha

$\mathrm{r}=$ raio externo do tubo

Figura 21 - Modelo para cálculo da máxima tensão atuante e flecha

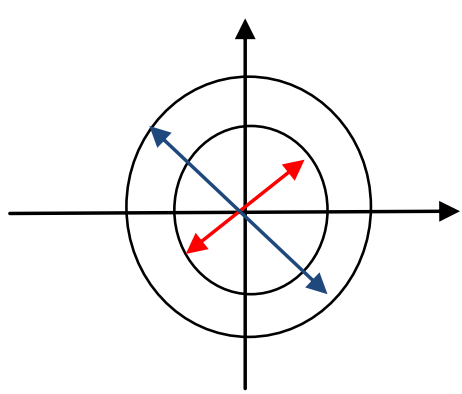

$$
\begin{aligned}
& \text { Seção tubular = D-d } \\
& I \text { x } I=\underline{\pi}\left(D^{4}-d^{4}\right)
\end{aligned}
$$

\section{4}

Tensão admissível

$\sigma \mathrm{adm}=\underline{\sigma \mathrm{e}}$

$$
\text { a.b.c.d }
$$

Figura 22 - Esquema para determinação da seção tubular

Foi considerado como carregamento máximo de projeto uma carga de $1,5 \mathrm{kN}$,

\begin{tabular}{|c|c|c|c|c|c|c|c|c|c|c|c|c|}
\hline Material & Liga & dimensões & & peso/m & $\mathrm{E}$ & $\overline{\sigma e}$ & Gadm & 1 & $f$ & omax & $\mathrm{N}$ & $\mathrm{P}$ \\
\hline & & $\phi \mathrm{e}$ & $\phi i$ & & & & & & & & & \\
\hline & & $\mathrm{mm}$ & $\mathrm{mm}$ & $\mathrm{kg}$ & GPa & $\mathrm{MPa}$ & $\mathrm{MPa}$ & $\mathrm{m} 4$ & $\mathrm{~mm}$ & $\mathrm{MPa}$ & & $\mathrm{N}$ \\
\hline \multirow[t]{5}{*}{ Alumínio } & 6063-T5 & 40 & 36 & 0,646 & 68,9 & 145 & 96,7 & $4,32158 \mathrm{E}-08$ & 4,5 & 104,1 & 0,93 & 1500 \\
\hline & 6063-T5 & 38 & 24 & 1,845 & 68,9 & 145 & 96,7 & $8,60681 \mathrm{E}-08$ & 2,3 & 49,7 & 1,95 & 1500 \\
\hline & 6063-T5 & 38 & 18,4 & 2,365 & 68,9 & 145 & 96,7 & $9,67276 \mathrm{E}-08$ & 2,0 & 44,2 & 2,19 & 1500 \\
\hline & & 38,1 & 31,75 & & \begin{tabular}{ll|}
68,9 \\
\end{tabular} & 145 & 96,7 & $5,35536 \mathrm{E}-08$ & 3,7 & 80,0 & 1,21 & 1500 \\
\hline & Schedule 4 & 42,2 & 35,08 & & \begin{tabular}{l|l|}
68,9 \\
\end{tabular} & 145 & 96,7 & $8,13379 \mathrm{E}-08$ & 2,4 & 58,4 & 1,66 & 1500 \\
\hline \multicolumn{13}{|l|}{ PVC-Rígido } \\
\hline & agua & 50 & 43,5 & & 3,02 & 48 & 32,0 & $1,31034 \mathrm{E}-07$ & 34,1 & 42,9 & 0,75 & 1500 \\
\hline & esgoto & 40 & 37 & & 3,02 & 48 & 32,0 & $3,36661 \mathrm{E}-08$ & 132,8 & 133,7 & 0,24 & 1500 \\
\hline & agua & 25 & 20,6 & & 3,02 & 48 & 32,0 & $1,03351 \mathrm{E}-08$ & 432,5 & 272,1 & 0,12 & 1500 \\
\hline & esgoto & 50,8 & 48,8 & & 3,02 & 48 & 32,0 & $4,85204 \mathrm{E}-08$ & 92,1 & 117,8 & 0,27 & 1500 \\
\hline
\end{tabular}
valor este que atende as especificações da norma ABNT9050 para barras de apoio e a distâncias máximas entre os apoios ( $l$ ) de 1,2m. (Tabela 4)

Tabela 4- Tubos, material, dimensões, tensão, flecha e coeficiente de segurança. 
A partir disso, decidiu-se pelo material para manufatura do protótipo da barra de apoio é o alumínio 6063 - T5 de $38 \mathrm{~cm} / 31 \mathrm{~cm}$. O material PVC - rígido não atende as exigências mecânicas necessárias para a fabricação do protótipo da barra de apoio.

\subsubsection{Fixadores por pressão}

Existe no mercado comercial atualmente, uma ampla variedade de fixadores por pressão denominada ventosa. Dentre as ventosas pesquisadas foram elencados as propriedades físicas das mesmas utilizadas para o transporte de vidros.

A ventosa de borracha (Fig.21a) é um corpo de borracha com sustentação do efeito de sugação pelo contato e apresenta propriedades mecânicas descritas como diâmetro igual a $\varnothing$ 60mm; altura: $45 \mathrm{~mm}$; peso igual a $0,020 \mathrm{Kg}$, capacidade de perpendicular aproximada igual a $90 \mathrm{Kg}$ e capacidade de carga perpendicular em prova igual a $18 \mathrm{Kg}$.

A ventosa única (Fig.21b) tem 1 boca de diâmetro igual a $\varnothing 120 \mathrm{~m}$, capacidade da carga igual a $40 \mathrm{~kg}$; carga máxima igual a $70 \mathrm{Kg}$, dimensões igual a 120 x 120 x $100 \mathrm{~mm}$ e peso igual a $0,500 \mathrm{Kg}$.

A ventosa dupla (Fig.21c) tem 2 boca de diâmetro igual a $\varnothing 120 \mathrm{~mm}$, capacidade da carga igual a $80 \mathrm{~kg}$, carga máxima igual a $120 \mathrm{~kg}$, dimensões igual a 330x120x100mm e peso igual a $1 \mathrm{~kg}$.

A ventosa tripla (Fig.21d) tem 3 bocas de diâmetro igual a $\varnothing 120 \mathrm{~m}$, capacidade da carga igual a $120 \mathrm{~kg}$, carga máxima igual a $175 \mathrm{~kg}$, dimensões igual a 330 x 235 x $100 \mathrm{~mm}$ e peso igual a $1.450 \mathrm{Kg}$.

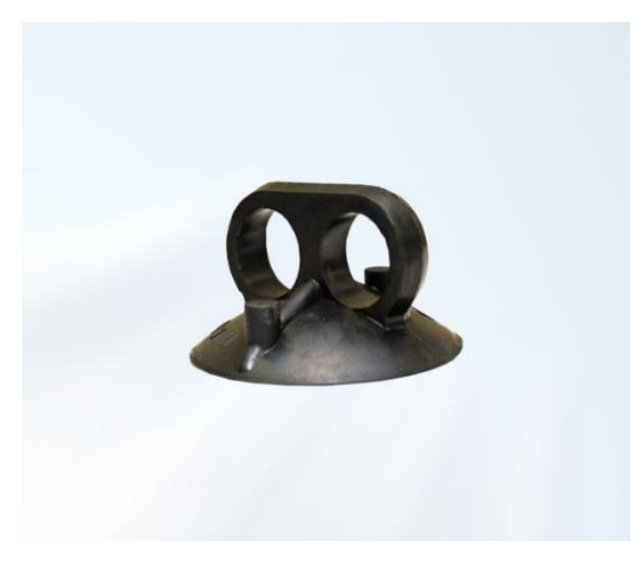

a)

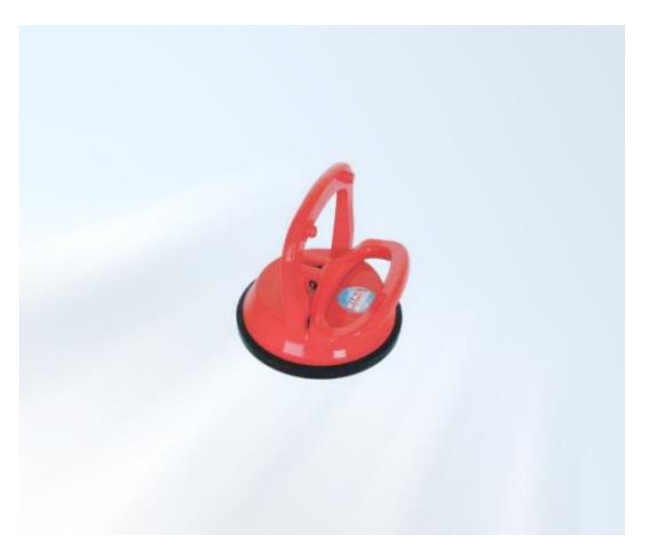

b) 


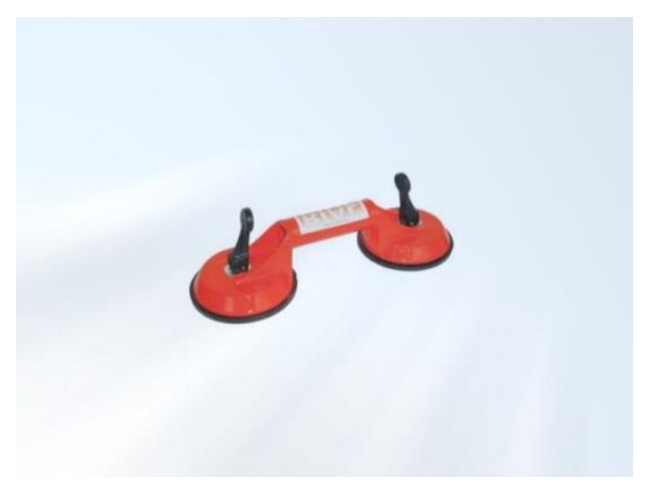

c)

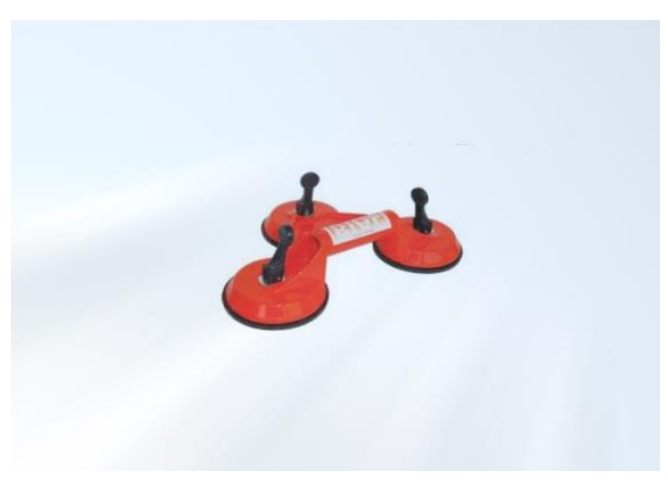

d)

Figura 23 - Fixadores por pressão a)ventosa de borracha b)ventosa única c) ventosa dupla d)ventosa tripla Fonte: http://www.gusmao.com.br /

As ventosas de borracha apresentam restrição de utilização quanto a superfície a ser aderida, restringindo o seu uso para superfícies lisas como os vidros.

A partir desta restrição, pesquisou-se o uso de adesivos.

\subsubsection{Fixação por Adesivos}

Os adesivos são substâncias não-metálicas capazes de unir materiais por fixação de superfície (aderência) com força interna adequada (coesão). A adesão é a capacidade de umectação e afinidade de um adesivo a um ou mais substratos. A força de adesão está baseada nas forças de atração entre as moléculas do adesivo e das superfícies a serem coladas. (WEYHER, D.F, 1970)

Entre as vantagens listadas pelos adesivos, cita-se que estes permitem a distribuição uniforme da tensão em grandes áreas; unem materiais finos ou espessos de qualquer tipo de superfície; unem diferentes ou iguais tipos de materiais; minimizam corrosão eletroquímica entre diferentes materiais; resistem à fadiga e aos movimentos repetitivos; permitem junção de superfícies lisas; permitem isolação de transferência de calor e condutância e amortecem vibração e choque. (WEYHER, D.F, 1970)

Os adesivos podem derivar de fontes naturais ou sintéticas. Os adesivos naturais derivam essencialmente de substâncias produzidas por animais e plantas. Já existe aproxidamente 25 tipos de adesivos sintéticos utilizados na engenharia. Novos tipos de adesivos são desenvolvidos a cada ano. Os adesivos são classificados segundo a base em água e base solvente. (WEYHER, D.F, 1970) 
Dentre os adesivos derivados de fontes naturais e renováveis, estabeleceu-se para a fixação da barra a aplicação dos adesivos termo - aplicáveis, sendo esta uma combinação dos componentes do breu, parafina e cera de abelha.

O breu é uma resina extraída de algumas espécies de pinheiros, é a fração não volátil da resina do pinheiro, é constituída essencialmente por ácidos, os chamados "ácidos resínicos", variando a sua composição com a espécie e origem geográfica do pinheiro. É muito utilizada na fabricação de adesivos, tintas, vernizes, borracha, chicletes, colas, moldes para fundição, abrasivos, esmalte para cerâmicas, cera de depilação e outras aplicações. (GM ceras, 2012) $)^{3}$

O breu é um sólido frágil, quebradiço, de cheiro ligeiramente aromático, translúcido, reage facilmente com sais metálicos e com álcool e insolúvel em água. Outras características físicas seguem na tabela 5:

Tabela 5 - Características do Breu

\begin{tabular}{c|c|c}
\hline \multicolumn{3}{c}{ Breu - Propriedades Físicas } \\
\hline Propriedades & un & Quantidade \\
\hline Temperatura fusão & ${ }^{\circ} \mathrm{C}$ & 78 (até 155) \\
\hline Densidade & $\mathrm{g} / \mathrm{cm}^{3}$ & $1,050 \mathrm{~A} \mathrm{1,085}$ \\
\hline Índice de refração & ${ }^{0} \mathrm{C}$ & 1,545 \\
\hline Solúvel em: & un & $\begin{array}{c}\text { Álcool etílico, } \\
\text { benzeno e } \\
\text { clorofórmio }\end{array}$ \\
\hline Ferro & ppm & 30 \\
\hline Cinzas & $\%$ peso & 0,082 \\
\hline
\end{tabular}

Fonte: LACERDA, 2003

A parafina é um derivado do petróleo descoberto por Carl Reichenbach. Conhecida por sua alta pureza, excelente brilho e odor reduzido, também pode ser usada como combustível. Possui propriedades termoplásticas e de repelência à água e é usada amplamente para a proteção de diversas aplicações, como em embalagens de papelão para a indústria alimentícia e revestimento de queijos e frutas. Por suas propriedades de combustível, é a matéria prima essencial na fabricação de velas.

\footnotetext{
${ }^{3}$ http://www.gmceras.com.br/
} 
Outras aplicações comuns à parafina incluem cosméticos, giz de cera, adesivos termo fusíveis, papel carbono, tintas, pinturas etc. (JOHN WILEY, SONS, 2005)

Apresenta como propriedades físicas as seguintes características listadas na Tabela 6:

Tabela 6 - Características da Parafina

\begin{tabular}{c|c|c}
\hline \multicolumn{3}{c}{ Cera de Parafina - Propriedades Físicas } \\
\hline Propriedades & un & Quantidade \\
\hline Temperatura fusão & ${ }^{0} \mathrm{C}$ & 59 \\
\hline Densidade & $\mathrm{g} / \mathrm{cm}^{3}$ & 0,91 \\
\hline Peso molecular & un & $18-32$ \\
\hline Exp. Térmica & $\mathrm{ppm}$ & 400 \\
\hline Tensão ruptura & $\mathrm{MPa}$ & 4 \\
\hline
\end{tabular}

Fonte: WRIGHT et al, 1989

A cera de abelha é produzida pelas abelhas na transformação do mel por elas ingerido com o auxílio de oito glândulas ceríngeas localizadas no lado ventral do abdômen das operárias. A cera é composta por ácido cerótico e palmítico, é isolante elétrico, funde a 63/64 graus centigrados, amolece a partir dos 35 graus, e tem densidade próxima da água. É solúvel em gorduras, azeites, benzina, sulfeto de carbono, terebintina, éter e clorofórmio. É muito maleável e utilizada para laminação de cera alveolada e utilizada para determinar a posição em que as abelhas deverão fundar os favos no interior da colmeia. É utilizada na fabricação de medicamentos e cosméticos além de cremes depilatórios. (WRIGHT et al, 1989)

$\mathrm{Na}$ Tabela 7, segue as características da cera de abelha.

Tabela 7 - Características da Cera de Abelha

\begin{tabular}{c|c|c}
\hline \multicolumn{3}{c}{ Cera de abelha - Propriedades Físicas } \\
\hline Propriedades & un & Quantidade \\
\hline Temperatura fusão & ${ }^{0 .} \mathrm{C}$ & $62-65$ \\
\hline Densidade & $\mathrm{g} / \mathrm{cm}^{3}$ & 0,96 \\
\hline Peso molecular & un & $45-60$ \\
\hline
\end{tabular}

Fonte:WRIGHT et al, 1989

Ao combinar as propriedades de fusão e adesão e rigidez da mistura após o resfriamento, foi possível a partir da combinação destes elementos a fixação a partir do aquecimento dessas substancias na base da barra de apoio. 
Cada um desses elementos misturados conferem as características essenciais para o adesivo termo aplicável, dentre elas, podemos citar que a cera de abelha confere a plasticidade, que é a propriedade dos materiais de se deixarem deformar permanentemente assumindo diferentes tamanhos ou formas sem sofrerem rupturas, rachaduras ou fortes alterações de estrutura quando submetidos a pressões ou choques compatíveis com as suas propriedades mecânicas. A parafina confere a fluidez, o inverso da viscosidade, ou seja, um conjunto de características químicas que confere movimento às moléculas, e permite interações químicas, sobretudo entre solventes e solutos; considera-se que quanto maior a fluidez do solvente, mais facilmente solutos estarão nele dissolvidos. E o breu confere a rigidez que é a resistência de um corpo elástico à deflexão ou deformação por uma força aplicada e é uma qualidade inerente ao material. (VLACK, MONTEIRO, 2003)

\subsubsection{Adesivo termo - aplicável}

O adesivo termo - aplicável que foi utilizado para a fixação da base da barra de apoio em uma superfície foi manufaturada a partir do aquecimento a $100^{\circ} \mathrm{C}$ em fogão a gás com a mistura das matérias - prima. Duas proporções foram testadas. Após o aquecimento e resfriamento a resina solidificou-se, conforme demonstra a figura 24 :

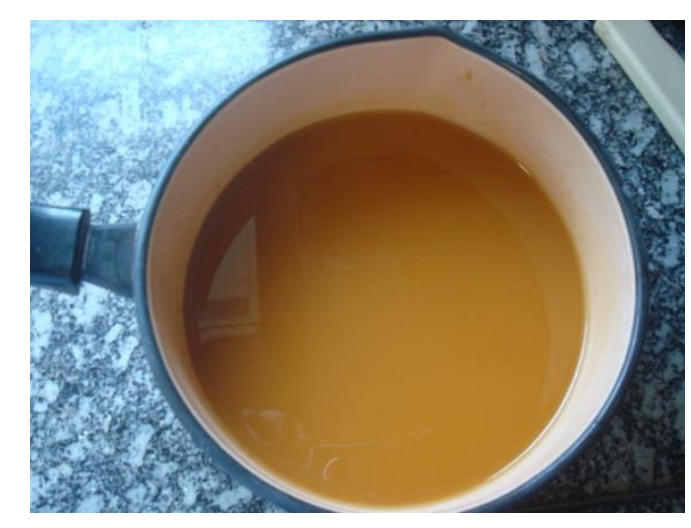

Figura 24- Resina termo- aplicável

Para facilitar o uso da resina pelos usuários, planeja-se disponibilizar a resina com o formato da parte inferior da base da barra de apoio para que esta se encaixe adequadamente na base e o usuário possa aquecê-la e fixar no solo com facilidade. E para o encaixe entre a base e o tubo também será manufaturada a resina no formato dessas ligações. O estudo quanto a adequação da resina termo- aplicável será descrita detalhadamente na validação, no teste de bancada da resina.

\subsubsection{Protótipos virtuais da barra de apoio modular removível}


De acordo com o estudo realizado quanto as especificações da barra de apoio, o primeiro modelo apresentado foi modificado e projetado o segundo modelo do protótipo utilizando o programa CAD Solid Edge (CAD - computer aided design ou Desenho auxiliado por computador), em que é composto por uma barra vertical curta com fixação na base por parafusos e possivelmente a utilização de um adesivo. A barra vertical curta apresentava 150 $\mathrm{cm}$ de altura e 0,50 cm de espessura. (Fig. 25-26)
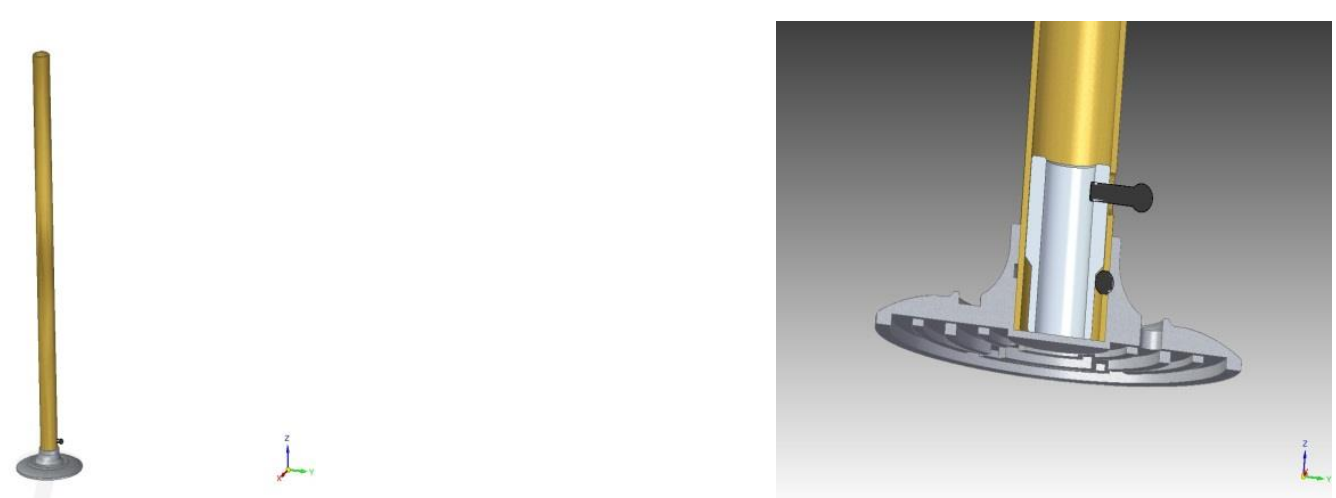

Figura 25 - Segundo modelo da barra de apoio e detalhe do encaixe do tubo a base
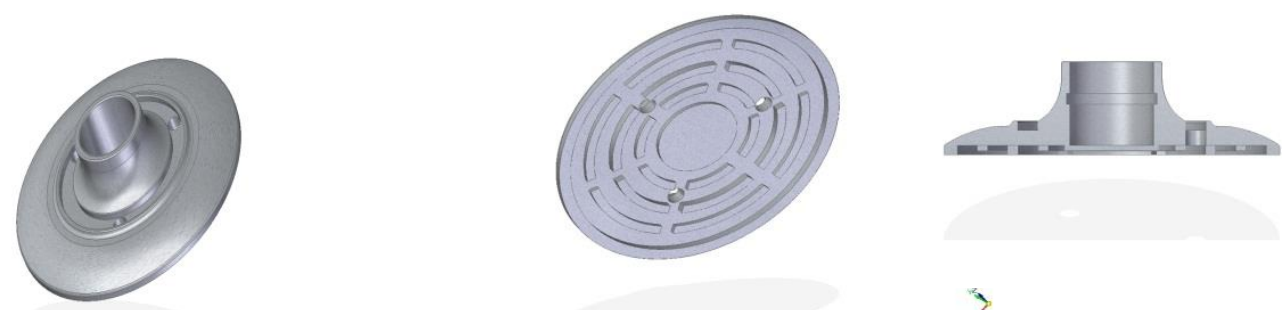

Figura 26 - Base do segundo modelo da barra de apoio

A partir desse segundo modelo foi realizada uma ampla pesquisa da matéria-prima disponível no mercado comercial que atendesse a estas especificações, especificamente quanto a espessura do alumínio disponível em tubos para comercialização. No entanto, essa especificação da espessura do alumínio em tubo da barra não estava disponível comercialmente.

Desta forma, conforme explicitado no item anterior foi definida uma nova espessura da barra de apoio, de $38 \mathrm{~cm} / 31 \mathrm{~cm}$ e altura de $90 \mathrm{~cm}$. O terceiro modelo desenvolvido consta da base de fixação por resina termo aplicável e segmentos tubulares como acessórios para montagem de diferentes desenhos segundo a necessidade do indivíduo. A partir disso a Figura 27 refere-se aos modelos de protótipos das peças virtuais que compõe a barra e possibilita a montagem de diferentes modelos. 
A base é um reservatório da resina, as ranhaduras permitem a distribuição do adesivo e auxílio na fixação. O rebaixo permite um acabamento externo contínuo sem ressaltos.

Os acessórios foram projetados pensando em atender as diferentes necessidades dos usuários, o Cotovelo $90^{\circ}$ permite a ligação entre os tubos verticais e horizontais, formando barra de apoio simples com dois apoios. Os Cotovelos mais e menos de $30^{\circ}$ permitem a montagem de barra de apoio com diferentes graus de inclinação, favorecendo a realização do apoio na barra horizontal de forma ergonômica e confortável. O Tee permite a ampliação do comprimento horizontal de barra de apoio. O Cotovelo - Tee permite a ligação entre tubos verticais e horizontais. Dessa forma, a barra de apoio projetada poderá ser utilizada não somente em domicílios, mas também, em instituições de saúde, na área da reabilitação, nas enfermarias, nas instituições de longa permanência e outros.

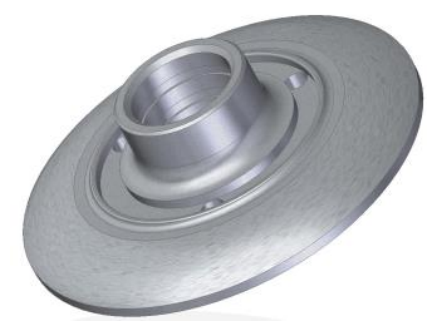

a)

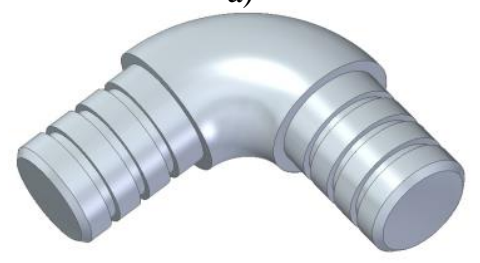

c)

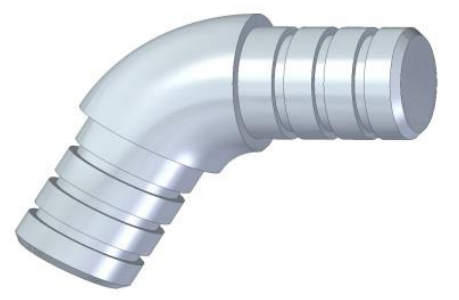

e)

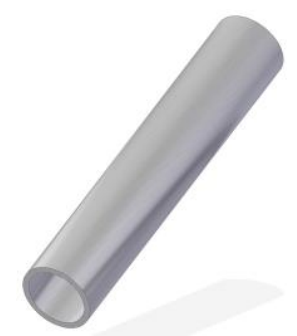

b)

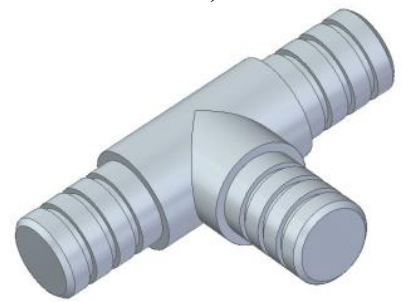

d)

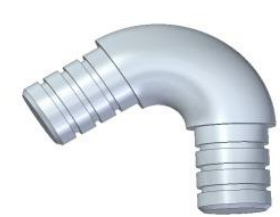

f) 


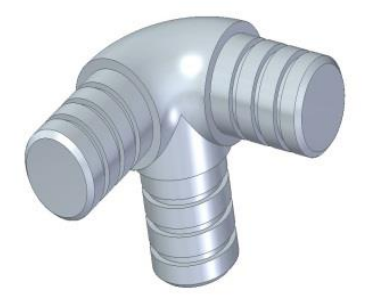

g)

Figura 27 - a) Base 0,50cm ; b) Tubo de 90 a $120 \mathrm{~cm}$; c) Cotovelo $90^{\circ}$; d) Tee; e) cotovelo mais de $30^{\circ}$; f) cotovelo menos de $30^{\circ}$; g) Cotovelo-Tee

Pretende-se oferecer aos usuários a compra separada de partes da barra de modo que ele adeque a configuração da barra de apoio às necessidades e espaço disponível. Abaixo se têm 2 exemplos do uso da barra de apoio nas figuras 28 e 29 :

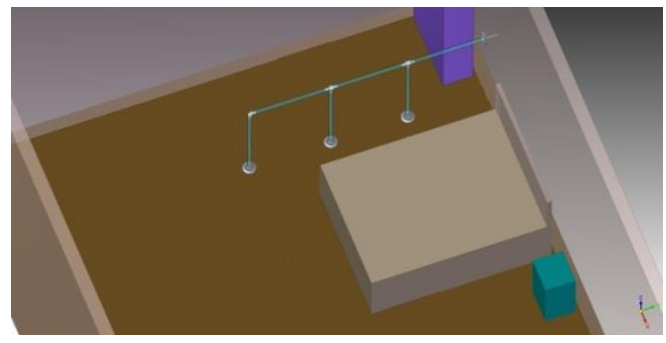

Figura 28- Exemplo 1 de uso da barra de apoio em um quarto

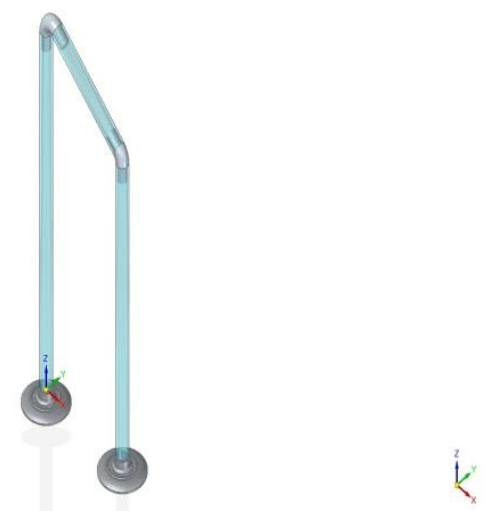

Figura 29 - Exemplo 2 de uso da barra de apoio, utilizando 2 bases, 1 tubo de $82 \mathrm{~cm}, 1$ tubo de $70 \mathrm{~cm}, 1$ tubo de $50 \mathrm{~cm}, 1$ cotovelo de $90^{\circ}$ e 1 cotovelo com menos de $30^{\circ}$.

Assim, decidiu-se que a barra de apoio terá as seguintes especificações, conforme a tabela 8 explicita: 
Tabela 8 - Especificações da barra de apoio modular removível

\begin{tabular}{|c|c|}
\hline Tubos & $\begin{array}{l}\text { - Altura de } 0,90 \mathrm{~m} \text {, considerando as medidas de alcance } \\
\text { frontal, quando a pessoa estiver sentada e para quando } \\
\text { a pessoa estiver em pé; } \\
\text { - Diâmetro da seção circular entre } 3,0 \mathrm{~cm} \text { e } 4,5 \mathrm{~cm} \mathrm{e} \\
\text { devem estar afastados no mínimo } 4,0 \mathrm{~cm} \text { da parede ou } \\
\text { outro obstáculo. } \\
\text { - Liga de alumínio } 6063-\mathrm{T} 5 \text { de diâmetro externo e } \\
\text { interno de } 38,1 \mathrm{~cm} / 31 \mathrm{~cm} \text {; }\end{array}$ \\
\hline Base & - Liga de alumínio usinado \\
\hline Conexões & - Liga de alumínio por fundição \\
\hline Fixação & $\begin{array}{l}\text { - Fixação das barras de apoio no chão, parede, e entre o } \\
\text { componente (base, conexões e tubos) por meio de } \\
\text { resina termo aplicável. }\end{array}$ \\
\hline
\end{tabular}




\section{RESULTADOS}

A partir dos modelos de protótipos virtuais foram definidos os métodos para o desenvolvimento de protótipos físicos, conforme descrito abaixo.

\subsection{Protótipos}

O processo de manufatura dos protótipos foi realizado no Laboratório de Tribologia e Compósitos - Escola de Engenharia de São Carlos da Universidade de São Paulo (LTCEESC-USP), e em duas empresas privadas: Tornearia Mecânica de Ribeirão Preto e Empresa de Fundição em Alumínio em São Carlos.

\subsubsection{Usinagem da base da barra de apoio}

Através do programa CAD - Solid Edge foi elaborado o desenho da base da barra de apoio para a usinagem da peça em maquinário Torno Mecânico. Como matéria-prima foi utilizado o disco de alumínio (Fig.30).

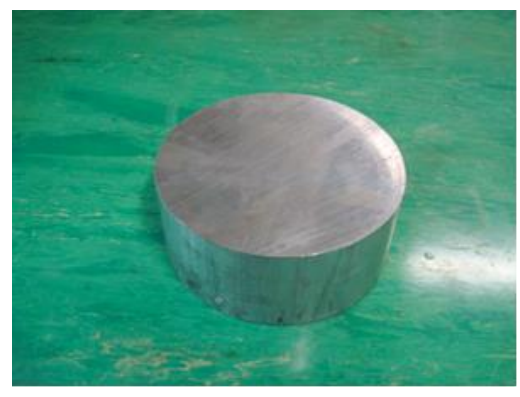

Figura 30 - Disco de alumino $\phi 150 \times 50 \mathrm{~mm}$

Abaixo segue o desenho da base da barra de apoio e suas especificações (Figura 31). 

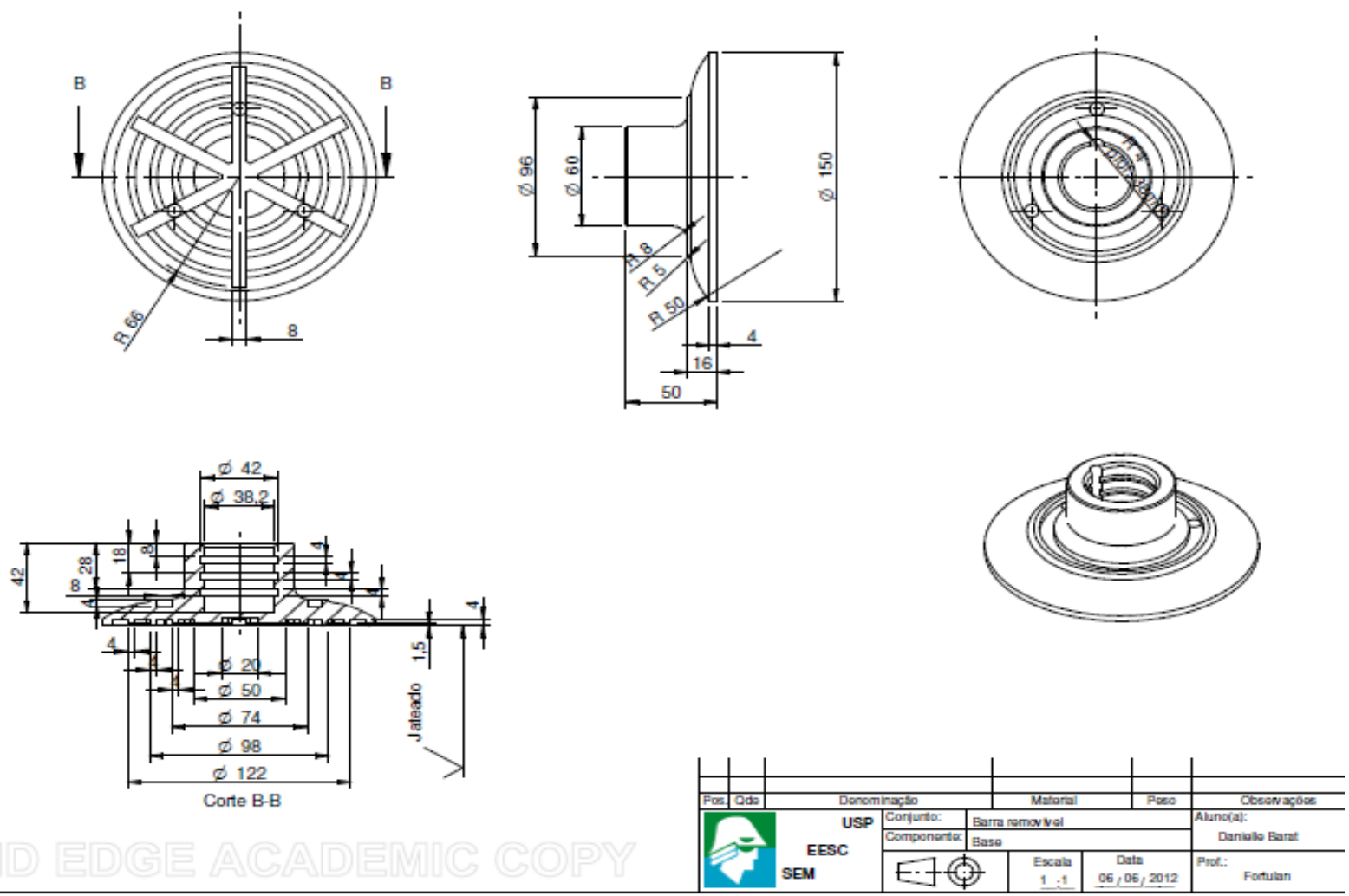

Figura 31- Desenho da base da barra de apoio

A usinagem da base da barra de apoio foi realizada no Torno Mecânico, uma máquinaferramenta que permite usinar peças de forma geométrica de revolução.

Através deste equipamento é possível confeccionar eixos, polias, pinos, qualquer tipo possível e imaginável de roscas, peças cilíndricas internas e externas, além de cones, esferas e os mais diversos e estranhos formatos. (WIKIPÉDIA, 2012)

A figura 32 mostra a usinagem da base da barra de apoio.

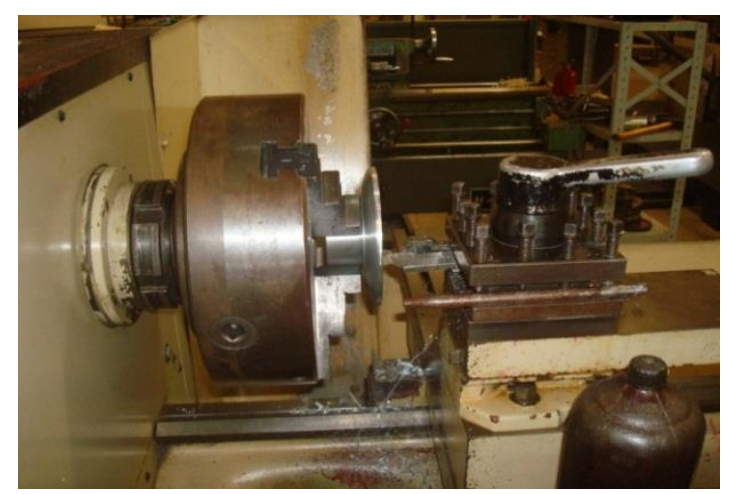

Figura 32 - Usinagem da base da barra de apoio

Abaixo, tem-se a vista superior e inferior da base da barra de apoio, mostrando as ranhaduras de distribuição da resina. (Figura 33) 

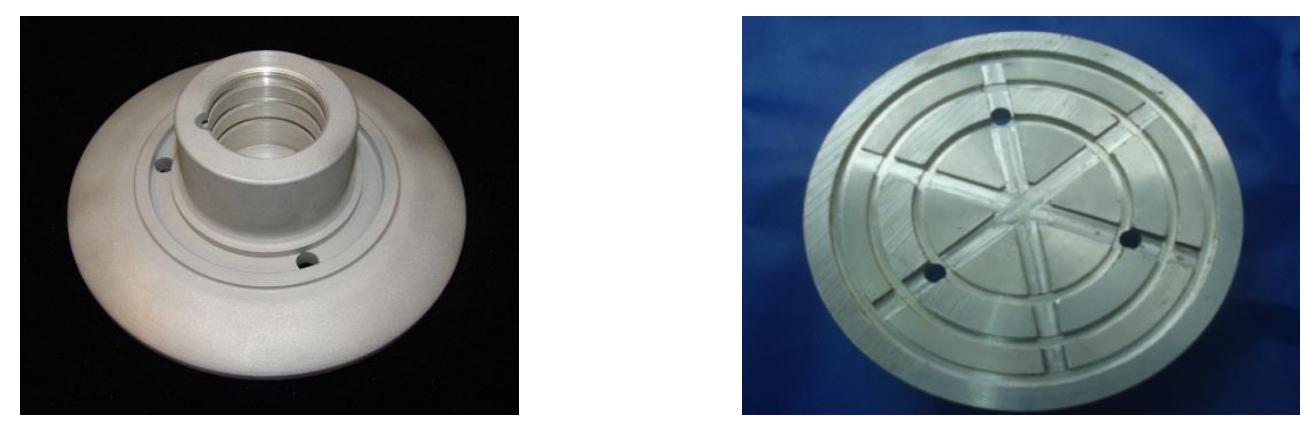

Figura 33 - Vista superior e inferior da base da barra de apoio

\subsubsection{Tubo}

O tubo utilizado como suporte vertical e horizontal nas diferentes configurações da barra de apoio é de alumínio liga 6063-T5 com diâmetro externo e interno de 38,1×31, 72, respectivamente e realizados os cortes das metragens necessárias. Como exemplo do protótipo testado, o tubo para uso vertical (2) foi cortado na altura de $0,90 \mathrm{~cm}$ e para uso horizontal foi cortado na altura de $1,10 \mathrm{~cm}$. (Fig. 34)

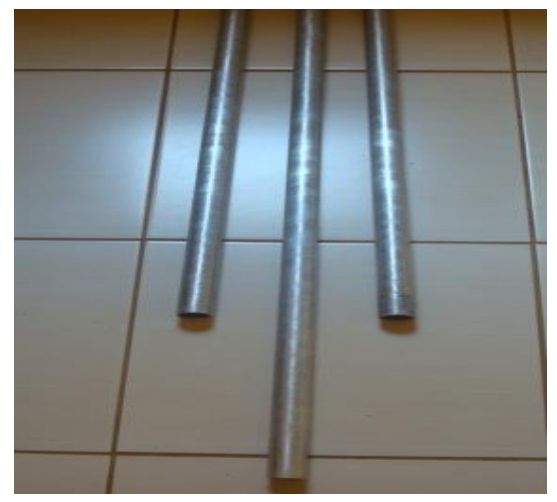

Figura 34 - Tubos

Para a prototipagem das demais peças da barra de apoio foi utilizada a técnica da prototipagem rápida, prototipagem em gesso e moldes em silicone para posterior fundição em alumínio.

\subsubsection{Cotovelos e Tee}

Os protótipos das peças Tee e Cotovelos foram manufaturados através da técnica de fundir o alumínio. Inicialmente, foi utilizada a técnica da prototipagem rápida, a prototipagem em gesso, confecção de molde em gesso e posteriormente em poliuretano para a finalização da fundição em alumínio. 


\subsubsection{A Técnica de prototipagem rápida}

O termo prototipagem rápida designa um conjunto de tecnologias usadas para se fabricar objetos físicos diretamente a partir de fontes de dados gerados por sistemas de projeto auxiliado por computador (C.A.D). Tais métodos são bastante peculiares, uma vez que eles agregam e ligam materiais, camada a camada, de forma a constituir o objeto desejado. Eles oferecem diversas vantagens em muitas aplicações quando comparados aos processos de fabricação clássicos baseados em remoção de material, tais como fresamento ou torneamento.

Tais métodos permitem aos projetistas criar rapidamente protótipos concretos a partir de seus projetos, ao invés de figuras bidimensionais, que constituem um auxílio visual excelente durante a discussão prévia do projeto com colaboradores ou clientes. Além disso, o protótipo pode permitir testes prévios como, por exemplo, ensaio em túnel de vento para componentes aeronáuticos ou análise fotoelástica para se verificar pontos de concentração de tensões na peça. (Z CORPORATION, 2012)

Estima-se que as economias de tempo e de custos proporcionadas pela aplicação das técnicas de prototipagem rápida na construção de modelos sejam da ordem de 70 a $90 \%$. Porém o termo "rápido" associado a esses processos é relativo. A construção de alguns protótipos pode levar de 3 a 72 horas, dependendo do tamanho e complexidade do objeto. Ainda assim esses processos são bem mais rápidos que os métodos tradicionais, tais como usinagem, que podem requerer dias ou mesmo meses para fabricar um único protótipo.Todos os processos de prototipagem rápida atualmente existente são constituídos por cinco etapas básicas:

1. Criação de um modelo CAD da peça que está sendo projetada;

2. Conversão do arquivo CAD em formato STL, próprio para estereolitografia;

3. Fatiamento do arquivo STL em finas camadas transversais;

4. Construção física do modelo, empilhando-se uma camada sobre a outra;

5. Limpeza e acabamento do protótipo.

Atualmente há sete diferentes técnicas de prototipagem rápida, o sistema de prototipagem rápida usado na fabricação de modelos utilizados neste trabalho foi o de Impressão por Jato de Tinta (MJT, Multi Jet Modeling; BPM, Ballistic Particle Manufacturing): que se refere a uma classe inteira de equipamentos que usam a tecnologia de jato de tinta. Os protótipos são construídos sobre uma plataforma situada num recipiente preenchido com material pulverulento. Um cabeçote de impressão por jato de tinta "imprime" seletivamente um agente 
ligante que funde e aglomera o pó nas áreas desejadas. O pó que continua solto permanece na plataforma para dar suporte ao protótipo que vai sendo formado. A plataforma é ligeiramente abaixada, adiciona-se mais material pulverulento e o processo é repetido. Ao se terminar o processo a peça "verde" é sintetizada, removendo-se o pó que ficou solto. Podem ser usados pós de materiais poliméricos, cerâmicos e metálicos. (Fig. 35)

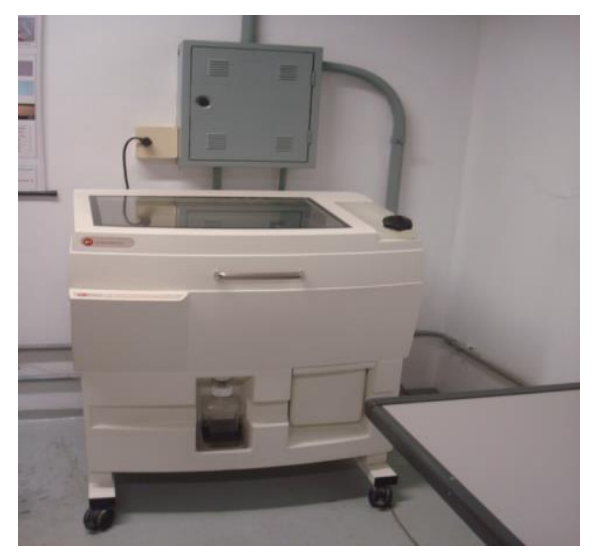

Figura 35 - Impressora Z PRINTER 310 - Z CORPORATION - LTC-EESC-USP

\subsubsection{Confecção das peças em gesso}

Escolheu-se fabricar protótipos em gesso para posterior confecção de moldes para reprodução em série de peças da barra de apoio.

\subsubsection{Confecção de molde em silicone}

A partir do modelo em gesso, confeccionou-se o molde em borracha de silicone, através da impressão negativa das referidas peças. O silicone P364A foi utilizado devido ao fácil preparo boa resistência e a possibilidade de reprodutividade. (Fig.36)

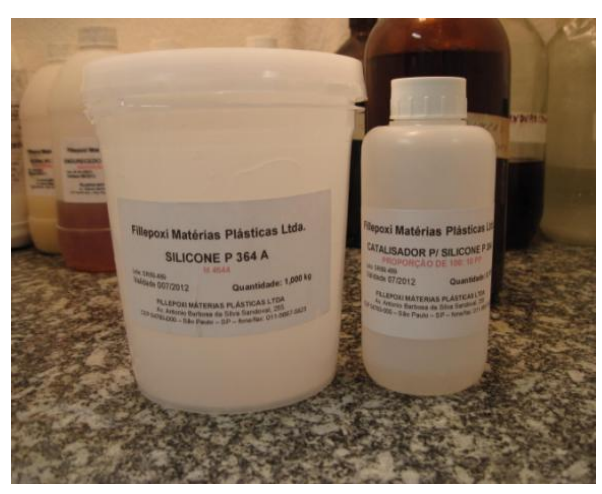

Figura 36 - SILICONE P364A e Catalisador 
Em um suporte de vidro com bordas de alumínio fixaram-se as peças impressas em gesso e acrescentou-se o preparado de borracha de silicone e catalisador (2:1), utilizando a bomba de vácuo para retirada de bolhas de ar, elaborou-se o molde.

Assim, conseguiram-se peças em silicone com o molde negativo de todas as peças desenvolvidas, tomando-se os devidos cuidados com a disposição das mesmas sobre a superfície de vidro, conseguindo um molde resistente para reprodução das peças.

\subsection{Confecção de peças em resina}

As peças em poliuretano (resina) foram confeccionadas a partir da injeção do preparado Fillepoxi (poliuretano) e endurecedor com proporção (1:1) nos moldes de silicone. Uma das características desta resina é o processo de secagem de aproximadamente 5 minutos após mistura.

Este material permite rápida e fácil manipulação com alguma tranquilidade. Esta resina também permite correções em caso de imperfeições das peças produzidas (bolhas).(Fig.37)
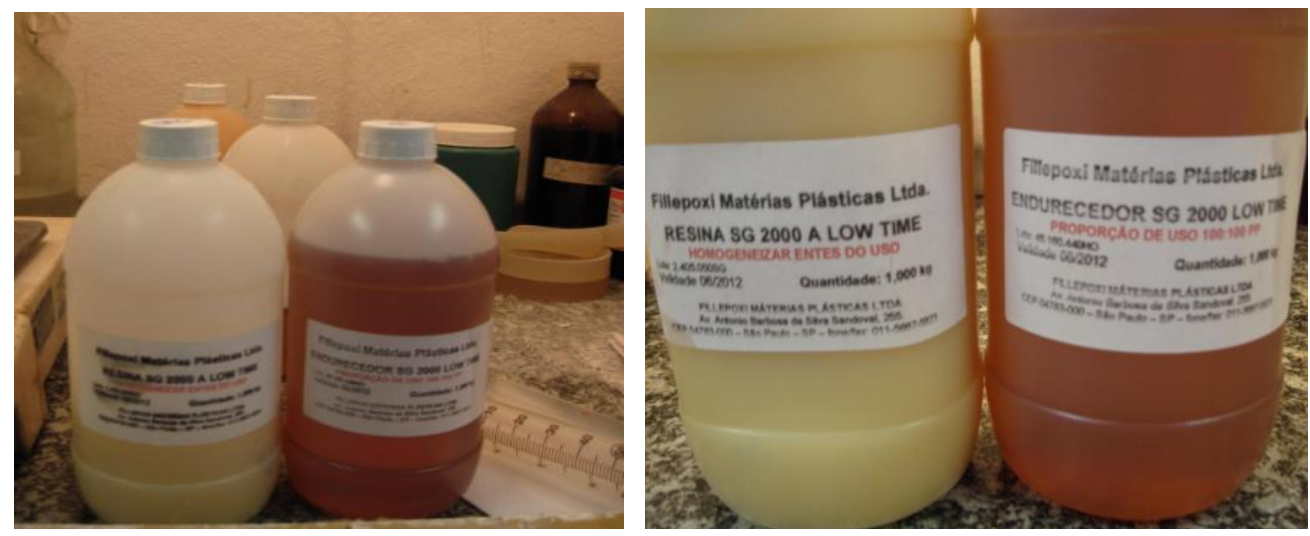

Figura 37 - Resina SG2000 e endurecedor. (poliuretano)

\subsubsection{Fundição em alumínio}

É um dos primeiros processos industriais utilizados na produção de artigos de metal. As propriedades do alumínio e a tecnologia moderna oferecem excelentes condições, com controles científicos adequados, para que se possam produzir grandes quantidades de peças mantendo uma qualidade uniforme. O mercado conta com excelentes ligas de alumínio que proporcionam uma grande variedade de propriedades para as peças fundidas. As principais são:

- Baixa temperatura de fusão;

- Forte tendência à oxidação;

- Baixa densidade; 
- Alta condutividade térmica;

- Elevado coeficiente de dilatação.

O vazamento de metal líquido em moldes de areia é uma das mais antigas artes industriais. Ainda é utilizado quando as peças fundidas são requeridas em pequenas quantidades, de tamanho excepcionalmente grande ou muito intricadas. Peças com melhor acabamento superficial são produzidas pela fundição em matriz por gravidade. O metal é vazado dentro de uma matriz de ferro ou de aço. Este processo torna-se econômico quando há uma demanda para um número considerável de peças.

A fundição pode ser feita por gravidade, com uso de areia ou molde metálico, e sob pressão, (alta ou baixa). Além desses há também processos especiais, com cera perdida e fundição centrifugada. (Associação Brasileira do Alumínio, 2012)

\subsubsection{Fundição em areia}

O processo utilizado na fundição das peças de "Cotovelo" e "Tee" foram a fundição em areia.

É um processo que pode ser feito por moldagem em areia verde e "Shell Modding", cura a frio, com dióxido de carbono e loast foam. Areias verdes são areias aglomeradas com argila no estado úmido. Esse material é constituído por granulados refratários chamados de areias-base e por um produto com capacidade de coesão e plasticidade - o aglomerante - que neste caso é a argila. As areias de fundição podem ser naturais, semi-sintéticas (com adições para correção ou melhoria das propriedades naturais) e sintéticas (obtida pela mistura dos constituintes básicos isoladamente tais como areia, aglomerantes, aditivos e plastificantes).(Associação Brasileira do Alumínio, 2012)

\subsubsection{Protótipos do Cotovelo 90ำ}

Abaixo se segue as figuras acerca do processo de prototipagem da peça "Cotovelo 90.” em gesso (Fig. 38), modelo inferior da fundição (Fig. 39), modelo em gesso no vidro com suporte de alumínio (Fig. 40), modelo inferior e superior em poliuretano (Figuras 41) e modelo em gesso, silicone e poliuretano (Figuras 42) sendo este último utilizado no processo da fundição de alumínio (Fig. 43). 


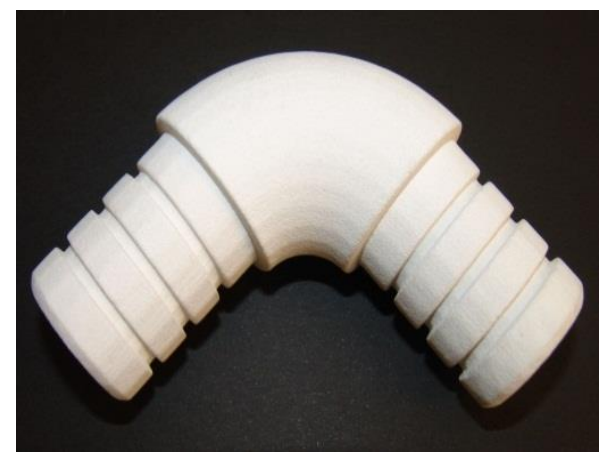

Figura 38 - Modelo em gesso cotovelo $90^{\circ}$.

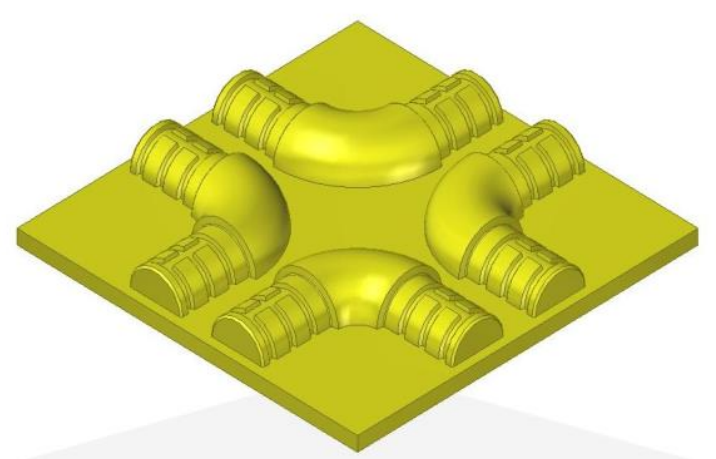

Figura 39- Modelo inferior da fundição

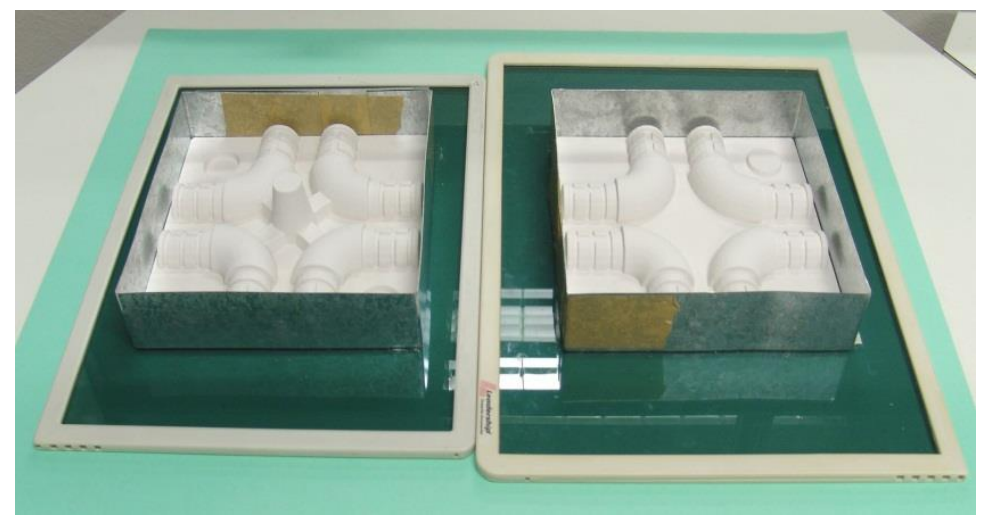

Figura 40 - Modelos em gesso preparado no vidro com suporte do alumínio para fundição do silicone
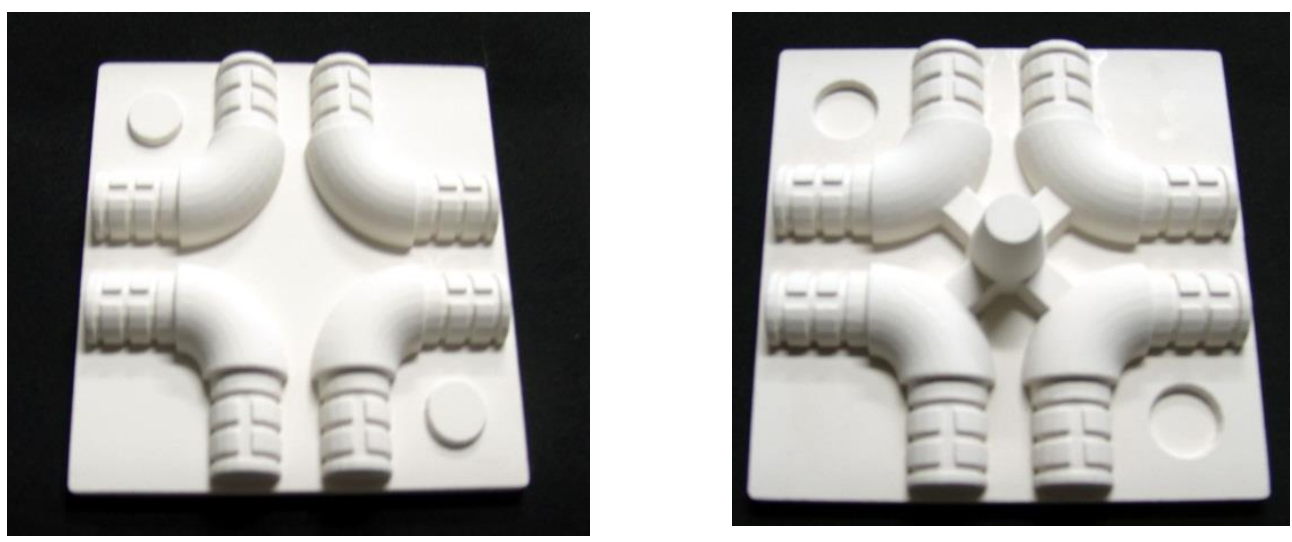

Figura 41 - Modelo superior e inferior em poliuretano 


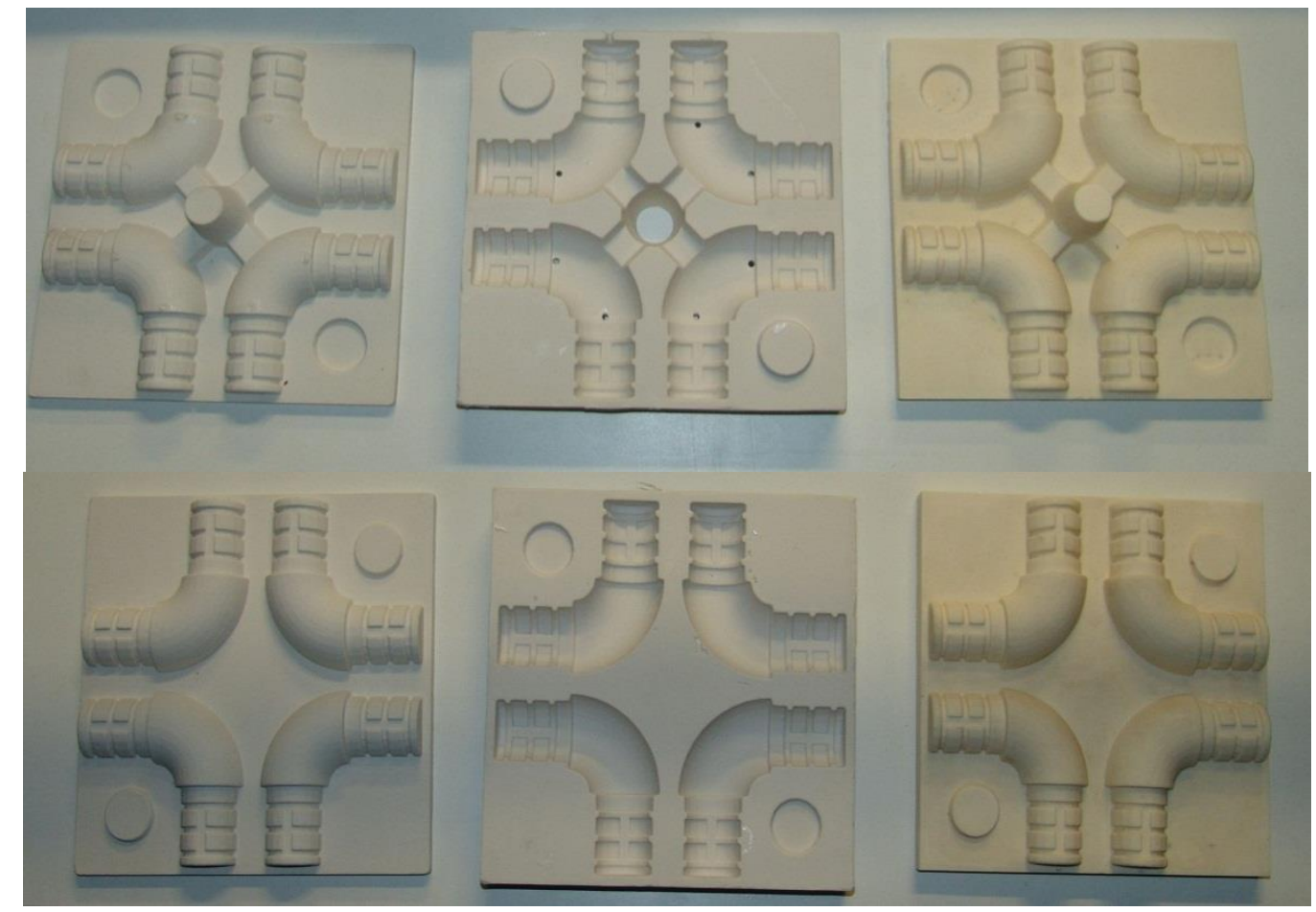

Figura 42 - Modelo Superior e Inferior Moldes em Gesso, Silicone e Poliuretano

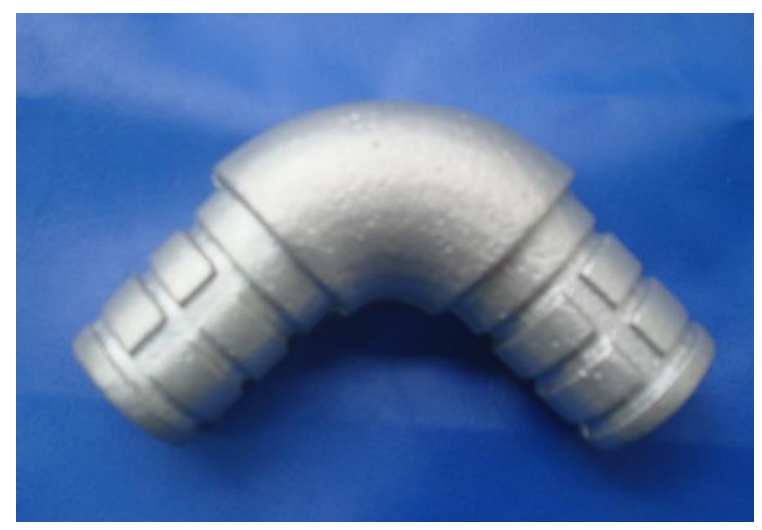

Figura 43 - Cotovelo $90^{\circ}$. fundidos em alumínio

\subsubsection{Protótipos Tee}

Abaixo se segue as figuras acerca do processo de prototipagem da peça "Tee" em gesso e modelo em gesso no vidro com suporte de alumínio (Fig. 44), estrutura lado A e lado B para a fundição e molde para fundição direta (Fig. 45) e sendo este último utilizado no processo da fundição de alumínio (Fig. 46 - 47). 

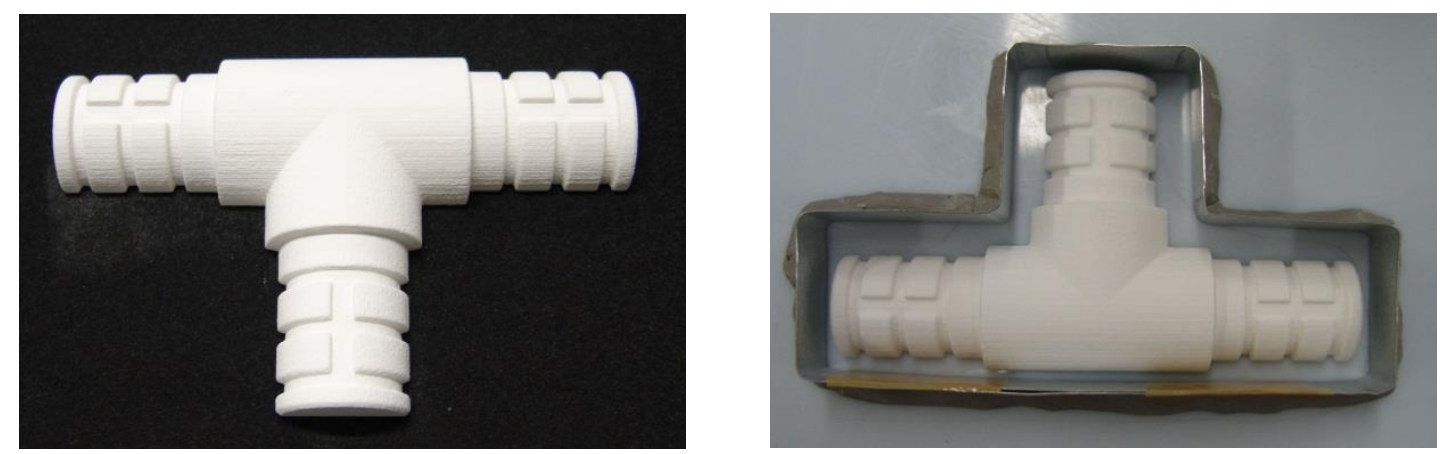

Figura 44 - Meio tee em gesso e preparação para moldagem em silicone

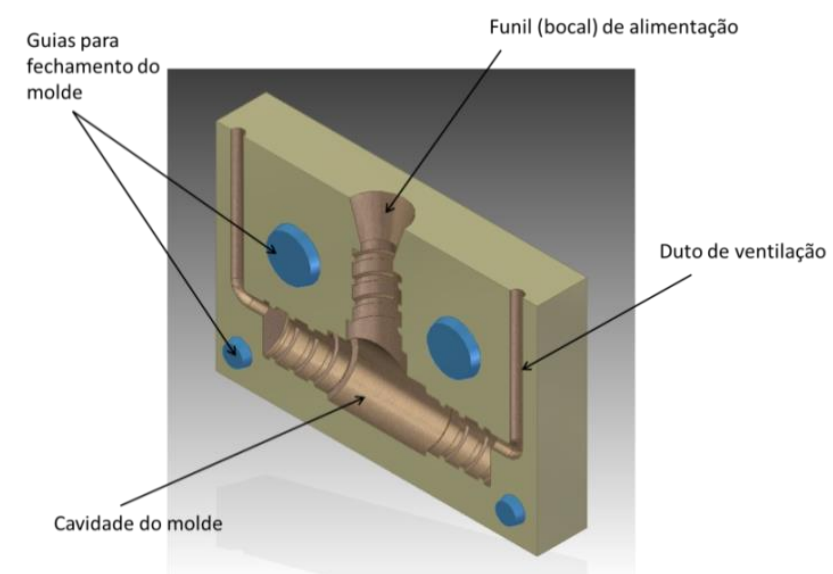

a)

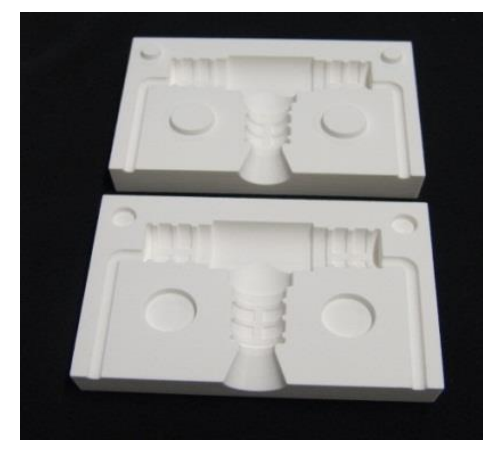

b)

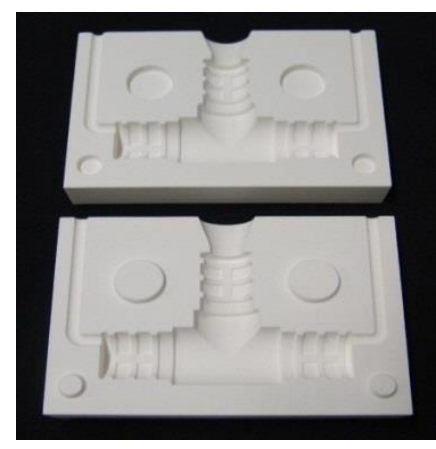

c)

Figura 45 - a) Modelo para fundição direta b) Molde Tee para fundição direta lado a e lado b c) Molde Tee para fundição direta

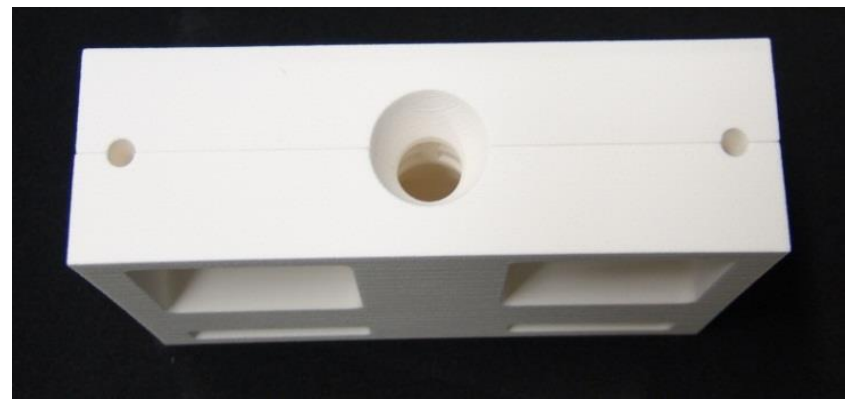

Figura 46 - Molde para fundição direta lado A + lado B 


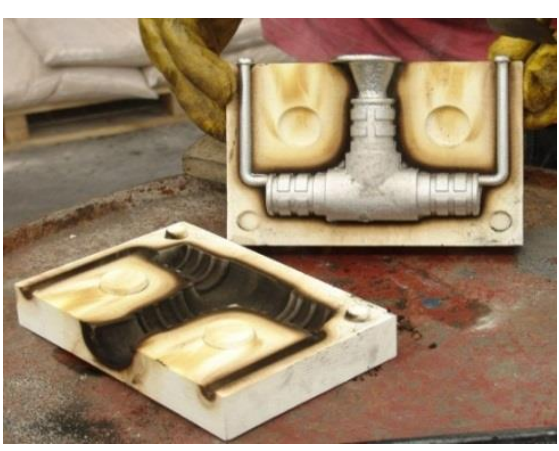

a)

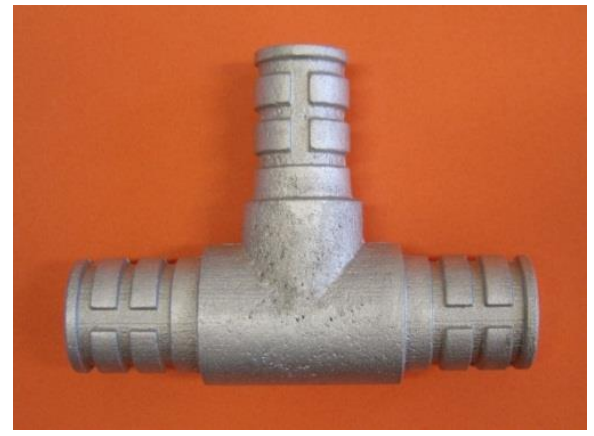

b)

Figura 47 - a)Tee recém-fundido e b) Tee fundido em alumínio

\subsubsection{Protótipos Cotovelo 60‥ e Cotovelo 120․}

Abaixo se segue as figuras acerca do processo de prototipagem das peças "Cotovelo $60^{\circ}$. e Cotovelo $120^{\circ}$." na figura 48.

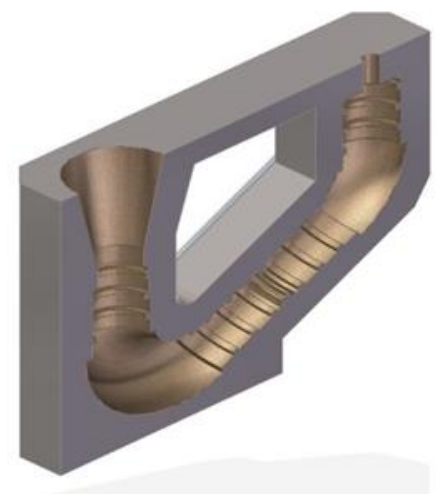

a)

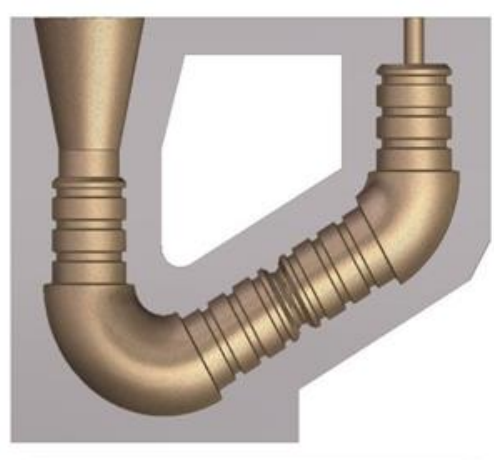

c)

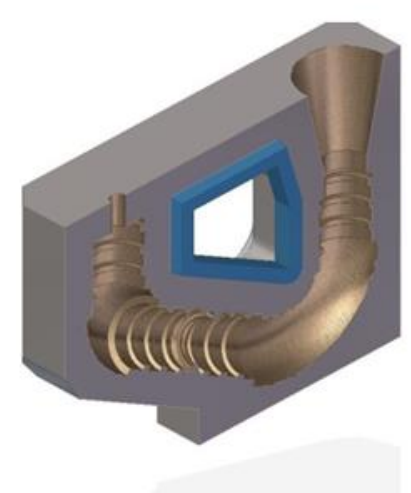

b)

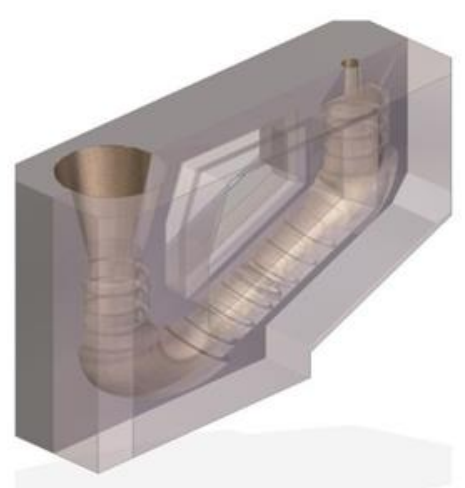

d) 


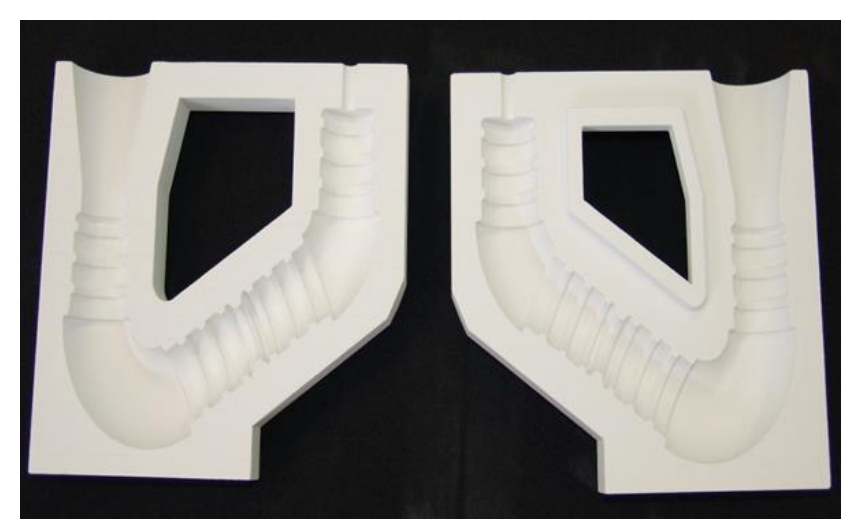

e)

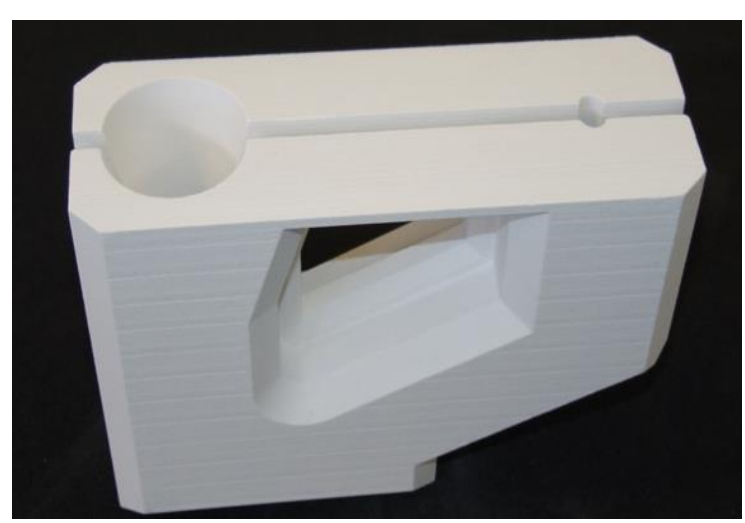

f)

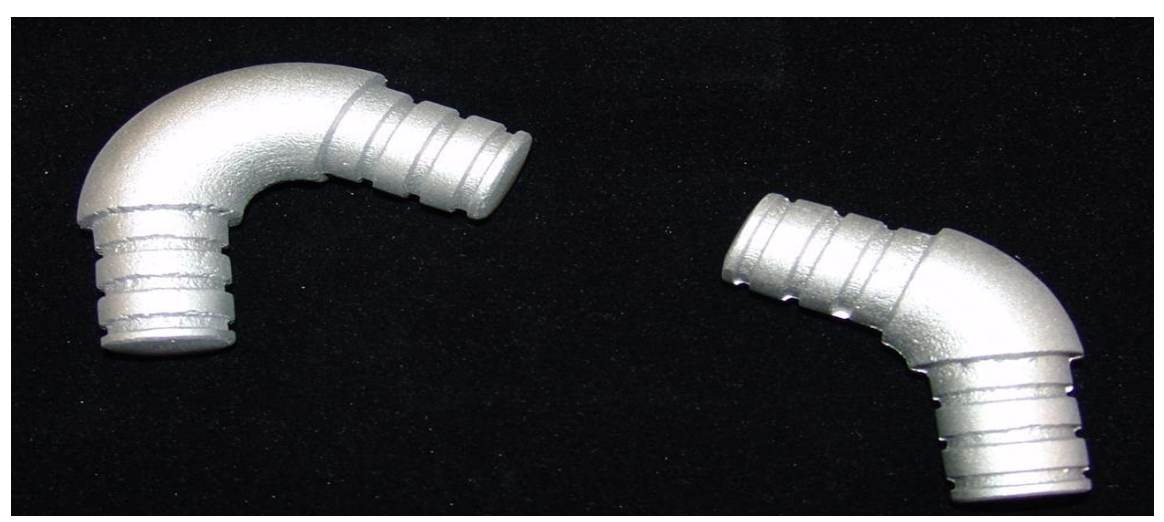

g)

Figura 48 - Molde dos cotovelos a) molde 60-120 lado direito b) molde 60-120 lado esquerdo c) molde 60120 vista frontal d) molde 60-120 - fechado e) molde esquerdo e direito para fundição direta f) molde para fundição direta fechado g) cotovelo $60^{\circ}$. e cotovelo $120^{\circ}$. fundidos

\section{2 Despesas e custos do protótipo}

Abaixo se segue os custos de cada peça de protótipo de barra de apoio e o peso de cada peça prototipada, peso da modelagem em silicone e resina de poliuretano e quanto ao custo de cada processo nas tabelas 9 a 13:

Tabela 9 - Custo dos tubos e disco de alumínio

\begin{tabular}{c|c|c|c}
\hline Quantidade & Unidade & Descrição & Valor \\
\hline 1 & $\mathrm{~m}$ & $\begin{array}{c}\text { Tubo de Alumínio } \\
\text { liga 6063-T5 } \phi 38,1 \mathrm{x}\end{array}$ & $\mathrm{R} \$ 35,00$ \\
& un & $\begin{array}{c}\text { Discos de alumino } \phi \\
150 \times 50 \mathrm{~mm}\end{array}$ & $\mathrm{R} \$ 45,00$ \\
\hline 1 & &
\end{tabular}

Tabela 10 - Custo dos materiais utilizados na prototipagem

\begin{tabular}{c|c|c|c}
\hline Quantidade & Unidade & Descrição & Valor \\
\hline 01 & Balde/14kg & Pó ZP 150 & $\mathrm{R} \$ 5.022,86$ \\
\hline 01 & Galão/3.8lt & Binder Zb 60 & $\mathrm{R} \$ 2.706,47$ \\
\hline
\end{tabular}




\begin{tabular}{c|c|c|c}
\hline 01 & un & $\begin{array}{c}\text { Cabeçotes de } \\
\text { impressão }\end{array}$ & $\mathrm{R} \$ 96,30$ \\
\hline 01 & $\mathrm{~kg}$ & $\begin{array}{c}\text { Resina para borracha } \\
\text { de Silicone }\end{array}$ & $\mathrm{R} \$ 35,00$ \\
\hline 01 & $\mathrm{~kg}$ & Poliuretano rígido & $\mathrm{R} \$ 25,00$ \\
\hline
\end{tabular}

Tabela 11 - Material consumido para prototipagem e custo

\begin{tabular}{c|c|c|c|c}
\cline { 2 - 5 } & \multicolumn{4}{c}{ Peso de cada peça do protótipo de barra de apoio } \\
\cline { 2 - 5 } & $0,8 \mathrm{~kg}$ & $1,75 \mathrm{~kg} / 4$ peças & $0,8 \mathrm{~kg} / 1 \mathrm{peça}$ & $0,8 \mathrm{~kg} / 1$ peça \\
\hline $\begin{array}{c}\text { Cada lado } \\
\text { prototipado para } \\
\text { fundição direta } \\
\text { do pó de } \\
\text { prototipagem }\end{array}$ & $1,2 \mathrm{~kg}$ & $0,66 \mathrm{~kg} / 4$ peças & - & \\
\hline $\begin{array}{c}\text { Modelagem em } \\
\text { silicone }\end{array}$ & - & $1,3 \mathrm{~kg} / 4$ peças & - & - \\
\hline $\begin{array}{c}\text { Resina de cada } \\
\text { lado }\end{array}$ & $\mathrm{R} \$ 942,00$ & $\mathrm{R} \$ 292,50$ & $\mathrm{R} \$ 855,60$ & $\mathrm{R} \$ 855,60$ \\
\hline Custo por peça & & & & \\
\hline
\end{tabular}

Tabela 12 - Custo da matéria - prima para resina termo reversível

\begin{tabular}{c|c|c|c}
\hline Quantidade & Unidade & Descrição & Valor \\
& & $\mathrm{kg}$ & Total \\
$\mathrm{nnn} \$ 250,00$ \\
\hline 05 & $\mathrm{Kg}$ & Parafina & \\
\hline 05 & $\mathrm{~kg}$ & Breu & \\
\hline
\end{tabular}

Tabela 13 - Custo do serviço de terceiro para usinagem e fundição das peças

\begin{tabular}{c|c|c|c|c|c}
\hline \multicolumn{7}{c}{ Serviço de Terceiros - Usinagem e Fundição de peças } \\
\hline Peça & Base & Tee & Cotovelo $^{\mathbf{0}}$. & $\begin{array}{c}\text { Cotovelo } \\
\mathbf{6 0}^{\mathbf{0}} .\end{array}$ & $\begin{array}{c}\text { Cotovelo } \\
\mathbf{1 2 0}^{\circ} .\end{array}$ \\
\hline $\begin{array}{c}\text { Processo de } \\
\text { Manufatura }\end{array}$ & $\begin{array}{c}\text { Usinagem } \\
\text { de cada } \\
\text { peça }\end{array}$ & $\begin{array}{c}\text { Fundição em } \\
\text { alumínio }\end{array}$ & $\begin{array}{c}\text { Fundição em } \\
\text { alumínio } \\
\text { em } \\
\text { alumínio }\end{array}$ & $\begin{array}{c}\text { Fundic̃a } \\
\text { Fundição em } \\
\text { alumínio }\end{array}$ \\
\hline $\begin{array}{c}\text { Peso de cada } \\
\text { peça }\end{array}$ & - & $4,2 \mathrm{~kg}$ & $2,9 \mathrm{~kg}$ & $0,80 \mathrm{~kg}$ & $0,80 \mathrm{~kg}$ \\
\hline $\begin{array}{c}\text { Valor do } \\
\text { processo }\end{array}$ & $\begin{array}{c}\mathrm{R} \$ 139,00 \\
\text { cada }\end{array}$ & $\begin{array}{c}\mathrm{R} \$ 30,00 / \\
\mathrm{kg}\end{array}$ & $\mathrm{R} \$ 30,00 / \mathrm{kg}$ & $\mathrm{R} \$ 30,00 / \mathrm{kg}$ & $\mathrm{R} \$ 30,00 / \mathrm{kg}$ \\
\hline Total & - & $\mathrm{R} \$ 126,00$ & $\mathrm{R} \$ 87,00$ & $\mathrm{R} \$ 24,00$ & $\mathrm{R} \$ 24,00$ \\
\hline
\end{tabular}


As despesas associadas à manufatura do protótipo apresentadas acima refletem o custo embutido no processo de desenvolvimento de um novo produto. A prototipagem rápida foi a etapa de maior custo no desenvolvimento do produto. A produção em larga escala e industrial que poderá utilizar outros métodos de prototipagem impactará na redução dos custos associados à manufatura do produto e garantia de venda a preço acessível aos usuários. 


\section{VALIDAÇÃO}

Nesta etapa do estudo foram realizados os testes de bancada para validação do protótipo da barra de apoio e de desenvolvimento da composição da resina com intuito de verificar a segurança e aderência da barra de apoio montada com diferentes materiais e averiguar as forças deformantes do movimento de sentado para em pé, as pesquisadoras realizaram testes com a barra de apoio:

$1^{\circ}$ Teste - verificar a aderência e a não danificação da resina em diferentes pisos utilizados nas residências brasileiras;

$2^{\circ}$ Teste- Teste de Bancada com os pesquisadores: os pesquisadores testaram a barra de apoio configurada com o tubo horizontal de $120 \mathrm{~cm}$ simulando a força de levantar apoiando na barra de apoio e observando o comportamento mecânico da aderência da resina na base, dos tubos e seus componentes;

$3^{\circ}$. Teste- ensaios mecânicos com a MTS - Bionix Servohydraulic Test System, foi testada a força máxima $(\mathrm{N})$ que a resina termo aplicável permite;

$4^{\text {o }}$. Teste - Teste Bancada com voluntários - aplicação clínica: voluntários com dificuldade para passar de sentado para em pé testaram a barra de apoio configurada com o tubo horizontal de $90 \mathrm{~cm} \times 120 \mathrm{~cm}$ simulando a força de levantar apoiando na barra de apoio e observando o comportamento mecânico da aderência da resina na base, dos tubos e seus componentes.

\section{1‥ Teste - Teste de Bancada com a Resina termo aplicável}

O teste de bancada com a resina termo - aplicável foi realizado no piso do Laboratório de Tecnologia Assistiva da FMRP-USP (LAPITEC) chamado comercialmente de granilete. A resina termo aplicável é constituída pela combinação da cera de abelha (Fig. 49), breu (Fig 50) e parafina (Fig.51). Ao combinar as propriedades de fusão e adesão e rigidez da mistura após o resfriamento, será possível a partir da combinação destes elementos a fixação a partir do aquecimento com o soprador térmico da resina (Fig. 52 - 53) na base da barra de apoio.

O breu é a substância que confere a rigidez a resina termo aplicável, foram estudadas duas composições da resina, diferenciando a porcentagem de uso do breu, e dividindo pela metade a porcentagem da parafina e cera de abelha. 


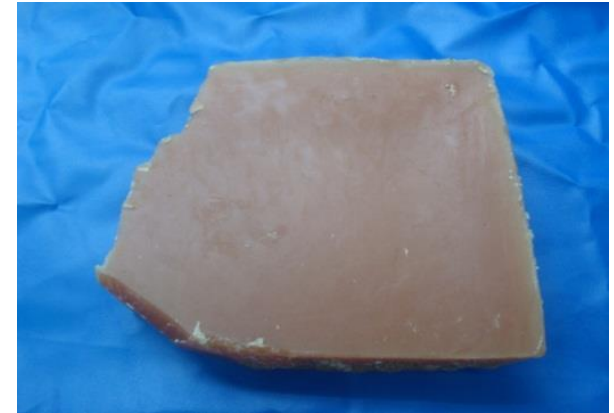

Figura 49 - Cera de abelha

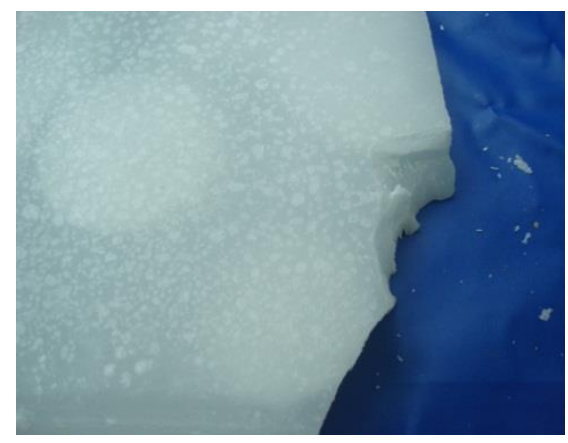

Figura 51 - Parafina

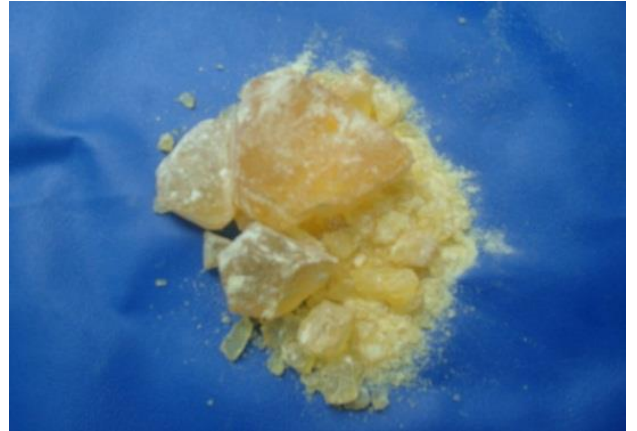

Figura 50 - Breu

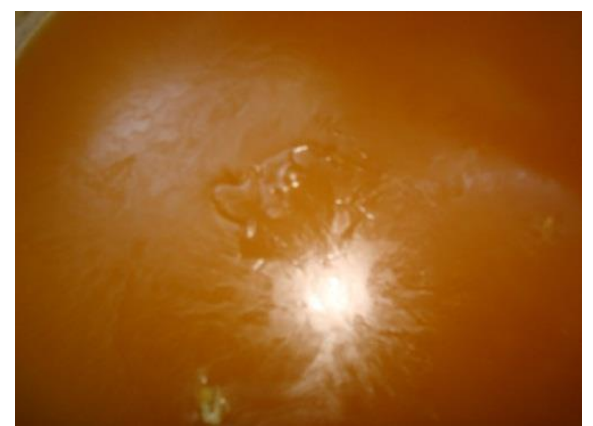

Figura 52 - Resina

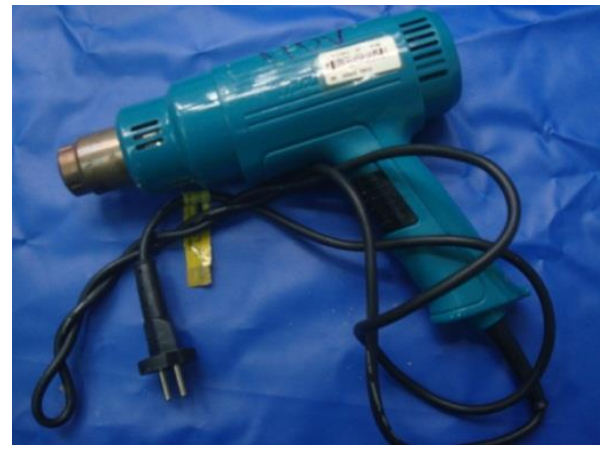

Figura 53 - Soprador Térmico

A resina termo aplicável foi aplicada na vista inferior da barra de apoio, esperado o resfriamento da resina termo-aplicável (Fig. 54)

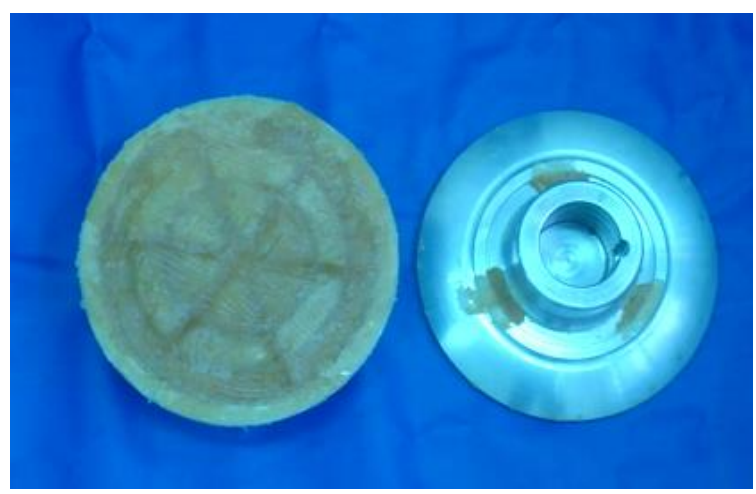

Figura 54 - Base vista inferior com resina termo -aplicável 
A superfície do piso do LAPITEC (Granilete) foi aquecida com o soprador térmico bem como a base com a resina e então foi fixada no chão e montados os tubos verticais e horizontal. (Fig. 55)
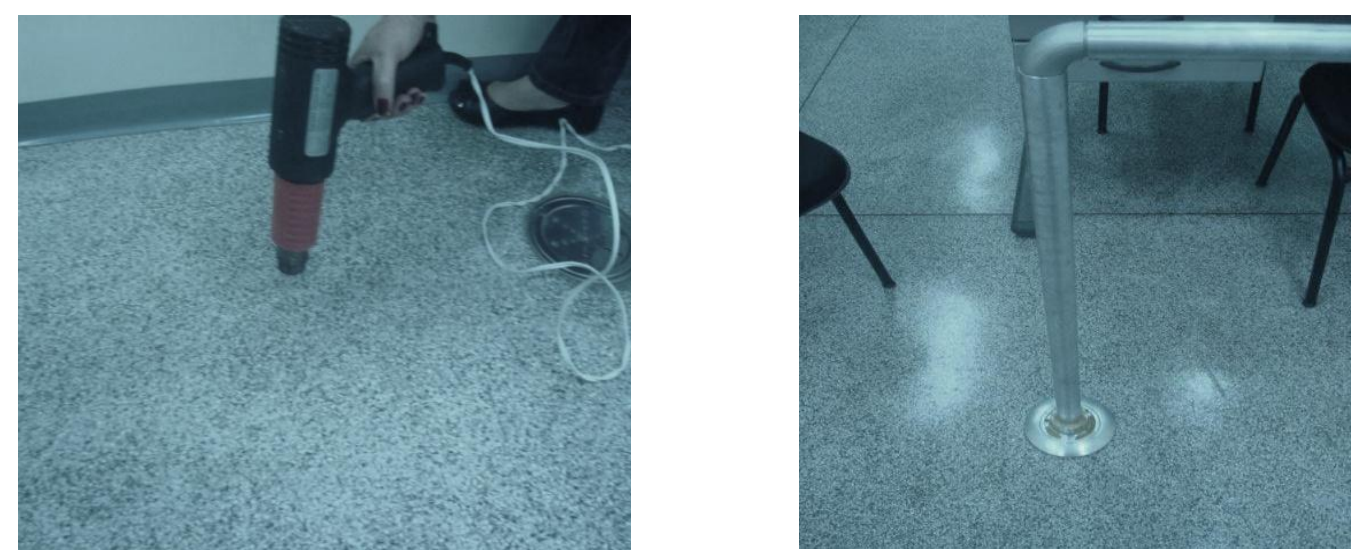

Figura 55- Aquecimento da superfície com soprador térmico e fixação da base com resina termo aplicável à superfície

No piso Granilete foi possível perceber que a aderência da resina termo aplicável foi prejudicada devido o piso estar "encerado". Após a remoção mecânica da cera presente no piso, houve boa aderência da resina termo aplicável ao piso.

Também foi testada a aderência da resina na união do piso frio com rejunte. Houve boa aderência da resina a esta superfície e não houve danos ao piso e nem ao rejunte. (Fig. 56). Percebeu-se que a resina aderiu completamente a base de alumínio e não houve ruptura da resina, quando esta foi removida.

No próprio piso frio também houve boa aderência da resina, não danificou o piso e não houve ruptura da resina ao ser reaquecido e removido do piso (Fig.57).

No piso de granito, comumente utilizado em banheiros e cozinhas, também houve boa aderência e a retirada da resina não danificou o piso, porém, ao ser reaquecido e removido, houve ruptura da resina, demonstrada pela permanência de resina no piso de granito. (Fig. 58) 


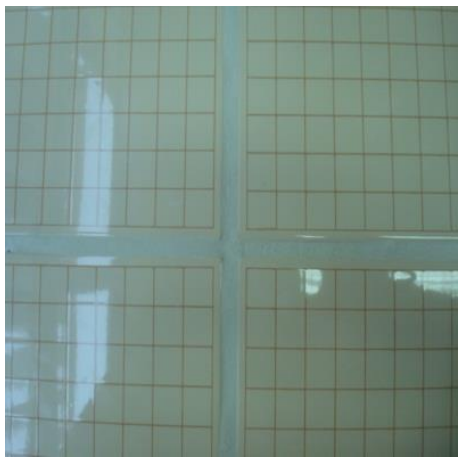

a)

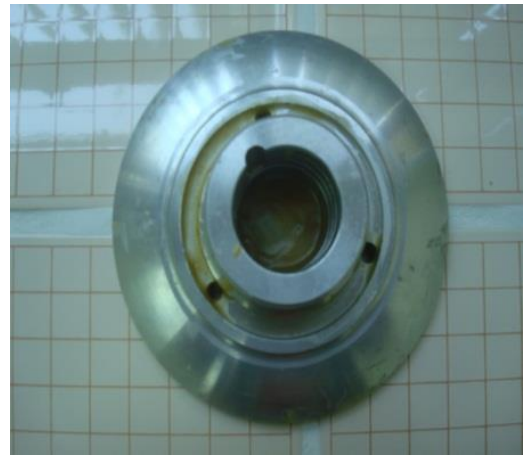

b)

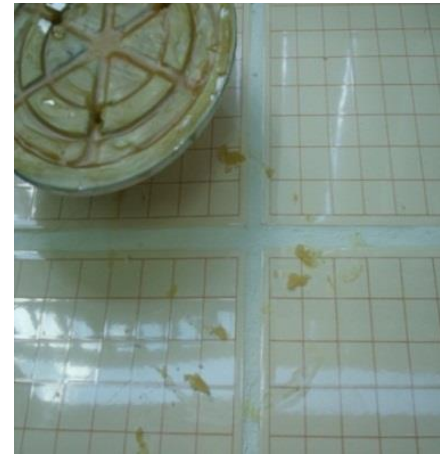

c)

Figura 56 - a)Piso frio e rejunte b) base fixa á superfície c) piso sem danos após aquecimento da resina com soprador térmico e retirada da base com resina

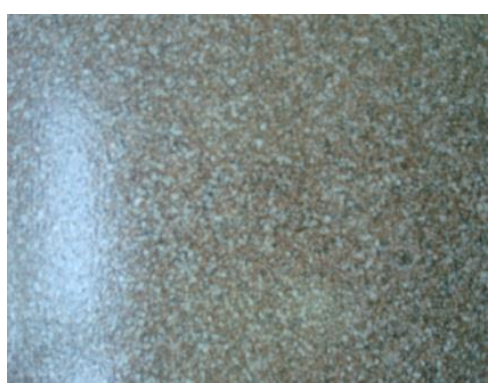

a)

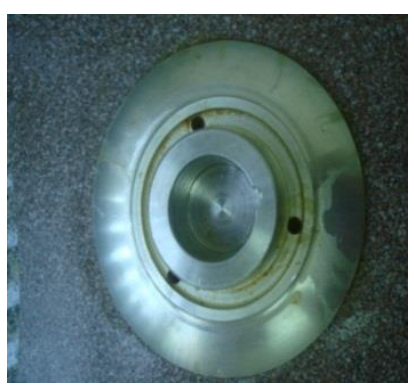

b)

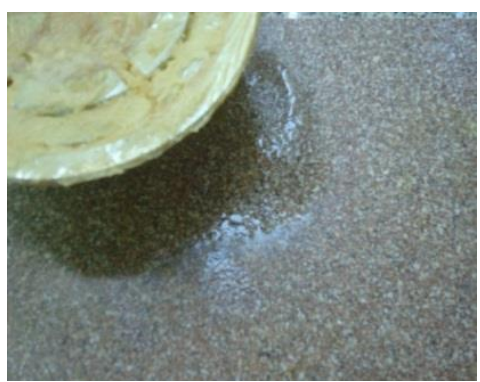

c)

Figura 57 - a) Piso frio b) base fixada á superfície do piso frio c) piso sem danos após aquecimento da resina com soprador térmico e retirada da base com resina

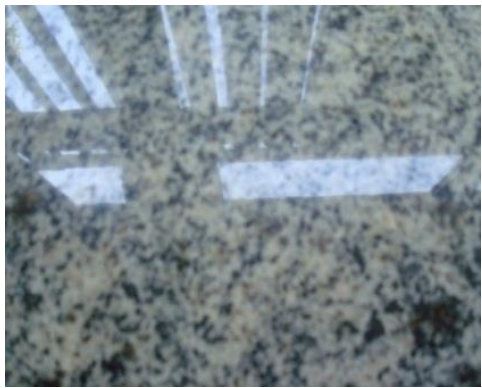

a)

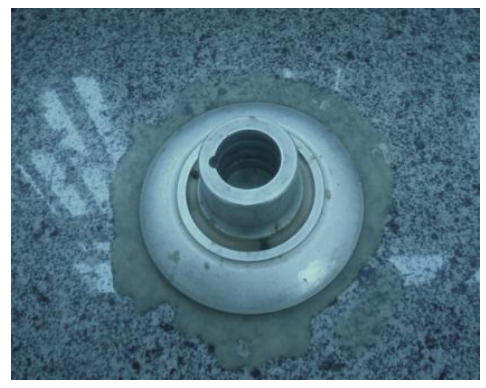

b)

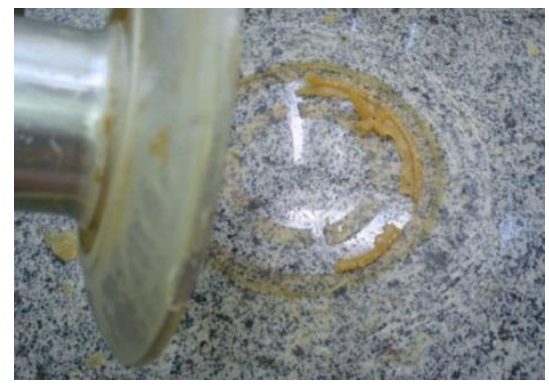

c)

Figura 58 - a) Granito b) base fixada á superfície do granito c) granito sem danos após aquecimento da resina com soprador térmico e retirada da base com resina

Em decorrência da ampla população brasileira ainda em situação desfavorável quanto à renda e o acesso a condições melhores de moradia, a resina foi testada no piso de cimento queimado "vermelhão" e no concreto. Em ambas as situações, a resina demonstrou ótima aderência e não houve danos à superfície bem como houve pouca ruptura da resina ao ser removida. (Fig. 59 - 60) 


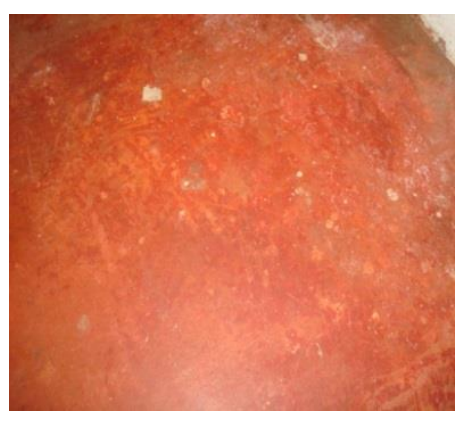

a)

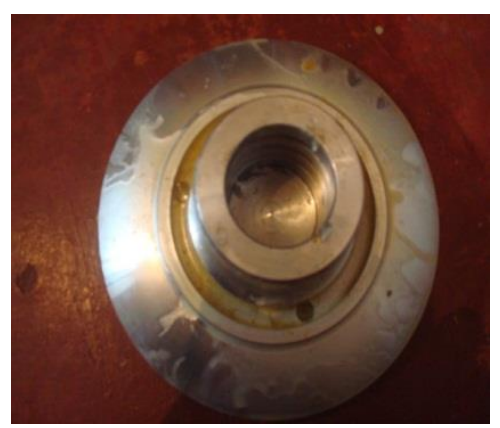

b)

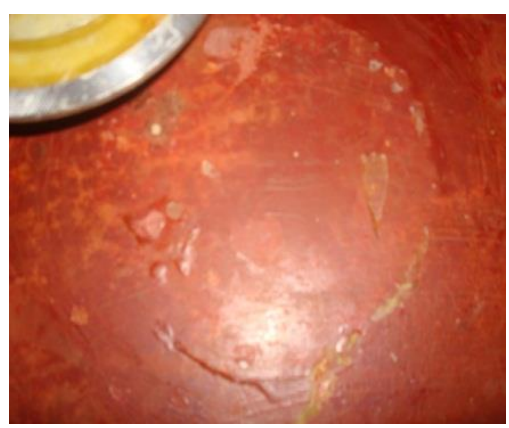

c)

Figura 59 - a) Piso cimento queimado ("vermelhão") b)base fixada á superfície c) Piso sem danos após aquecimento da resina com soprador térmico e retirada da base com resina

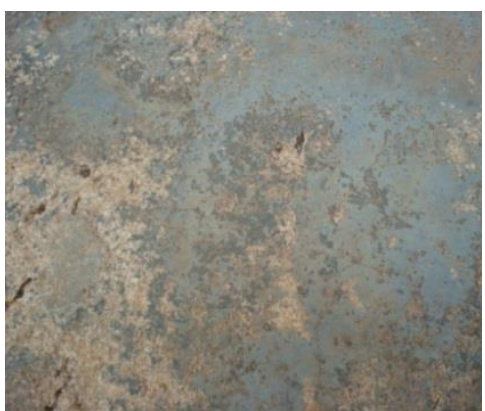

a)

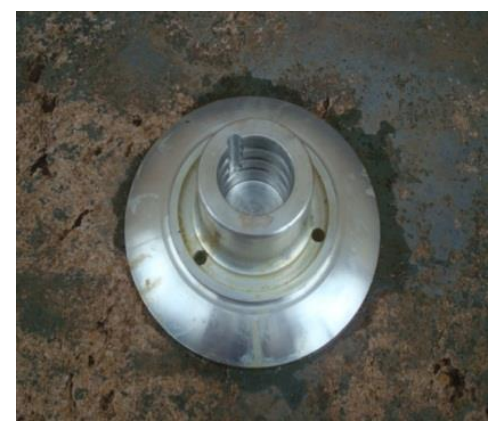

b)

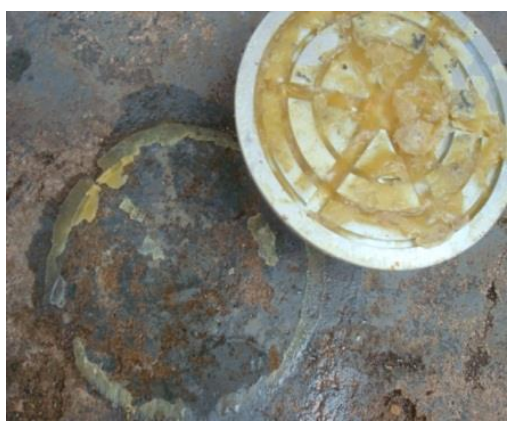

c)

Figura 60 - a)Piso em concreto b) base fixada no piso de concreto c) piso sem danos após aquecimento da resina com soprador térmico e retirada da base com resina

2‥ Teste - Teste de bancada com os pesquisadores (que não apresentam dificuldades de passar ST/DP)

De acordo com a metodologia adotada, o segundo teste com a barra de apoio foi montada no LAPITEC utilizando:

Conforme a figura abaixo (Fig.61), e os pesquisadores repetiram por diversas vezes o movimento de ST - DP. 


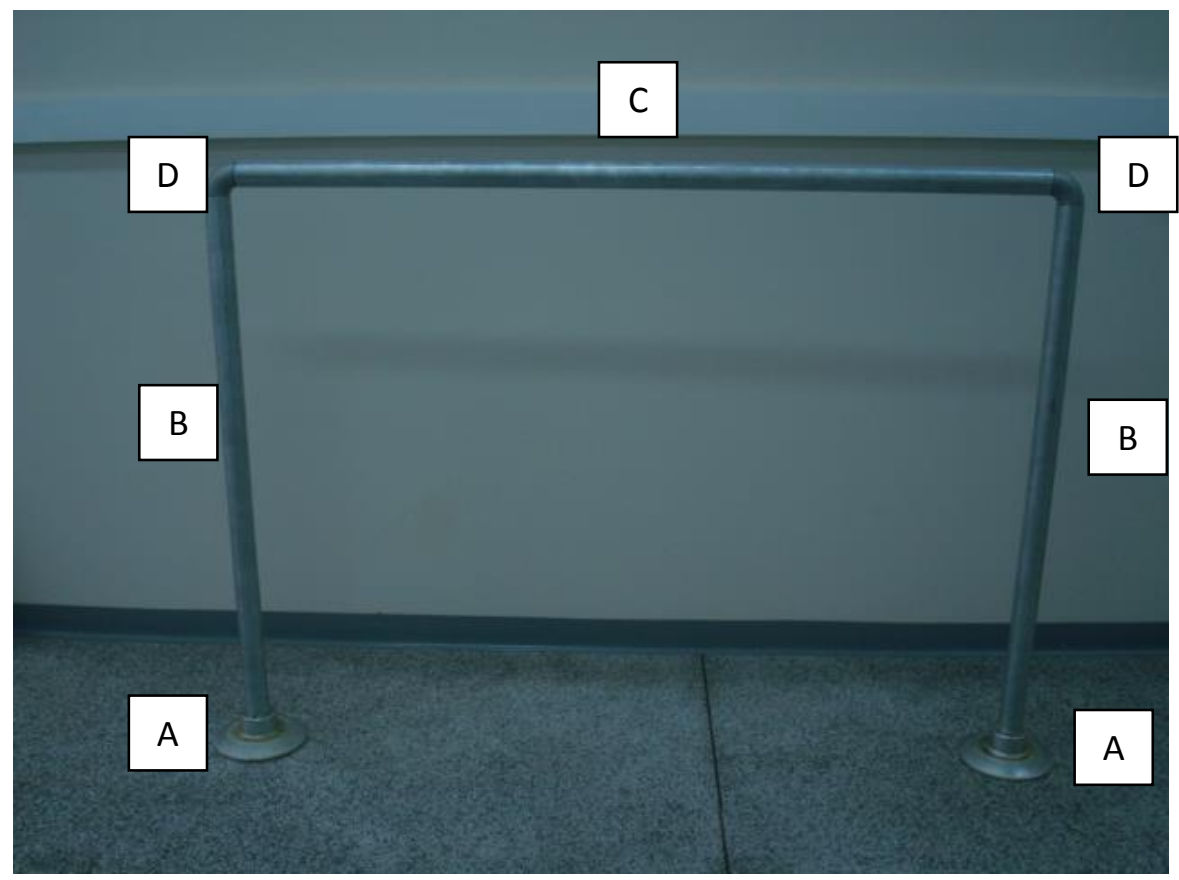

Figura 61 - Barra de apoio modular removível. Legenda: A: base da barra de apoio,- B: tubos verticais de $90 \mathrm{~cm}, \mathrm{C}$ : tubo horizontal de $120 \mathrm{~cm}, \mathrm{D}$ : cotovelos $90^{\circ}$.

Nos testes com as pesquisadoras, que não apresentam dificuldade para levantar, percebeu-se que a barra de apoio modular removível permitiu o apoio de maneira satisfatória e segura. No entanto, os pesquisadores repetiram por diversas vezes o movimento de ST - DP e percebeu -se que ao aumentar a força aplicada a barra de apoio, considerando que ambas apresentam aproximadamente $80 \mathrm{~kg}$, quando realizaram o apoio total de seus pesos e ao mesmo tempo forçaram a barra de apoio, ocorreu o descolamento de uma das bases da barra de apoio do piso.

Dessa forma, fez-se necessário, realizar testes específicos quanto à resistência da resina em suportar a força aplicada durante o movimento de ST-DP. De acordo com a NBR 9050, as barras de apoio devem suportar a força máxima de $1,5 \mathrm{kN}$, em um ponto equidistante e a máxima tensão atuante deve ser menor que a tensão admissível no material/tubo com coeficiente de segurança igual a 1,2 , seja: $\sigma_{\mathrm{adm}} / \sigma_{\max } \geq 1,2$.

\section{3‥ Teste - Ensaio mecânico da resina termo aplicável}

Anteriormente, foram pesquisadas as normas quanto ao método de ensaio padrão para a resistência à tração de adesivos por meio de amostras de barras e haste, de acordo com a ASTM International. ASTM International (ASTM), originalmente conhecida como American Society for Testing and Materials, é um órgão estadunidense de normalização. A ASTM desenvolve e publicam normas técnicas para uma ampla gama de materiais, produtos, sistemas e serviços. 
A ASTM D2095 - 96 (Reaprovada em 2008) estabelecem os critérios para o ensaio mecânico quanto à resistência à tração de adesivos por meio de amostras de barra e haste. A resistência a tração de um adesivo foi definido como a tensão máxima de tração a qual é capaz de ser sustentado. Força de tração é calculada a partir da carga máxima durante um teste de tensão carregado para a ruptura e a área da secção transversal original do espécime.

No Laboratório de Tribologia e Compósitos - LTC - do Departamento de Engenharia Mecânica da Escola de Engenharia de São Carlos - USP, seguindo as normas definidas pela ASTM D2095 - 96, foram realizados ensaios mecânicos com a MTS - Bionix Servohydraulic Test System, (Figura 62) máquina que permite caracterizar as propriedades dinâmicas de materiais biomédicos e componentes.

Os sistemas de teste Bionix de mesa estão disponíveis em configurações axiais ou axial / torsional para atender às suas necessidades de testes de biomateriais. Estes sistemas são integrados e idealmente adequados para estudos de vida em fadiga, estudos de crescimento, a tensão de fratura, assim como testes de flexão e de compressão.
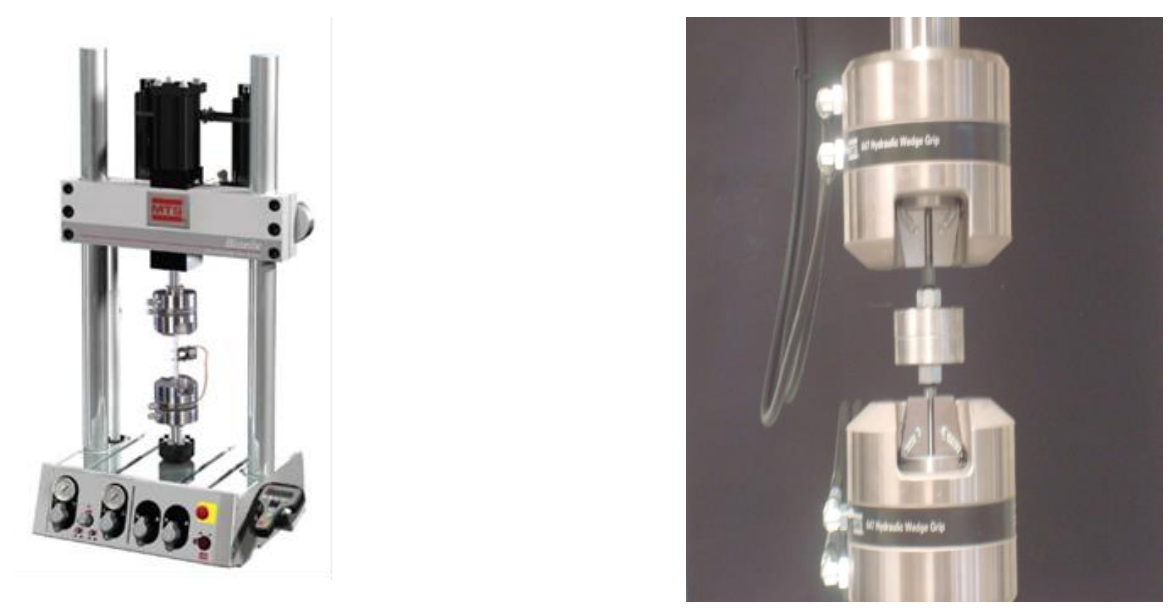

Figura 62 - MTS - Bionix Servohydraulic Test System e detalhe do braço fixo e braço móvel (LTC-EESC-USP)

Os ensaios mecânicos visando conhecer a aderência da resina ao metal foram realizados em metal - resina termo aplicável - metal, aço inoxidável 316, com área de 62 $\mathrm{mm}^{2}$, desengordurada com acetona. Os testes simulando a tração foram realizados em um deslocamento de $0,05 \mathrm{~mm} / \mathrm{s}$, em um comprimento de $0,1 \mathrm{~m} / \mathrm{s}$, com 1 decímetro de resina termo aplicável. Conforme explicitado anteriormente, a composição da resina foi testada com 2 porcentagens diferentes de quantidade de breu, por ser a matéria-prima que confere a rigidez à resina. 


\section{1a Ensaio Mecânico}

- Condições de ambiente: $26,6^{\circ} \mathrm{C}$ de temperatura e 53\% de umidade

- Composição da Resina (50\% breu, 25\%parafina e 25\% cera de abelha)

$-\mathrm{Pico}=4522 \mathrm{~N}$

- Força $=4280 \mathrm{~N}$

- Tensão de ruptura: $1,5 \mathrm{MPa}$

- Resultado: houve aderência da resina em ambas as superfícies, não houve a soltura da resina na superfície de metal, mas sim sua ruptura, o que indica que a introdução de micro ou nano fibras podem melhorar suas propriedades sem perda considerável da fluidez. (Fig. 63)

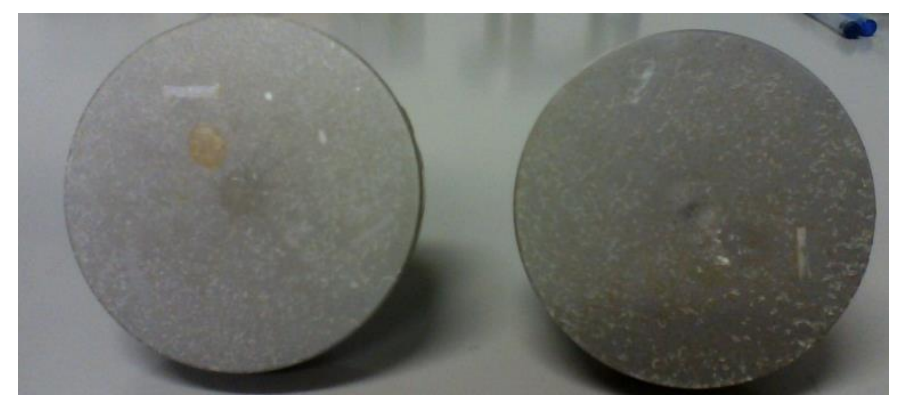

$1 b$ Ensaio Mecânico

Figura 63- Superfície após ensaio 1a

- Condições de ambiente: $28{ }^{\circ} \mathrm{C}$ de temperatura e $46 \%$ de umidade

- Composição da Resina (60\% breu, 20\%parafina e 20\% cera de abelha)

- Força $=5103,1 \mathrm{~N}$

- Tensão de ruptura: 1,64 MPa

- Resultado: houve aderência da resina em ambas as superfícies, houve a soltura da resina na superfície semelhantemente ao ensaio mecânico anterior. (Fig. 64)

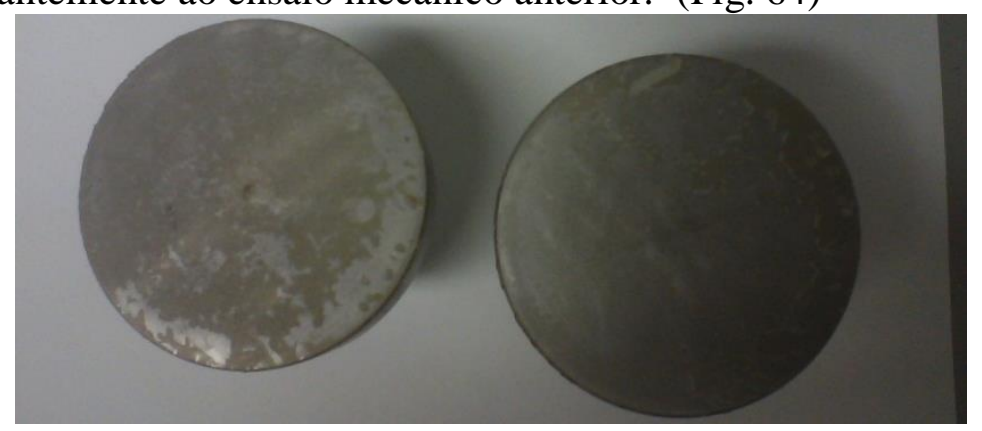

Figura 64 - Superfície após ensaio $1 \mathrm{~b}$

Assim, transpondo os dados para o ambiente real de uso da barra de apoio, temos: 


\section{Modelo Real}

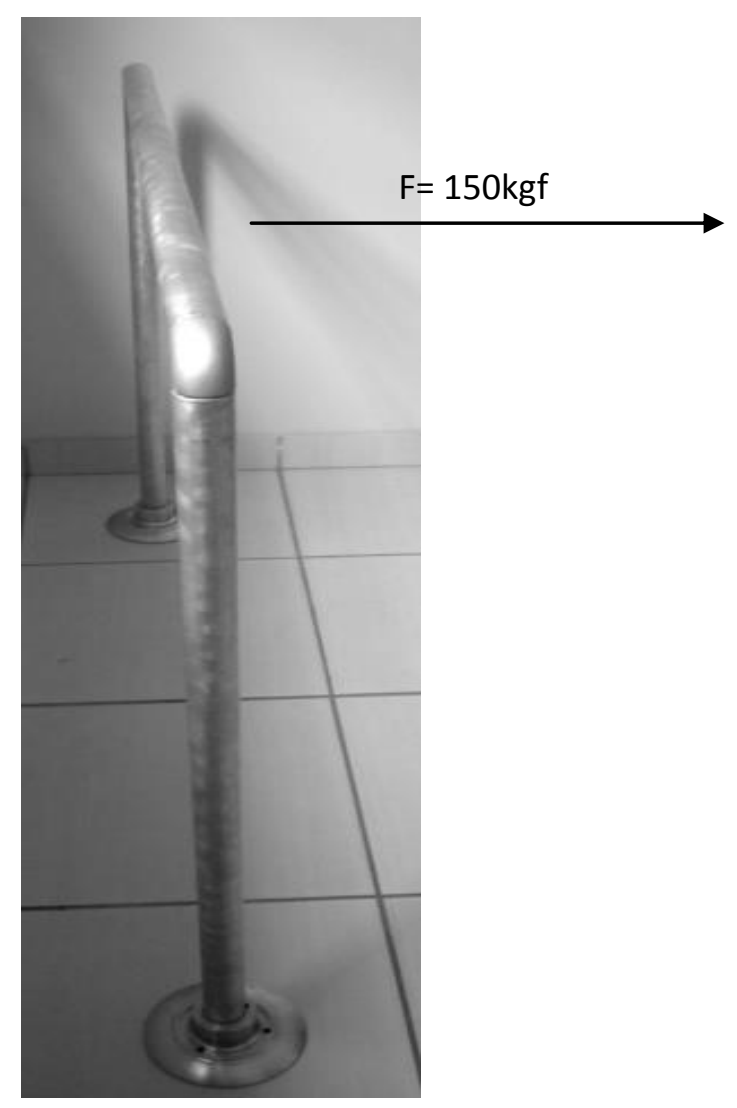

\section{Diagrama do corpo livre}
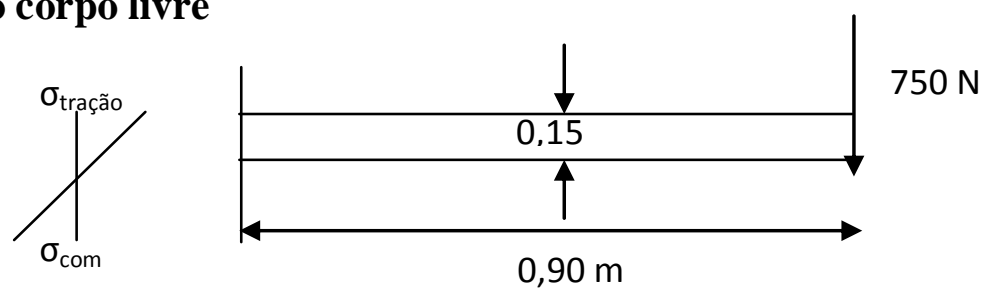

$\sigma_{\max }=\frac{\underline{\mathrm{M}}_{\mathrm{f}}}{\mathrm{W}_{\mathrm{f}}}=\frac{750 \times 0,90}{\frac{\pi .0,15^{3}}{32}}$

$\sigma_{\max }=2,05 \mathrm{MPa}$

\section{Alternativa}

Aumentando o diâmetro da base para $200 \mathrm{~mm} \sigma_{\max }=0,86 \mathrm{Mpa}$

Desta forma, a partir dos ensaios mecânicos realizados com a MTS - Bionix Servohydraulic Test System pode-se determinar que para que a barra de apoio suporte a força máxima de $1,5 \mathrm{kN}$, em um ponto equidistante e a máxima tensão atuante menor que a tensão 
admissível no material/tubo com coeficiente de segurança igual a 2 , seja: $\sigma_{\mathrm{adm}} / \sigma_{\max } \geq 2$ haverá a necessidade de alterar o diâmetro da base da barra de apoio de $150 \mathrm{~mm}$ para $200 \mathrm{~mm}$.

Assim, a barra de apoio necessita manter a altura mínima de $0,90 \mathrm{~m}$ nos tubos verticais e um comprimento mínimo de $0,02 \mathrm{~m}$ na barra horizontal, que poderá ter comprimentos diferentes de acordo com a necessidade do usuário e a composição da resina termo aplicável com $60 \%$ de breu.

\section{4‥ Teste - Teste de bancada com voluntários (com dificuldade)}

Com a autorização do comitê de ética em pesquisa do HCFMRP-USP, pode-se testar a barra de apoio em pacientes e verificaram-se os resultados do produto desenvolvido, na utilização de pessoas com dificuldade para realizar o movimento de ST-DP.

Após assinado o Termo de Consentimento Livre e Esclarecido, os voluntários foram avaliados solicitando a eles que realizassem o movimento de ST-DP sem apoio e após isso respondessem um questionário para levantar as estratégias que cada voluntário utilizava para conseguir levantar-se/sentar-se. Os voluntários fizeram uso da barra de apoio modular removível com a barra de apoio fixada no piso frio. E após o uso, foi solicitado que respondessem outro questionário acerca de sua opinião quanto ao uso, efetividade da barra de apoio e os pontos positivos e negativos do uso dessa barra de apoio.

\section{Teste de bancada - Voluntário 1}

O voluntário 1, 72 anos, sexo masculino, procedente de Ribeirão Preto tem o diagnóstico de desgaste da coluna lombar e cervical, apresenta dificuldade para ST-DP do vaso sanitário, tendo que se apoiar. O voluntário testou a barra de apoio e referiu que a barra ajuda a realizar o movimento de levantar-se (Fig.65)
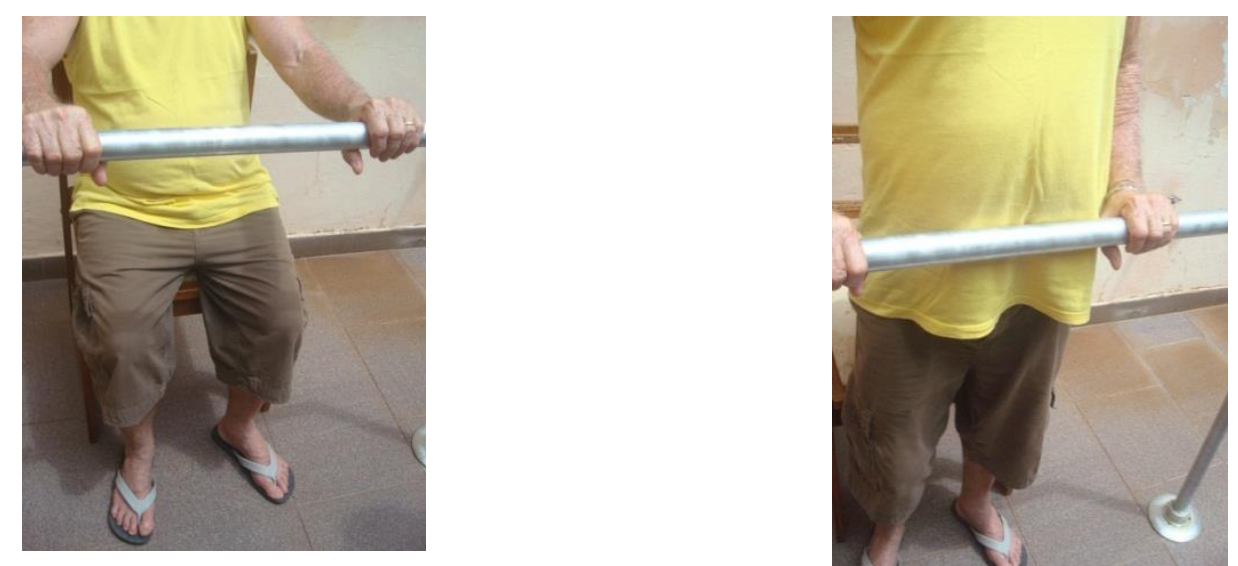

Figura 65- Voluntário 1 sentado e voluntário 2 em pé 


\section{Teste de Bancada - Voluntário 2}

O voluntário 2, 71 anos, sexo feminino, procedente de Ribeirão Preto, aposentada, tem o diagnóstico de desgaste da coluna lombar, apresenta dificuldade para levantar-se/sentar-se do sofá, quando este é muito baixo, tendo que se apoiar. O voluntário testou a barra de apoio e referiu que a barra ajuda a realizar o movimento de levantar-se, mas ficou insegura, com receio desta soltar e opinou sobre a possibilidade de fazer uma barra de apoio com o tubo horizontal com o comprimento menor já que ela justificou que em seu banheiro, o modelo de barra testado não seria adequado. (Fig. 66)
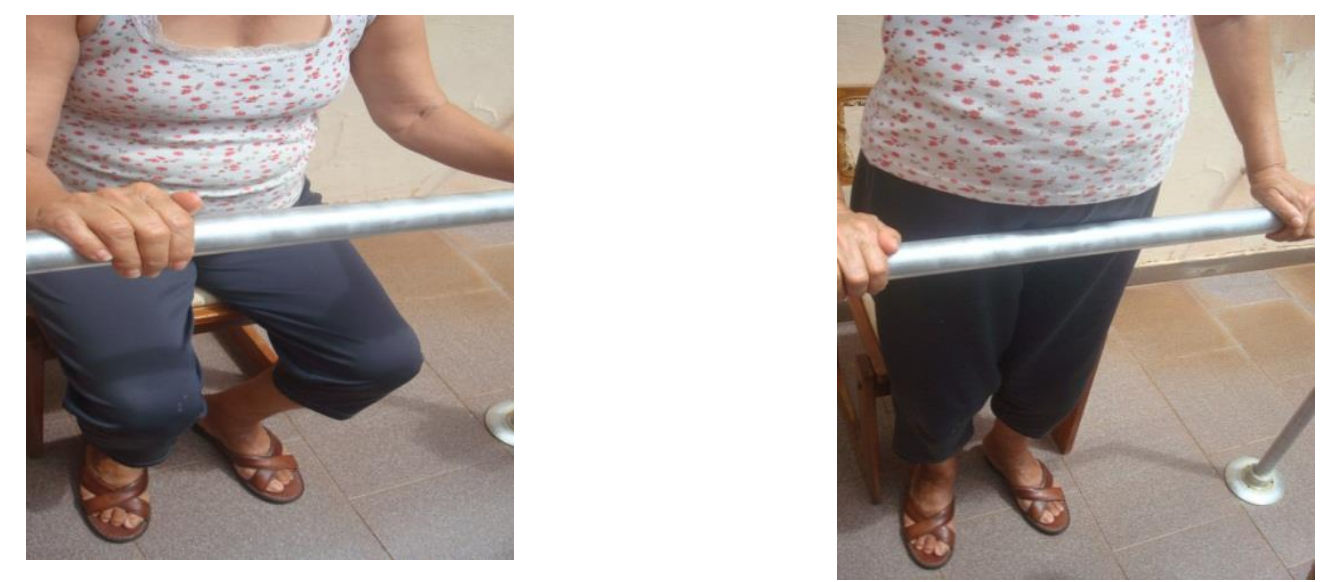

Figura 66 - Voluntário 2 sentado e voluntário 2 em pé

\section{Teste de Bancada - Voluntário 3}

O voluntário 3, 51 anos, sexo feminino, procedente de Ribeirão Preto, comerciante, tem o diagnóstico de lombalgia, apresenta dificuldade para levantar-se/sentar-se de locais baixos, tendo que se apoiar. O voluntário testou a barra de apoio e referiu que a barra ajuda a realizar o movimento de levantar-se, e opinou sobre a possibilidade dos tubos horizontais serem de outros tamanhos para poder adequar aos locais de diferentes metragens dos domicílios. (Fig.67) 

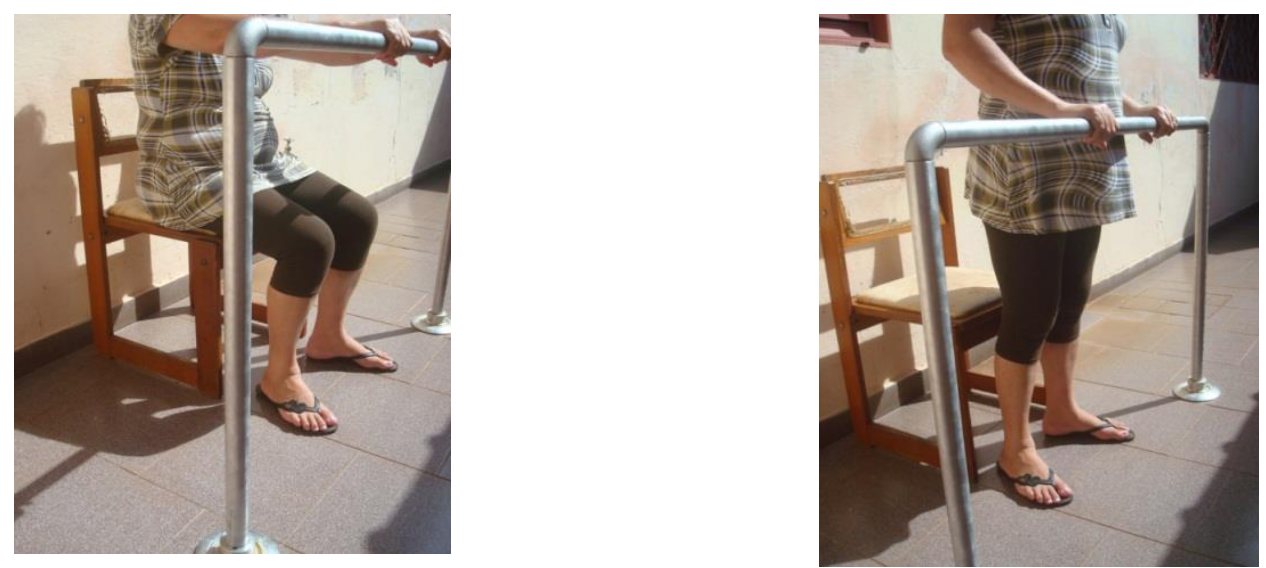

Figura 67 - Voluntário 3 sentado e voluntário 3 em pé

\section{Teste de Bancada - Voluntário 4}

O voluntário 4, 50 anos, sexo masculino, procedente de Ribeirão Preto, comerciante, tem o diagnóstico de osteoartrose de joelhos, apresenta dificuldade para levantar-se/sentar-se de qualquer local devido a dor nessas articulações. O voluntário testou a barra de apoio e referiu que a mesma ajuda a realizar o movimento de levantar-se, e relatou que a possibilidade de remover a barra de apoio com facilidade e sem danificar o piso é interessante já que acredita que as pessoas de baixa renda precisam de dispositivos desse tipo. (Fig.68)
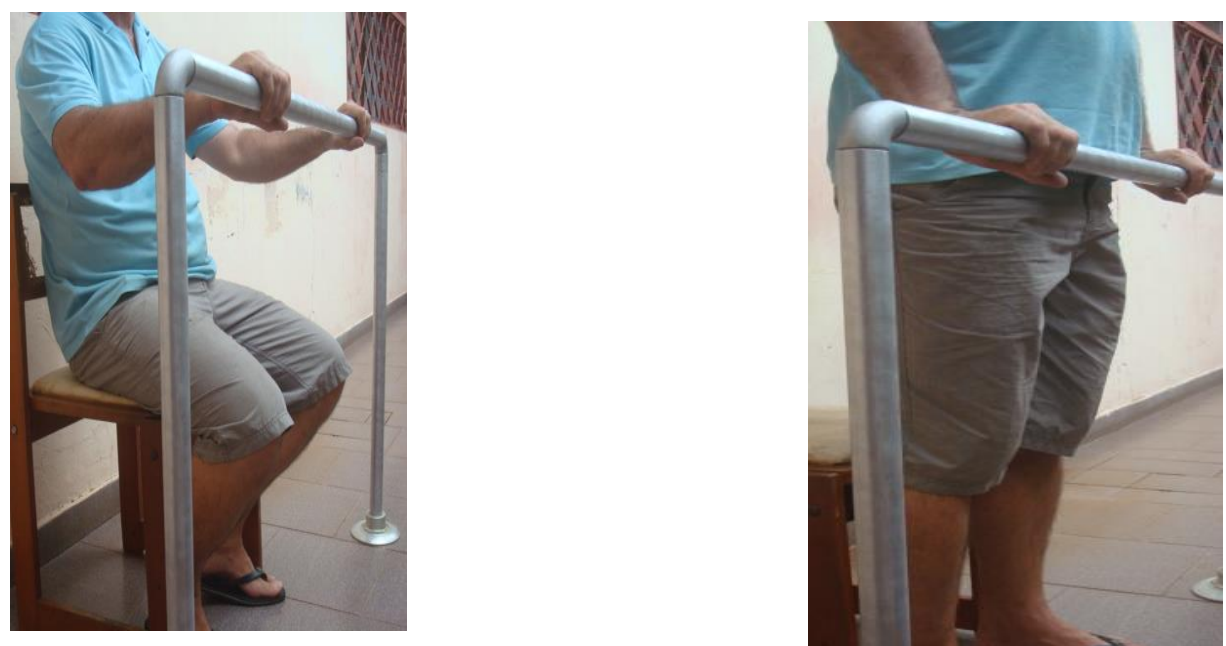

Figura 68 - Voluntário 4 sentado e voluntário 4 em pé

Como já citado anteriormente, é possível elencar diferentes composições para a barra de apoio modular removível.

O exemplo a) (Fig.69a) pode ser adaptado através do uso dos tubos, bases e das conexões, os cotovelos mais de $30^{\circ}$ e menos de $30^{\circ}$. Esta configuração pode ser utilizada em diferentes cômodos da casa como a cozinha, quarto e o banheiro. O tubo horizontal pode ter comprimentos de no mínimo 0,02 m e máximo de acordo com a necessidade do usuário e espaço disponível. É uma modelo que permite conforto e ergonomia ao realizar o movimento de ST-DP. 
O exemplo b) (Fig.69b) pode ser utilizado especificamente no banheiro, para auxílio do movimento de ST-DP no vaso sanitário. Neste exemplo, podem-se utilizar os tubos, as bases e as conexões como Tee, e os cotovelos.

O exemplo c) (Fig. 70a) pode ser utilizado no quarto, ao lado da cama, especificamente para pessoas com dificuldade para passar de ST-DP e para caminhar até o cômodo mais próximo, por exemplo, o banheiro. Neste exemplo, as bases, os tubos, o Tee pode ser adaptado para formar essa configuração.

O exemplo d) (Fig. 70b) também pode ser usado no quarto, ao lado da cama, para facilitar o movimento de passar de ST-DP, utilizando as bases, os tubos, os Tee e os cotovelos $90^{\circ}$.

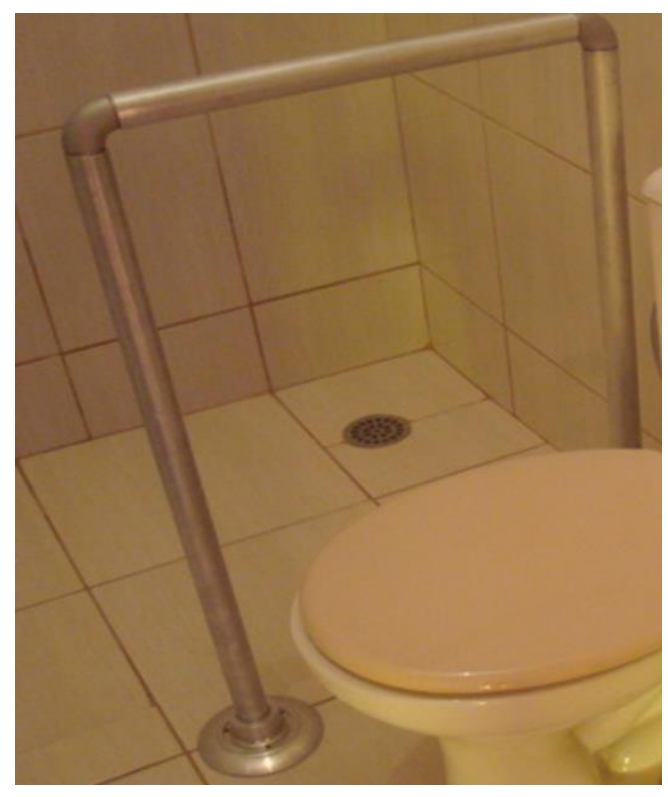

a)

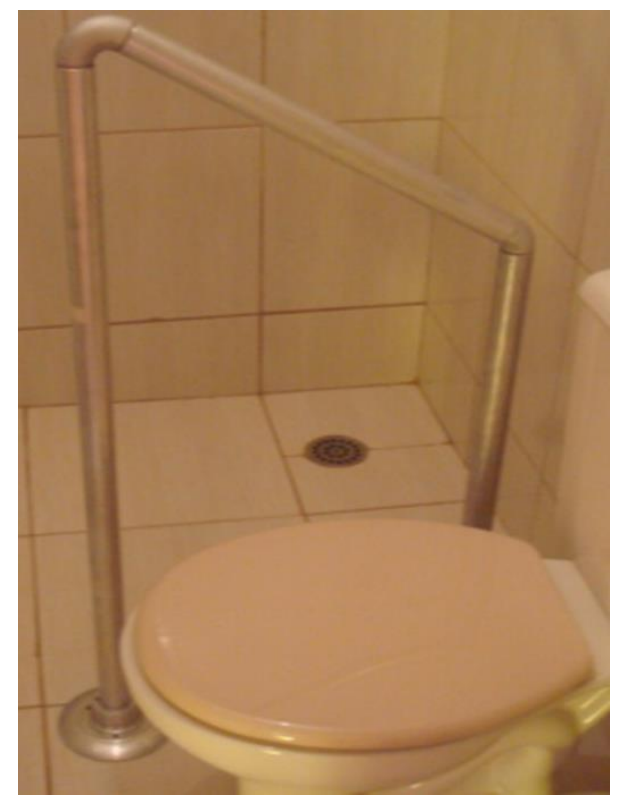

b)

Figura 69 - Exemplo a) e b) possíveis de uso da barra de apoio

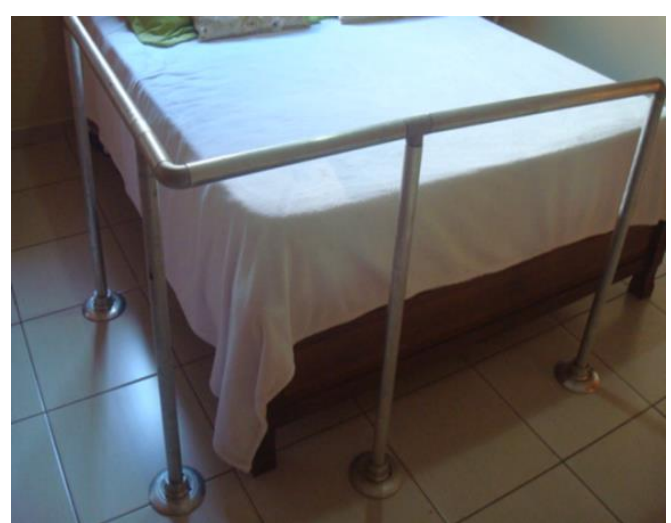

c)

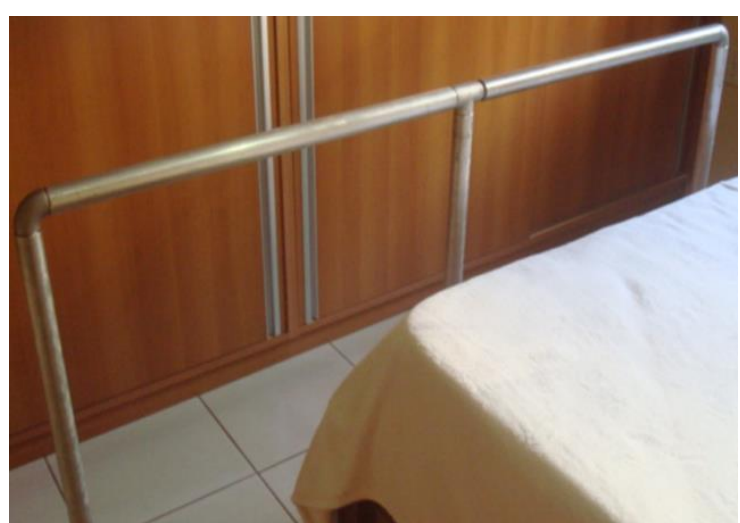

d)

Figura 70 - Exemplo c) e d) possíveis de uso da barra de apoio no quarto 


\section{1 Empunhadura}

$\mathrm{Na}$ pesquisa de reconhecimento de necessidade, os indivíduos participantes relataram como preferência a barra de apoio ser fabricada com material antiderrapante assim como os voluntários que participaram da validação do protótipo.

Analisando o uso da barra de apoio, percebeu-se que os voluntários, quando realizam a preensão no tubo da barra de apoio, em alguns momentos, ocorriam o escorregamento, que pode ser definido como um decréscimo intenso no valor do coeficiente de atrito entre o corpo em movimento e a superfície de apoio, ocorrido de maneira bastante rápida.

Assim, de forma a proporcionar que a superfície possa resistir e dar proteção ao escorregamento além de conforto e ergonomia pode-se empregar o apoio antiderrapante nos tubos da barra de apoio.

Os exemplos de materiais que podem ser empregados na barra de apoio são:

- fita antiderrapante safety walk $3 \mathrm{M}^{4}$

- RT Grip - faixa antiderrapante ${ }^{5}$

- Emborrachado antiderrapante ${ }^{6}$

Dessa forma, projeta-se que o apoio antiderrapante facilite ainda mais a preensão e consequentemente a segurança durante o uso da barra de apoio.

\footnotetext{
${ }^{4}$ www.ligacao.com.br/Fita-Antiderrapante-Safety-Walk--5-Metros-Transparente-Detalhes-293491.htm

${ }^{5}$ www.revesttech.com.br/Industrias/wfServicos.aspx?id=6

${ }^{6}$ www.gramasonline.com.br/piso-emborrachado-antiderrapante-pisos.php
} 


\section{DESCONTINUIDADE}

Após o desenvolvimento do protótipo da barra de apoio, é necessário o estudo quanto as adequações de acabamento, pintura e marketing para a manufatura industrializada e venda aos consumidores. Neste trabalho, ainda não foi possível a realização destas etapas.

Posteriormente a estas fases, segue-se a fase de descontinuidade, processo de descarte ou reutilização da matéria - prima do produto.

O principal material utilizado pela barra de apoio é o alumínio, que é 100\% reciclável. A reciclagem de alumínio é o processo pelo qual o alumínio pode ser reutilizado em determinados produtos, após ter sido inicialmente produzido. O processo resume-se no derretimento do metal, o que é muito menos dispendioso e consome muito menos energia do que produzir o alumínio através da mineração de bauxita. A mineração e o refino deste requerem enormes gastos de eletricidade, enquanto que a reciclagem requer apenas $5 \%$ da energia para produzi-lo. (WIKIPEDIA, 2013)

O Brasil é pentacampeão na reciclagem de latas de alumínio em países onde a reciclagem de embalagens não é obrigatória por lei. O país reciclou $96,2 \%$ das latas disponíveis no país, o que equivale a 127,6 mil toneladas de latas em 2005. Desde então, o país vem sendo seguido pelo Japão, Argentina e Estados Unidos embora existam países no mundo que possuam índices de reciclagem maiores que o brasileiro. A reciclagem do alumínio gera benefícios para o país e o meio ambiente, além de ser menos custoso de obter do que através da sua produção por mineração. (WIKIPEDIA, 2013)

A resina termo-aplicável que consiste na mistura de cera de abelha, breu e parafina são derivados de fontes naturais e renováveis, com excessão da última, derivada do petróleo, que não é renovável, mas que podem ser reaproveitados e não são poluentes. 


\section{CONSIDERAÇÕES FINAIS}

A elaboração de conceitos ligados à tecnologia assistiva é considerado assunto importante, na formação e atuação dos terapeutas ocupacionais, por isso, este trabalho ofereceu algumas sugestões ou direções para pesquisas que possibilitariam um melhor direcionamento daqueles que trabalham com pessoas com deficiência ou com o desenvolvimento de produtos destinados a atender as necessidades dessa parcela específica da população.

Além disso, pode-se possibilitar aos profissionais da saúde e mais especificamente ao terapeuta ocupacional um embasamento teórico-metodológico a fim de ampliar sua atuação direta com os pacientes para atuações junto a equipes de manufatura de produtos utilizados por pessoas com diferentes deficiências e assim possibilitar um maior reconhecimento da atuação do terapeuta ocupacional assim como um meio de prover sua valorização quanto a sua remuneração financeira.

De acordo com os preceitos da metodologia de desenvolvimento de produto, podemos delimitar a metodologia para a elaboração de um recurso de tecnologia assistiva, utilizando os de forma que os terapeutas ocupacionais possam disponibilizar recursos importantes para outras pessoas que possuam as mesmas necessidades do usuário/paciente/cliente ao qual foi confeccionada a Tecnologia Assistiva

O conceito da barra de apoio modular removível proposta atinge os objetivos, de ser de fácil montagem, mesmo para pessoas com ou sem conhecimento técnico, permite o uso em diferentes configurações, sem alterar a estrutura física do ambiente e com isso podendo atender as demandas e necessidades da maioria da população brasileira quanto a usabilidade e universalidade.

Durante o processo de desenvolvimento do projeto da barra de apoio modular removível foi possível integrar os conhecimentos de normas brasileiras e internacionais de forma a atender as especificidades necessárias a barra de apoio.

Utilizou-se também, o conhecimento matemático e tecnológico que permitiram determinar os materiais e a manufatura mais adequada ao desenvolvimento de barra de apoio.

O que norteou o projeto conceitual foram as necessidades dos consumidores e usuários (indivíduos com dificuldade para levantar-se e sentar-se) estudadas umas em relação a outras: 
a) possibilidade de adequação da altura e dos comprimentos do tubo horizontal e adequação das medidas de acordo com os parâmetros antropométricos, com o intuito de atender uma maior gama de usuários, bem como para permitir que o produto seja utilizado à medida que o usuário necessite de mudanças; b) estudo dos materiais disponíveis comercialmente e estudo das configurações possíveis a barra de apoio com o objetivo de proporcionar maior apoio e consequente estabilidade e conforto ao usuário, c) estudo da capacidade da resina termo aplicável em suportar os esforços decorrentes do apoio do indivíduo durante o movimento de ST-DP e vice -versa para garantir a segurança ao usuário; d) garantia de que o equipamento possa ser utilizado em diversos ambientes (sala, quarto, cozinha etc.) da residência ou local do uso; e) facilidade de operação e condução do produto quando da sua utilização (instalção e desinstalação. Como todos estes aspectos são igualmente importantes para que a atividade de levantar-se e sentar-se seja realizada com sucesso, optou-se por considerar todas estas características listadas com a mesma importância.

A preocupação de gerar um produto que atendesse todas as exigências físicas demandadas pelos usuários e que também atendesse aos anseios e desejos dos consumidores orientou o desenvolvimento do protótipo, e concentrou-se primordialmente em aspectos relacionados à funcionalidade do produto e os aspectos estéticos. A análise crítica do protótipo foi dividida em análise da tarefa e ergonomia e análise das funções do produto.

Levando em conta as demandas dos usuários, optou-se por adotar como parâmetros norteadores as características descritas por Soares, Martins, (2000) como fundamentais para produtos projetados para pessoas com deficiência. Da análise crítica assim realizada sobre o produto final desenvolvido (protótipo), depreenderam-se as seguintes observações:

- Segurança física: apesar de ser um equipamento destinado a operar em situação de risco de escorregamento e queda, como pode ser considerado o levantar-se e sentar-se, projetou-se uma estrutura estável, apropriada para acomodar satisfatoriamente os usuários, sejam eles adultos ou idosos, e podem-se planejar acessórios de segurança como dispositivos sonoros que alertem aos usuários o desprendimento de uma das bases, por exemplo, de fácil manejo;

- $\quad$ Portabilidade: a capacidade de ser desmontado garante ao produto a fácil transportabilidade, seja pelo carregamento manual ou no porta-malas de veículos;

- Usabilidade: a simplicidade do design do produto confere facilidade à sua utilização, já que o usuário pode adequar a composição da barra de apoio a sua necessidade de apoio e auxílio ao movimento de ST-DP, conseguindo-se assim, atender aos diferentes tipos de dificuldades; 
- $\quad$ Conforto físico e adequação pessoal: a possibilidade de ajuste no comprimento horizontal do tubo e as conexões que promovem variação da composição da barra de apoio proporcionam o conforto físico do usuário, ao mesmo tempo em que a como um todo, promove biomecânica favorável ao usuário na execução do movimento de ST-DP e viceversa;

- Facilidade de montagem e manutenção: as bases e as conexões são de fácil manejo e exigem conhecimento mínimo para sua montagem e, além disso, a estrutura do protótipo foi confeccionada em material considerado leve, o manuseio das peças projetadas para serem encaixadas e ajustadas é fácil, dispensando qualquer esforço excessivo para sua execução.

- Facilidade de reparo e higienização: em relação aos acessórios ou partes da barra de apoio, houve a preocupação de que fossem confeccionados em material de fácil aquisição e manuseio. Também houve a preocupação, no projeto do produto, de possibilitar a fácil retirada destes dispositivos, o que também contribui para uma melhor higienização, garantindo menos riscos à saúde do usuário.

Neste contexto, a implantação do uso de equipamentos destina-se a assistir, aumentar ou favorecer o desempenho funcional (performance) do indivíduo frente a uma tarefa a ser realizada, que neste estudo referiu-se exclusivamente a atividade de vida diária de levantar-se e sentar-se durante as atividades de alimentação, banho, vestuário, higiene e uso do vaso sanitário. Assim, nesse estudo a TA objetivou intervir oferecendo equipamento adaptativo que promova o posicionamento adequado ao indivíduo com dificuldade para levantar-se e sentarse devido a patologias diferentes, além de proporcionar biomecânica postural favorável ao indivíduo durante a execução da tarefa.

Especificamente quanto a análise biomecânica do movimento de ST-DP, auxiliado pelo apoio dos braços, percebeu-se que os três maiores desafios relacionados a transição de sentado para em pé e as duas maiores falhas, que são colocar o CM para a frente, na vertical elevando o CM a partir do assento para a posição de pé, e fazer a transição a partir de uma base relativamente grande e estável de apoio sentado a uma base de apoio consideravelmente menor em pé e a insuficiência de voltar a sentar e a incapacidade de parar num posição de pé estável, respectivamente é muito facilitado pelo apoio dos braços a uma barra de apoio. $\mathrm{O}$ apoio dos braços amplia a base de suporte do corpo e, isto aumenta a estabilidade postural, facilitando a mudança dinâmica necessária ao movimento de ST-DP. O uso dos braços durante o movimento de ST-DP reduz os torques nas articulações do quadril e do joelho em 50\%.(AKRAM, MCILROY, 2011; BAHRAMI et. al., 2000). 
Por outro lado, quanto ao desenvolvimento do produto, a escolha de um dispositivo de assistência, ou seja, um equipamento que promova o aumento e/ou participação do indivíduo com incapacidade na execução de uma atividade é uma tarefa complexa, mas extremamente necessária aos usuários que apresentam dificuldades e importante para os profissionais que visam possibilitar a função e melhorar a qualidade de vida como é o caso do terapeuta ocupacional. (PAIN; McLELLAN, 2003).

Durante todo o processo de elaboração e desenvolvimento do produto, o sucesso no uso e aceitação de um dispositivo de TA por parte do usuário e de seus cuidadores, seja ele produzido de forma seriada (em massa) ou confeccionado sob medida, frequentemente envolve um somatório de fatores econômicos, ergonômicos e estéticos na sua fase de desenvolvimento, os quais, juntos, agregam valor ao produto que, enfim, se destina a ampliar ou facilitar a participação do indivíduo e/ou cuidadores nas atividades, refletindo-se numa melhor qualidade de vida.

Por se tratar de protótipo ainda em fase de teste, as características adequação, durabilidade e eficiência não puderam ser aferidas. O que se pode adiantar é que, apesar de, neste momento, não se ter realizado estudos direcionados para o mercado, no que se refere aos fatores de comercialização do produto, houve preocupação constante em projetar um produto de custo viável e de fácil manutenção (adequação). Sendo necessário ainda acompanhar o indivíduo usuário durante o todo o processo de uso do produto (durabilidade/adaptabilidade); e verificar se o produto atendeu além das demandas físicas específicas do público usuário, as necessidades do consumidor e/ou cuidador, por meio da atenção ao favorecimento de uma melhor biomecânica postural durante a atividade, proporcionada, entre outros fatores, pela capacidade da regulagem de composições.

Assim, o desenvolvimento do protótipo e o teste com os possíveis usuários da barra de apoio possibilitou a troca de informações importantes entre pesquisadores e usuários quanto ao uso, a montagem e as composições da barra de apoio e dessa forma, poder projetar modificações para o projeto que possibilite a aceitabilidade do público.

No entanto, para trabalhos futuros são necessários estudos aprofundados acerca da viabilidade técnica e de custo de materiais aplicáveis às estruturas e acessórios que compõem os dispositivos assistivos, assegurando que o mesmo satisfaça as demandas listadas como essenciais aos usuários, realizar análise do posicionamento do usuário enquanto faz uso do equipamento, bem como se as alternativas de ajustes e acessórios do dispositivo se adequam ao usuário; investigar a viabilidade de custo e o estabelecimento de fabricação seriada do equipamento, bem como o real interesse comercial do mercado pelo dispositivo; e realizar 
uma análise mercadológica do produto, avaliando aspectos como viabilidade de mercado, marca, cor, modelos e suas variações, canais de comercialização e distribuição.

No sentido da preservação do ambiente, este trabalho utilizou materiais e métodos ecologicamente corretos, que não produzem lixo ou toxidade ao meio ambiente.

A tendência é que este projeto evolua no sentido de desenvolverem-se estudos mais avançados de mercado, que deverão ser realizados para que o produto tenha um apelo mais comercial, bem como para que atenda as exigências de segurança de forma mais completa.

Apesar da necessidade de mudança no diâmetro da base e melhoria no acabamento da barra de apoio constatou-se através da opinião dos voluntários que o uso deste modelo é confortável e que sua instalação é mais fácil, que os modelos apresentados no mercado comercial.

O uso da resina termo aplicável possibilita tanto possibilidades de uso para a população financeiramente bem assistida quanto para as populações de baixa renda.

Vislumbramos que o uso dessa nova barra de apoio e que a segurança promovida por ela no desempenho do movimento de ST-DP, traga melhoras na qualidade de vida do usuário/consumidor, conforto, e prevenção de quedas, bem como, melhora da funcionalidade promovendo independência no desempenho nas atividades diárias.

Visa-se o patenteamento do produto final, visto que este é um produto original. 


\section{CONCLUSÕES}

De acordo com os objetivos estabelecidos neste trabalho, conseguiu-se:

- Projetar e desenvolver o conceito de uma barra de apoio nacional, de fácil instalação, que utiliza materiais renováveis e original, com a função de facilitar o movimento de passar de sentado para em pé e vice-versa. Determinar o modelo e protótipo utilizando o programa CAD Solid Edge;

- Classificar os possíveis materiais;

- Dimensionar a barra de apoio de acordo com os materiais disponíveis;

- Fabricar protótipos físicos para testes quanto à viabilidade de uso e de adequação quanto ás normas nacionais e internacionais;

- Realizar ensaios mecânicos de bancada e testes em pacientes que possibilitaram verificação da aplicabilidade e a facilitação do movimento de passar de ST-DP;

- Constatar a eficácia através da opinião favorável dos voluntários ao uso da barra de apoio. 


\section{REFERÊNCIA ${ }^{7}$}

ABE, D.; HOTTA, N.; FUKUOKA, Y.; OHTA,Y.; HAMASAKI, K. Biomechanical Analysis of Gait and Sit-to-Stand Patterns Using a Specially Made Knee Supporter in Healthy Young and Elderly Individuals Journal Physiologia Anthropologia, n. 29, p. 65-70, 2010

ADA - American with Disabilities ACT 1994. Disponível em: <www.resna.org/taproject/library/laws/techact94.htm > Acessado em 15 maio 2009

ASTM International D2095-96 (Reaprovada em 2008) Standard Test Method for Tensile Strenght of Adhesives by Means of Bar and Rod Specimens.

AKAO, Y. "Development History of Quality Function Deployment". The Customer Driven Approach to Quality Planning and Deployment. Asian Productivity Organization Japão. 1966

AKRAM, S. B.; MCILROY, W. E. Challenging Horizontal Movement of the Body During Sit-to-Stand: Impact on Stability in the Young and Elderly, Journal of Motor Behavior, n. 43, vol. 2, p. 147-153, 2011

AMADIO, A. C.; SERRÃO, J. C. Contextualização da biomecânica para a investigação do movimento: fundamentos, métodos e aplicações para análise da técnica esportiva Rev. bras. Educ. Fís. Esp., São Paulo, v.21, p.61-85, dez. 2007. N. Esp.• 61

AMADIO, A.C. Fundamentos da Biomecânica do esporte: Considerações sobre a análise cinética e aspectos neuro-musculares do movimento . São Paulo: EEFUSP, 1989. 119 p. (Livre Docência).

ANSON, D - Tecnologia Assistiva IN: PEDRETTI, L.W. EARLY, M.B. A Terapia Ocupacional - Capacidades práticas para as Disfunções Físicas - São Paulo: Roca, 2005

ANTONELI, M., Prescrição de Cadeira de Rodas, IN: Terapia Ocupacional na Reabilitação Física, E. Teixeira, et al., Editors. 2003: São Paulo.

AOTA - American Occupational Therapy Association. Occupational therapy practice framework: Domain and process (2nd ed.). American Journal of Occupational Therapy, n. 62,p. 625-683, 2008

\footnotetext{
${ }^{7}$ De acordo com a Associação Brasileira de Normas Técnicas. NBR 6023
} 
ASIMOW, M. Introduction To Design. Irentice Hall, 1968.

BACK, N.; FORCELlinI, F.A. Projeto de Produtos. Apostila (Disciplina de Projeto Conceitual e Projeto para Manufatura do Programa de Pós-Graduação em Engenharia Mecânica). UFSC, Florianópolis, 2003.

BAHRAMI,F.; RIENER,R.; JABEDAR-MARALANI,P.;SCHIMIDT,G. Biomechanical analysis of sit-to-stand transfer in healthy and paraplegic subjects. Clinical Biomechanics. vol. 15 , p. $123-133,2000$

BARATA, D.A.; ELUI,V.M.C. Terapia Ocupacional, hemofilia e tecnologia assistiva. Trabalho de Conclusão de Curso apresentado ao Curso de Terapia Ocupacional da Faculdade de Medicina de Ribeirão Preto - Universidade de São Paulo, realizada com apoio da Fundação de Amparo à Pesquisa do Estado de São Paulo - FAPESP, Ribeirão Preto, 2009

BAXTER, M. Projeto de produto: guia prático para o design de novos produtos. 2. ed. São Paulo: Edgard Blücher, 2003.

BENETI, G. M.; SILVA, D. L. D. Síndrome de Guillain-Barré Seminário: Ciências Biológicas e Saúde, Londrina, v. 27, n. 1, p. 57-69, janeiro/junho, 2006

BERSCHI R. Introdução à tecnologia assistiva CEDI - Centro Especializado em Desenvolvimento Infantil Porto Alegre - RS 2008 disponível em: <www.assistiva.com.br/Introducao\%20TA\%20Rita\%20Bersch.pdf> Acessado em : 16 maio 2009

BRANDÃO, L.; FERRAZ, M. B.; ZERBINI, C. A. F. Avaliação da qualidade de vida na artrite reumatóide: revisão atualizada. Revista Brasileira Reumatologia - vol. 37, n. 5, Set/Out, 1997

BRASIL. Subsecretaria Nacional de Promoção dos Direitos da Pessoa com Deficiência. Comitê de Ajudas Técnicas. Tecnologia Assistiva. - Brasília: CORDE, 2009. 138 p.

BRASIL. Ministério da Saúde: Política Nacional de Saúde da Pessoa com Deficiência. Brasília, DF, 2009. Disponível em: <http://portal.saude.gov.br/portal/arquivos/pdf/manual2.pdf> Acesso em: 04 fev 2011. 
BRASIL. Ministério das Cidades. Déficit Habitacional no Brasil. Brasília, DF, 2009 Disponível em: <http://www.cidades.gov.br/> Acesso em 04 fev 2011.

CAlvanti, A. GAlVÃO, C. Adaptação ambiental e doméstica. IN: CALVANTI, A.GALVÃO, C. - Terapia Ocupacional - fundamentação e prática. Rio de Janeiro: Guanabara Koogan, 2007

CALVANTI, A. GALVÃO, C. MIRANDA, S.G.S Mobilidade. IN: CALVANTI, A.GALVÃO, C. - Terapia Ocupacional - fundamentação e prática. Rio de Janeiro: Guanabara Koogan, 2007

CAMARGOS, A. C. R.; CÓPIO, F. C. Q.;SOUSA, T. R. R.; GOULART, F. O impacto da doença de parkinson na qualidade de vida: uma revisão de literatura. Revista brasileira de fisioterapia vol. 8, n. 3, p. 267-27, 2004.

CASSEMIRO, C.R.' ARCE, C. G. Comunicação visual por computador na esclerose lateral amiotrófica. Arquivos Brasileiros Oftalmologia. vol.67 n.2 ,São Paulo, Março/Abril, 2004

CAVALCANTI,A.;SILVA,P.G.;ASSUMPÇÃO,T.S. Doenças reumáticas. IN: CALVANTI, A.GALVÃO, C. - Terapia Ocupacional - fundamentação e prática. Rio de Janeiro: Guanabara Koogan, 2007

CRELL, T.R; ADLER, C.; TIPTON-BURTON, M.; LILlIE, S.M.. Mobilidade IN: PEDRETTI, L.W.; EARLY, M.B. A Terapia Ocupacional - Capacidades práticas para as Disfunções Físicas - São Paulo: Roca, 2005

DE LEVA, P. Adjustments to Zatsiorky-Seluyanov's segment inertia parameters. Journal Biomechanics, Vol. 29, N. 9 pg. 1223-1230, 1996

DUTRA, F. C. M.; GOUVINHAS, R. P. Desenvolvimento de protótipo de cadeira de banho para indivíduos com paralisia cerebral tetraparética espástica. Produção, São Paulo, v. 20, n. 3, Set. 2010.

EUROPEAN COMMISSION - DGXIII - Empowering Users Through Assistive Technology, 1998. Disponível em: <http://www.siva.it/research/eustat/index.html>. Acesso em: $26 \mathrm{dez}$ 2012.

FÄNGE, A., IWARSSON, S. Changes in accessibility and usability in housing: An exploration of the housing adaptation process. Occupational Therapy International, n.12, vol.1, p. 44-59, 2005 
FARIA, J. C., DIAS, R. C., MACHALA, C. C., ALENCAR, M. A., ARANTES, P. M. M. E DIAS, J. M. D. Transferência da posição sentada para em pé: estudo comparativo entre idosas assintomáticas e idosas com osteoartrite e correlação entre tempo da tarefa e função muscular. Revista brasileira de fisioterapia vol. 9, n. 3 ,p. 305-311, 2005

GILLETTE, J. C.; STEVERMER, C. A. The effects of symmetric and asymmetric foot placements on sit-to-stand joint moments Gait \& Posture n. 35, p. 78-82, 2012

GOLDBERG, A., The five-times-sit-to-stand-test (FTSST), the short version of the activitiesspecific balance confidence (ABC) scale, and fear of falling predict step execution time (SET) in older adults. Arch. Gerontol. Geriatr. 2011

GOUlART, F.; CHAVES, C. M.; CHAGAS; VALLONE, M. L. D.;CARVALHO, J.A.; SAIKI, K. R.O movimento de passar de sentado para de pé em idosos: implicações para o treinamento funcional. Acta Fisiátrica vol.10,n.3, p.138-143, 2003

HORA, E. C.; SOUSA, R. M. C. Os efeitos das alterações comportamentais das vítimas de trauma crânio-encefálico para o cuidador familiar. Revista Latino-americana em Enfermagem vol. 13, n.1 p. 93-98, janeiro-fevereiro, 2005.

IIDA, I. Ergonomia: projeto e produção, $2^{\mathrm{a}}$ edição Revista Ampliada, São Paulo. Ed.Blucher, 2005. Cap. 2-4.

INSTITUTO DE TECNOLOGIA SOCIAL - ITS. Conhecimento e Cidadania. São Paulo, 2007. Disponível em: < http://www.itsbrasil.org.br/publicacoes/cadernos/conhecimento-ecidadania-tecnologia-social-1 >. Acesso em:26 dez 2012.

Introduction to RP Technologies. Rapid Prototyping Tutorial. Disponível em: < http://www.ucg.br/site_docente/fabio/design/mat3/aula15/RP.pdf> Acesso em 26 dez 2012

INSTITUTO DE TECNOLOGIA SOCIAL - ITS. Conhecimento e Cidadania. São Paulo, 2007. Disponível em: <http://www.itsbrasil.org.br/pages/23/CadernoTS2007.pdf>. Acesso em: 02 dez 2012.

IWARSSON S., ISACSSON Å., LAUKE J. ADL dependence in the elderly. The influence of functional limitations and physical environment demand. Occupational Therapy International n. 5, p. 65-70, 1998. 
IWARSSON, S. Assessing the fit between older persons and their home environments. Focus on aging in context: Sociophysical environments. Annual Review of Gerontology and Geriatrics n. 23, p. 85-109, 2003.

IWARSSON, S., STÅHL, A. Accessibility, usability, and universal design: Positioning and definition of concepts describing person-environment relationships. Disability and Rehabilitation n. 25, p. 57-66, 2003

KAMINSKI, P. C. Desenvolvendo produtos com planejamento, criatividade e qualidade. Rio de Janeiro: LTC, 2000.

LANA, R. C. Caracterização cinemática da atividade de passar de sentado para andar em indivíduos com Doença de Parkinson Dissertação de Mestrado. Programa de PósGraduação da Escola de Educação Física, Fisioterapia e Terapia Ocupacional da Universidade Federal de Minas Gerais, Belo Horizonte, Minas Gerais 2010

LAURENTI, K.C.; FORTULAN, C.A.; PURQUERIO, B.M. A Ergonomia em Projeto Mecânico com Dummy 3D em CAD. Projeto PAE - Disciplina CAD - Escola de Engenharia de São Carlos, Universidade de São Paulo, ANO

LUZO, M.C.M.; MELLO, M.AF.;CAPANEMA,V.M. Recursos Tecnológicos em Terapia Ocupacional - Órteses e Tecnologia Assistiva IN: DE CARLO, M.M.R.P.; LUZO, M.C.M. Terapia Ocupacional-reabilitação física e contextos hospitalares. São Paulo: Roca, 2004

MARQUES, A. P.; KONDO, A. A fisioterapia na osteoartrose: uma revisão da literatura Revista Brasileira de Reumatologia. vol. 38, n. 2 , Março/Abril, 1998

MAZINI, E.J. Tecnologia Assistiva: definição descrição, e aplicação Revista Brasileira Edição Especial, Marília, , v.14, n.3, p.511-512, Set.-Dez. 2008

Normas da ABNT-9050 - Normas Brasileiras - Acessibilidade a edificações, mobiliário, espaços e equipamentos urbanos, 2004 disponível em: <http://www.mpdft.gov.br/sicorde/NBR9050-31052004.pdf> Acesso em 04 fev 2011. 
NOVIELLO, T. B.; NOVIELLO, T, C. B.; PURISCH, LAMOUNIER, S.; REIS, R. N.; J. S.; MENEZES, P. A. F. C; CALSOLARI, M. R. Cetoacidose diabética associada com síndrome de Guillain-Barré: relato de caso Arquivos Brasileiros Endocrinologia Metabólica vol.52 n.3, São Paulo, Abril 2008

OLIVEIRA, E. M. L.; ANNES, M; OLIVEIRA, A. S. B.; GABBAI, A. A. Esclerose múltipla: estudo clínico de 50 pacientes acompanhados no Ambulatório de Neurologia UNIFESP-EPM. Arquivos Neuro-Psiquiatria, vol.57, n.1, p. 51-55. ,1999.

OMS - ORGANIZAÇÃO MUNDIAL DA SAÚDE. CIF: Classificação Internacional de Funcionalidade, Incapacidade e Saúde [Centro Colaborador da Organização Mundial de Saúde para a Família de Classificações Internacionais, org.; coordenação da tradução Cássia Maria Buchalla]. São Paulo: Editora da Universidade de São Paulo, 2003.

PALACIOS, A. El modelo social de discapacidad: orígenes, caracterización y plasmación en la Convención Internacional sobre los Derechos de las Personas con Discapacidad. Madrid: CERMI-Cinca, 2008.

PAHL, G.; BEITZ, W. Projeto na Engenharia. 6 ed., São Paulo: Edgard Blücher, 2005.

PAIN, H.; McLELLAN, D. L. The relative importance of factors affecting the choice of bathing devices. British Journal Of Occupational Therapy, v. 66, n. 9, p. 396-401, 2003.

PELOSI, M. O Papel do terapeuta Ocupacional na tecnologia assistiva. Cadernos de Terapia Ocupacional da UFscar, vol.13, n. 1, 2005

PUGH, S. Total Design. Integrated Methods for Successful Product Engineering.,1995

RADANOVIC, M. Características do atendimento de pacientes com acidente vascular cerebral em hospital secundário. Arquivos Neuropsiquiatria vol.58, n.1, p.99-106, 2000

RASCH, P. J., Cinesiologia e Anatomia Aplicada, Guanabara Koogan, Rio de Janeiro, (7 edição), 1991

ROCHA, E. F.; CASTIGLIONI, M. C. Reflexões sobre recursos. Rev. Ter. Ocup. Univ. São Paulo, v. 16, n. 3, p. 97-104, set./dez., 2005 
ROCHA, E. F.; CASTIGLIONI, M. C. Reflexões sobre recursos. Revista Terapia Ocupacional da Universidade de São Paulo, v. 16, n. 3, p. 97-104, set./dez., 2005

ROZENFELD, H. et al. Gestão de desenvolvimento de produtos: uma referência para a melhoria do processo. $1^{\circ}$. ed., São Paulo: Saraiva, 2006.

SANGLARD, R.C.F., HENRIQUES, G.R.P., RIBEIRO, A.S.B., CORRÊA, A.L., PEREIRA, J.S. Alterações dos parâmetros da marcha em função das queixas de instabilidade postural e quedas em idosos. Fitness \& Performance Journal, v.3, n.3, p. 149-156, 2004

SAURON, F.N. Lesões da Medula Espinhal. IN: CALVANTI, A.GALVÃO, C. - Terapia Ocupacional - fundamentação e prática. Rio de Janeiro: Guanabara Koogan, 2007

SCHENKMAN, M., BERGER; R.A., RILLEY, P.O., MANN, R.W., HODGE, W.A. Wholebody movements during rising to standing from sitting. Physyatric Therapy n.70, p:638-51, 1990

SHOEMAKER, L.L.; LENKER, J.A.; FUHRER, M.J.; JUTAI, J.W.; DEMERS, L.; DERUYTER, F. Development and evaluation of a new taxonomy of mobility-related assistive technology devices. American Journal Physical Medicina Rehabilitation n. 89, p. 795-808, 2010

SHOEMAKER, L.L.; LENKER, J.A.; FUHRER, M.J.; JUTAI, J.W.; DEMERS, L.; DERUYTER, F. Mobility-related assistive technology device classifications: implications for outcomes research. American Journal Physical Medicina Rehabilitation n. 88, p.1020 1032,2009

SLACK, N. et al. Administração da Produção. 2 ed., São Paulo: Atlas, 2002.

SOARES, M. M.; MARTINS, L. B. Design universal e ergonomia: uma parceria que garante acessibilidade para todos. In: ALMEIDA, A. T.; SOUZA, F. M. C. Produção e competitividade: aplicações e inovações. Recife: Ed. Universitária da UFPE, 2000. p. 127156.

TEIXEIRA, E. ; ARIGA, M.Y.;YASSUKO,R. Adaptações. IN: TEIXEIRA, E. ; SAURON, F.N. SANTOS, L.S.B.; OLIVEIRA, M.C. Terapia Ocupacional na Reabilitação Física. São Paulo: Rocca, 2003

TEIXEIRA-SALMELA, L. F., LIMA, R. C. M., LIMA, L. A. O., MORAIS, S. G. E GOULART, F. Assimetria e desempenho funcional em hemiplégicos crônicos antes após 
programa de treinamento em academia. Revista brasileira de fisioterapia. vol. 9, n. 2,p. 227233,2005

TEIXEIRA-SALMELA, L. F.; OLIVEIRA, E. S. G.; SANTANA, E. G. S.;RESENDE, G. P. Fortalecimento muscular e condicionamento físico em hemiplégicos Acta Fisiátrica vol. 7, n.3, p.: 108-118, 2000

TOLDRÀ, R.C. PÉREZ, M.A.G., MATTA, M.A.P. Acesso e qualidade da atenção à pessoa portadora de deficiência física em serviços públicos de saúde do município de Campinas. Revista Terapia Ocupacional da Universidade de São Paulo, v.11 n.2/3,p.72-8, maio/dez, 2000 .

TSUKAHARA , A.; KAWANISHI, R.; HASEGAWA , Y. ; SANKAI, Y. Sit-to-Stand and Stand-to-Sit Transfer Support for Complete Paraplegic Patients with Robot Suit HAL Advanced Robotics n.24, p 1615-1638, 2010

ULRICH, K.T.; EPPINGER, S.D. Product design and development. 3 ed., New York, USA: McGraw Hill, 2004

URBAN, G. L.; HAUSER, J. R. Design and marketing of new products. 2. ed. EnglewoodCliffs: Prentice Hall, 1993.

VAN DER HEIJDEN, M. M.P.; MEIJER, K.; WILLEMS, P. J.B.; SAVELBERG, H. H.C.M. Muscles limiting the sit-to-stand movement; An experimental simulation of muscle weakness Gait \& Posture n.30, p110-114, 2009

VAN VLACK, L.H.; MONTEIRO, E. Princípios de ciência e tecnologia dos materiais Ed. Campus, 2003

WALDRON, D.; LAYTON, N. Hard and soft assistive technologies: Defining roles for clinicians Australian Occupational Therapy Journal, n. 1, vol. 55, p. 61-64, 2008

WEYHER, D.F (org) Adhesives in modern manufacturing. Society of Manufacturing Engineers Dearborn Michigan, 1970

WRIGHT, J.K.; EVANS, J.R.G.; EDIRISINGLE, M.J. Degradation of polielefin blends used for ceramic injection molding. Journal American Ceramic Society, vol.72, n.10, p. 1822$1828,1989$. 
YOSHIOKA, S.; NAGANO, A.; HAY, D.C.; FUKASHIRO, S. The minimum required muscle force for a sit-to-stand task. Journal of Biomechanics n.45, p 699-705, 2012

ZATSIORSKY, W.; ARUIN, A.; SELUYANOV,W. Biomechanik des Menschlichen Bewegungsaooarates. Sportverlag. 1984

< http://www.constroifacil.com.br/internas/materiais/grupo_3.asp> Acesso em: 13 fev 2011

$<$ http://produto.mercadolivre.com.br/MLB-167330805-tripe-com-ventosa-targus-omtgtsp_JM> Acesso em: 13 fev 2011

<http://www.royalmaquinas.com.br/> Acesso em: 13 fev 2011

<http://www.lojaodaborracha.com> Acesso em: 13 fev 2011

<http://www.rehabmart.com/product/healthcraft> Acesso em: 13 fev 2011

<http://www.inmetro.gov.br/legislacao/resc/pdf/RESC000117.pdf > Acesso 10 fev 2012

<http://www.matweb.com/search/QuickText.aspx >Acesso em 10 jan 2012

<http://www.abal.org.br/aluminio/processos_fundicao.asp> Acesso em 12 dez 2012

<http://www.abal.org.br/aluminio/processos_fundicao.asp> Acesso em 12 dez 2012

<http://pt.wikipedia.org/> Acesso em 13 fev 2011 


\section{APÊNDICES}

\section{APÊNDICE A \\ TERMO DE CONSENTIMENTO LIVRE E ESCLARECIDO}

Convidamos você, que é seguido no Hospital das Clínicas e/ou seu complexo e/ou no Instituto de Reabilitação Rede Lucy Montoro, a participar do projeto intitulado "Desenvolvimento de barra vertical de apoio para indivíduos com acometimento do aparelho locomotor. Este projeto, de autoria de Danielle Aline Barata Assad, desenvolvido como parte da dissertação de mestrado pelo "Programa de Pós-graduação Interunidades em Bioengenharia - USP”, e orientado pela Profa. Dra. Valéria Meirelles Carril Elui, que trata do desenvolvimento de uma barra vertical de apoio móvel (não necessário fixar no piso ou na parede com cimento, cola etc) com o objetivo de oferecer aos usuários maior conforto e segurança durante o "levantar" com isto podendo diminuir a dor, e exigir menos força das pernas, e propiciar maior equilíbrio, tendo para isto o auxilio das mão nesta barra. O equipamento a ser desenvolvido será fácil de utilizar.

Se aceitar participar, você responderá a um questionário de forma individual com 12 perguntas,por aproximadamente 15 minutos, com o objetivo de saber a sua opinião se o desenvolvimento dessa barra poderia ser uma alternativa que ajudaria no levantar. Ao responder estas perguntas você não terá nenhum prejuízo para seu tratamento já realizado ou em atendimento nestes locais. As perguntas serão realizadas antes ou após a sua consulta agendada em um local disponível, segundo a sua disponibilidade.

Possíveis Benefícios: Este trabalho de pesquisa não trará nenhum benefício específico a você. Mas esta pesquisa poderá auxiliar a ter uma nova opção de apoio para se levantar (barra vertical de apoio móvel), podendo dar no futuro condições a pessoas que apresentam dificuldades e/ou cansaço no levantar-sentar", como por exemplo do sofá, cadeira, cama, e do vaso sanitário.

Desconforto e Risco: Este experimento não trará nenhum tipo de desconforto ou risco à sua saúde e sua identidade será mantida em sigilo absoluto.

Seguro de Saúde ou de Vida: Não existirá nenhum tipo de benefício, seguro de saúde ou de vida que possa a vir a beneficiá-lo em função de sua participação neste estudo. Também não haverá nenhum auxílio em dinheiro pela sua participação e isto não trará nenhum tipo de custo adicional a você por participar desta.

Liberdade de Participação: Sua participação neste estudo é voluntária. É seu direito interrompê-la a qualquer momento sem que isso leve a qualquer penalidade ou prejuízo à sua pessoa. O pesquisador tem o direito de excluir seus dados deste estudo no caso de coleta incompleta ou não adequação dos dados ao objetivo desse trabalho.

Sigilo de Identidade: As informações obtidas nesta pesquisa não serão de maneira alguma associadas à sua identidade e não poderão ser consultadas por pessoas leigas sem sua autorização oficial. Estas informações poderão ser utilizadas para fins de estudo e poderão ser divulgados e publicados, desde que sua identidade seja mantida em segredo. Durante a participação na pesquisa, podem ser tiradas fotos para fins de documentação, sem identificar o seu rosto.

Em caso de dúvidas, você poderá fazer todas as perguntas que achar necessário, assim como críticas e sugestões para o estudo, a qualquer momento. Eu,

$\begin{array}{lllllll}\begin{array}{l}\text { Portador do } \\ \text { complemento_ }\end{array} & \text { RG } & \begin{array}{c}\mathrm{n}^{\circ} \\ \text { bairro__ }\end{array} & \text { residente à } & & \mathrm{n}^{\circ} & \text { Estado }\end{array}$

Declaro que tenho____ anos de idade e que concordo em participar, voluntariamente, da pesquisa conduzida pela pesquisadora responsável e por sua respectiva orientadora.

Para questões relacionadas a este estudo contate:

Profa. Dra. Valéria Meirelles Carril Elui Curso de Terapia Ocupacional - Faculdade de Medicina de Ribeirão Preto - FMRP-USP Fone: (0XX16) 3602-4417 e-mail: velui@ fmrp.usp.br

Ou Pós-graduando: Danielle Aline Barata Assad e-mail: danielle.aline.barata@gmail.com

Caso deseje saber mais sobre este estudo entre em contato com os seus idealizadores. Sua participação deve ser livre e espontânea. É seu direito manter uma cópia deste consentimento de participação.

Nome do Voluntário: de de $2011 / 2012$.

Assinatura do voluntário:

Pesquisador: Danielle Aline Barata Assad: Orientador:

Valeria

M.

C.

Elui: 
APÊNDICE B - Questionário para levantamento de necessidades quanto a recurso adaptativo para auxilio ao movimento de mudança de sentado para em pé

Data da entrevista:

Nome: Registro:

Data de nascimento: Idade: Sexo: • Masculino • Feminino

Estado Civil: Procedência:

Escolaridade: Atividade profissional:

Diagnóstico:

1. O Sr. (a) apresenta dificuldade para mudar da posição de sentado para de pé (ST-DP) e viceversa?

a) $\mathrm{Sim}$

b) Não

2. Se sim, esta dificuldade lhe atrapalha nas atividades do seu dia-dia?

c) $\operatorname{Sim}$

a) Não

3. Quais atividades das listadas abaixo são prejudicadas por esta dificuldade?

a) Levantar-se/sentar-se da cama

b) Levantar-se/sentar-se do sofá

c) Levantar-se/sentar-se de cadeiras para a refeição.

d) Levantar-se/sentar-se do vaso sanitário

e) Levantar-se/sentar-se para vestir peças de roupa

f) Levantar-se/sentar-se da cadeira de banho

4. O Sr. (a) tem o hábito de tentar se apoiar em moveis próximos aos locais onde o Sr.(a) referiu ter dificuldade para conseguir realizar estes movimentos (levantar-se/sentar-se)?
a) $\quad \operatorname{Sim}$
b) Não

5. Caso houvesse um recurso adaptativo que oferece apoio quando necessário a realização destes movimentos (levantar-se/sentar-se), o Sr. (a) acredita que estes movimentos seriam mais fáceis de serem realizados?
a) $\operatorname{Sim}$
b)Não

6. Considerando a possibilidade de uma barra vertical de apoio, o Sr.(a) acredita que esta seria mais segura em relação aos apoios utilizados anteriormente (móveis)?
a) $\operatorname{Sim}$
b) Não

7. Qual material o Sr.(a) considera que seja mais confortável para se apoiar nesta barra vertical de apoio?
a) Aço
d) seja recoberto com material macio
b) Alumínio
e) seja anti-derrapante e duro
c) Plástico

8. O Sr. (a) tem preferência pela barra vertical ser fixa (no chão) ou móvel (você põe e tira sem necessidade de pedreiro e em qualquer lugar que tenha piso)?
a) Fixa
b) Móvel 
9. O Sr. (a) gostaria de ter esta barra vertical de apoio para uso em quais locais de sua casa? (pode assinalar mais de 1 resposta)
a) Banheiro
b) Quarto
c) Cozinha
d) Sala
e) Todos os citados anteriormente

10. O Sr. (a) prefere uma barra vertical com altura máxima próxima ao seu alcance quando sentado? (Figura 1)
a) $\mathrm{Sim}$
b) Não

11. O Sr.(a) prefere uma barra vertical com altura que alcance teto? (Figura 2)

a. $\operatorname{Sim}$

b. Não

12. Para segurar uma barra vertical de apoio, como o Sr. (a) gostaria que fosse o apoio?

a) Figura 1(altura alcance quando sentado e apoio reto)

b) Figura 2 (altura até o teto e apoio na própria barra)

c) Figura 3 (apoio inclinado)

O Sr. (a) tem algum comentário, crítica, sugestão ou elogio a fazer, além do que foi colocado nas questões acima?

Figura 1

Figura 2

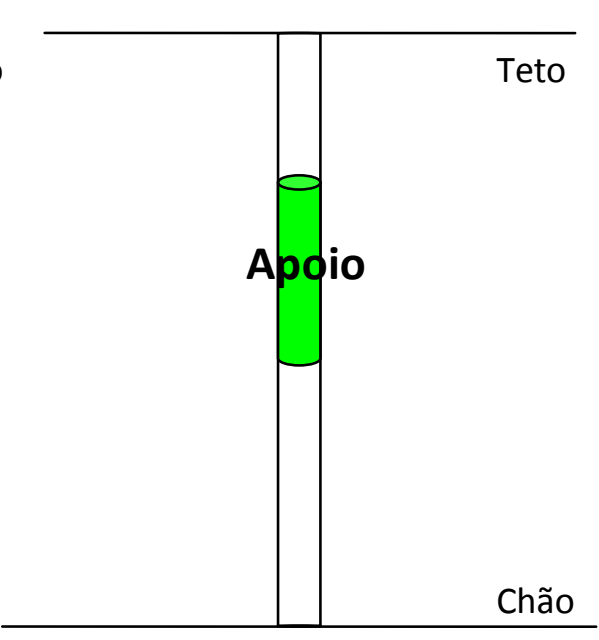

Figura 3

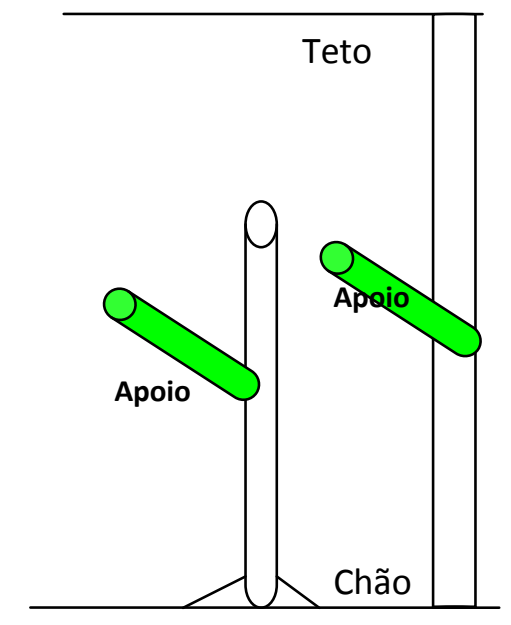




\section{APÊNDICE C - LISTA DE CATEGORIAIS PROFISSIONAIS (ELABORADO PELOS PESQUISADORES) \\ $>$ Superior/Gerência}

Dirigente superior, administração pública e industrial

Gerente industrial

Engenheiro, arquiteto e afins

Veterinário

Dentista

Advogado

Economista, administrador e contador

Publicitário

Profissionais da saúde

Jornalista

Professor

Técnico/ Administrativo

Técnico construção civil

Técnico informática

Técnico ensino médio

Técnico ciências contábeis e administrativas

Bancário, economiário, secretário.

$>$ Comércio/ Prestador de serviços

Atendimento ao público, caixa, despachante

Representante comercial e afins

Vendedor e prestador de serviços do comercio, ambulante, caixeiro-viajante

Nível Básico

Reparo e manutenção

Trabalhador da construção civil

Trabalhador da área rural

Trabalhador da indústria em geral

Trabalhador da agropecuária

Serviços diversos

$$
\text { Do Lar }
$$

Serviços domésticos

Outros

Sem profissão definida 


\section{APÊNDICE D}

\section{TERMO DE CONSENTIMENTO LIVRE E ESCLARECIDO}

Convidamos você, que é seguido no Hospital das Clínicas no seu Centro de Reabilitação, a participar do projeto intitulado "Desenvolvimento de barra vertical de apoio para indivíduos com acometimento do aparelho locomotor. Este projeto, de autoria de Danielle Aline Barata Assad, desenvolvido como parte da dissertação de mestrado pelo "Programa de Pós-graduação Interunidades em Bioengenharia - USP", e orientado pela Profa. Dra. Valéria Meirelles Carril Elui, que trata do desenvolvimento de uma barra vertical de apoio móvel (não necessário fixar no piso ou na parede com cimento, cola etc) com o objetivo de oferecer aos usuários maior conforto e segurança durante o "levantar" com isto podendo diminuir a dor, e exigir menos força das pernas, e propiciar maior equilíbrio, tendo para isto o auxilio das mãos nesta barra. O equipamento a ser desenvolvido será fácil de utilizar.

Se aceitar participar, você responderá a um questionário de forma individual com 5 perguntas, por aproximadamente 15 minutos, com o objetivo de saber as dificuldades, e estratégias utilizadas para ajudar no movimento de levantar. Ao responder estas perguntas você não terá nenhum prejuízo para seu tratamento já realizado ou em atendimento nestes locais. As perguntas serão realizadas antes ou após a sua consulta agendada em um local disponível, segundo a sua disponibilidade. Após isso, o Sr.(a) irá testar o uso da barra vertical de apoio móvel, e serão feitas fotografias e vídeos do momento do seu uso para analise pelos pesquisadores posteriormente. Ao final, o Sr. (a) responderá outro questionário com 3 perguntas para saber a sua opinião a respeito do uso da barra vertical de apoio móvel.

Possíveis Benefícios: Este trabalho de pesquisa não trará nenhum benefício específico a você. Mas esta pesquisa poderá auxiliar a ter uma nova opção de apoio para se levantar (barra vertical de apoio móvel), podendo dar no futuro condições a pessoas que apresentam dificuldades e/ou cansaço no levantar-sentar", como por exemplo do sofá, cadeira, cama, e do vaso sanitário.

Desconforto e Risco: Este experimento não trará nenhum tipo de desconforto ou risco à sua saúde e sua identidade será mantida em sigilo absoluto.

Seguro de Saúde ou de Vida: Não existirá nenhum tipo de benefício, seguro de saúde ou de vida que possa a vir a beneficiá-lo em função de sua participação neste estudo. Também não haverá nenhum auxílio em dinheiro pela sua participação e isto não trará nenhum tipo de custo adicional a você por participar desta.

Liberdade de Participação: Sua participação neste estudo é voluntária. É seu direito interrompê-la a qualquer momento sem que isso leve a qualquer penalidade ou prejuízo à sua pessoa. O pesquisador tem o direito de excluir seus dados deste estudo no caso de coleta incompleta ou não adequação dos dados ao objetivo desse trabalho.

Sigilo de Identidade: As informações obtidas nesta pesquisa não serão de maneira alguma associadas à sua identidade e não poderão ser consultadas por pessoas leigas sem sua autorização oficial. Estas informações poderão ser utilizadas para fins de estudo e poderão ser divulgados e publicados, desde que sua identidade seja mantida em segredo. Durante a participação na pesquisa, podem ser tiradas fotos para fins de documentação, sem identificar o seu rosto.

Em caso de dúvidas, você poderá fazer todas as perguntas que achar necessário, assim como críticas e sugestões para o estudo, a qualquer momento. $\mathrm{Eu}$, Portador do RG $\mathrm{n}^{\mathrm{o}}$ residente à

cidade: Estado complemento bairro

Declaro que tenho___ anos de idade e que concordo em participar, voluntariamente, da pesquisa conduzida pela pesquisadora responsável e por sua respectiva orientadora.

Para questões relacionadas a este estudo contate:

Profa. Dra. Valéria Meirelles Carril Elui Curso de Terapia Ocupacional - Faculdade de Medicina de Ribeirão Preto - FMRP-USP Fone: (0XX16) 3602-4417 e-mail: velui@ fmrp.usp.br

Ou Pós-graduando: Danielle Aline Barata Assad e-mail: danielle.aline.barata@gmail.com

Caso deseje saber mais sobre este estudo entre em contato com os seus idealizadores. Sua participação deve ser livre e espontânea. É seu direito manter uma cópia deste consentimento de participação.

Ribeirão Preto , de de 2012

Nome do Voluntário:

Assinatura do voluntário:

Pesquisador: Danielle Aline Barata Assad:

Orientador: Valeria M. C. Elui: 
APÊNDICE E - Questionário 1- Levantamento de estratégias de facilitação para o movimento de mudança de sentado para em pé

Data da entrevista:

Nome: Registro:

Data de nascimento: Idade: Sexo: • Masculino • Feminino

Estado Civil: Procedência:

Escolaridade: Atividade profissional:

Diagnóstico:

1 -O Sr. (a) apresenta dificuldade para mudar da posição de sentado para de pé (ST-DP) e viceversa?

d) $\mathrm{Sim}$

e) Não

2- Se sim, esta dificuldade lhe atrapalha nas atividades do seu dia-dia?

f) $\mathrm{Sim}$

b) Não

3. Quais atividades das listadas abaixo são prejudicadas por esta dificuldade?

g) Levantar-se/sentar-se da cama

h) Levantar-se/sentar-se do sofá

i) Levantar-se/sentar-se de cadeiras para a refeição.

j) Levantar-se/sentar-se do vaso sanitário

k) Levantar-se/sentar-se para vestir peças de roupa

l) Levantar-se/sentar-se da cadeira de banho

4.O Sr. (a) tem o hábito de tentar se apoiar em moveis próximos aos locais onde o Sr.(a) referiu ter dificuldade para conseguir realizar estes movimentos (levantar-se/sentar-se)?
b)
Sim
b) Não

5. Que outras estratégias o Sr.(a) utiliza para conseguir levantar-se/sentar-se? 
APÊNDICE F - Questionário 2 - Levantamento de opinião quanto ao uso, efetividade da barra vertical de apoio móvel.

1. O Sr. (a) acredita que a barra vertical de apoio móvel ajudou $-\mathrm{o}$ e/ou facilitou no movimento de levantar (passar de sentado para em pé)?Foi mais seguro o uso dessa barra vertical de apoio móvel do que as estratégias que o Sr.(a) utilizava antes?

2. O Sr. (a) acha que a altura, material, cor, forma, estrutura está adequado?

3. Aponte os pontos positivos e negativos do uso dessa barra vertical de apoio móvel. 


\section{APÊNDICE G}

Grupo constituinte das reuniões de Brainstorming realizado em 4 sessões de 30 minutos cada no primeiro semestre de 2011, durante a disciplina do curso de Pós Graduação intitulada: SEM5910 - INTRODUÇÃO À METODOLOGIA DE PROJETO EM ENGENHARIA.

Profa. Dra Zilda De Castro Silveira - responsável pela disciplina

Alunos:

Danielle Aline Barata Assad - Terapeuta Ocupacional

José Matheus Sanches - Tecnólogo

Livia Martinelli Tinelli - Engenheira de Produção

Marcus Vinícius Vitoratti De Araújo - Engenheiro Mecatrônico

Rodrigo Mendes Lima - Engenheiro Mecânico

Os participantes autorizaram a divulgação de seus nomes neste trabalho. 


\section{ANEXOS}

ANEXO A - Carta de aprovação do Comitê de Ética e Pesquisa do HCFMRP

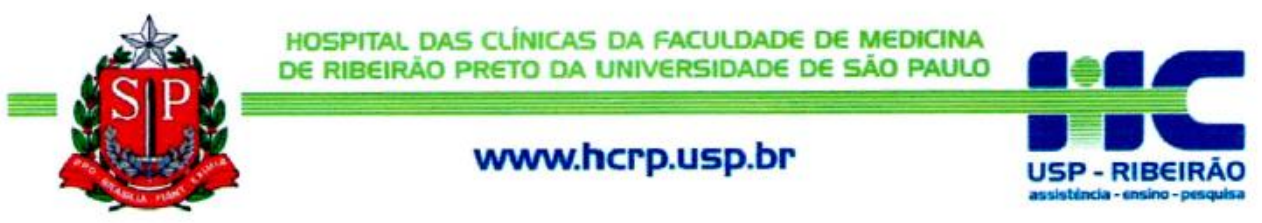

Ribeirão Preto, 11 de maio de 2011

Ofício $\mathrm{n}^{\circ} 1603 / 2011$

$\mathrm{CEP} / \mathrm{MGV}$

Prezadas Senhoras,

O trabalho intitulado "DESENVOLVIMENTO DE BARRA VERTICAL DE APOIO MÓVEL PARA INDIVÍDUOS COM APARELHO LOCOMOTOR ACOMETIDO" foi analisado pelo Comitê de Ética em Pesquisa, em sua $323^{a}$ Reunião Ordinária realizada em 09/05/2011 e enquadrado na categoria: APROVADO, bem como o Termo de Consentimento Livre e Esclarecido, de acordo com o Processo HCRP $\mathrm{n}^{\circ} 2953 / 2011$.

Este Comitê segue integralmente a Conferência Internacional de Harmonização de Boas Práticas Clínicas (IGH-GCP), bem como a Resolução $n^{\circ}$ 196/96 CNS/MS.

Lembramos que devem ser apresentados a este CEP, o Relatório Parcial e o Relatório Final da pesquisa.

Atenciosamente.

$$
\begin{aligned}
& \text { Juarcióa of llawove } \\
& \text { Coordenadora do Comitê de Ética em } \\
& \text { Pesquisa do HCRP e da FMRP-USP }
\end{aligned}
$$

Ilustrissimas Senhoras

DANIELLE ALINE BARATA ASSAD

PROF' DR ${ }^{a}$ VALERIA MEIRELLES CARRIL ELUI (Orientadora)

Depto. de Neurociências e Ciências do Comportamento - Terapia Ocupacional 